Aus der Abteilung Psychiatrie und Psychotherapie

(Prof. Dr. med. P. Falkai)

im Zentrum Psychosoziale Medizin

der Medizinischen Fakultät der Universität Göttingen

\title{
Assoziation der Autoimmunthyreoiditis mit depressiven Störungen
}

\author{
INAUGURAL-DISSERTATION \\ zur Erlangung des Doktorgrades \\ der Medizinischen Fakultät \\ der Georg-August-Universität zu Göttingen \\ vorgelegt von \\ Merle Haust \\ aus \\ Kassel
}

Göttingen 2011 
Dekan: Prof. Dr. med. C. Frömmel

I. Berichterstatter: Prof. Dr. med. E. Rüther

II. Berichterstatter/in: Prof. Dr. med. J. Meller

III. Berichterstatter/in:

Tag der mündlichen Prüfung: 20.03.2012 


\section{INHALTSVERZEICHNIS}

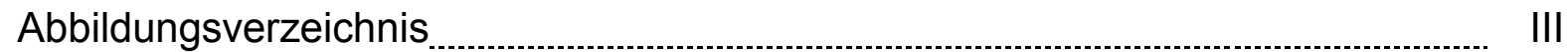

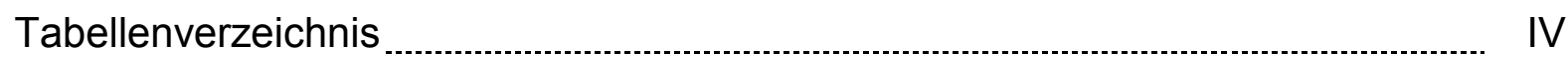

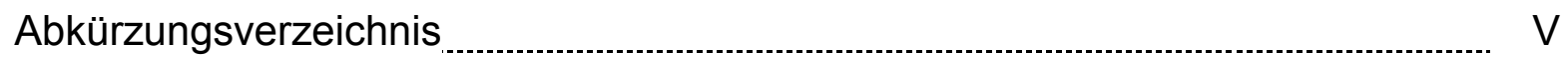

1. Einleitung

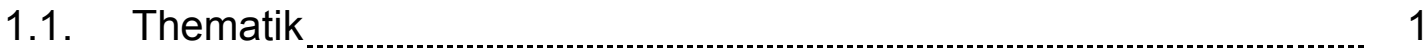

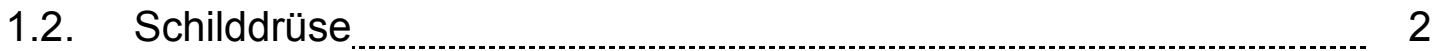

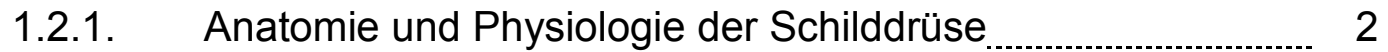

1.2.2. Schilddrüsen-Dysfunktionen ................................................. 4

1.2.3. Immunthyreopathien ............................................................ 6

1.2.4. Assoziierte Autoimmunerkrankungen ....................................... 18

1.2.5. Hashimoto-Enzephalopathie _................................................. 18

1.3. Psychische Störungen ....................................................................... 20

1.3.1. Definition, Epidemiologie _........................................................ 20

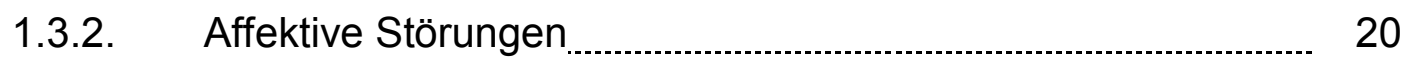

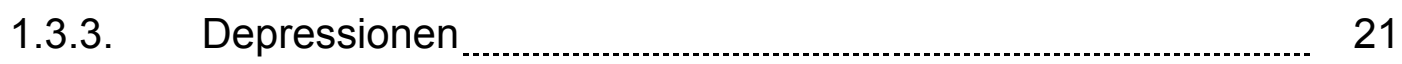

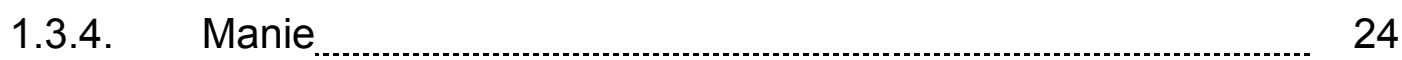

1.3.5. Bipolare affektive Störungen …............................................... 25

1.3.6. Schizophrenie

1.4. Schilddrüse und Psyche

1.5. Zielsetzung ............................................................................................ 35

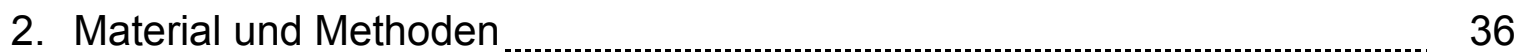

2.1. Psychiatrischer Teil .................................................................... 36

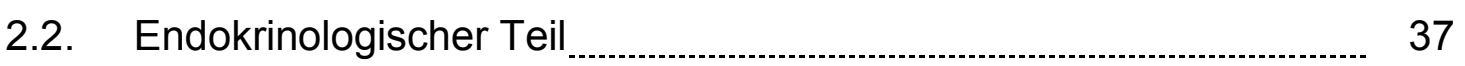

2.2.1. Schilddrüsenhormonparameter ............................................ 37

2.2.2. Schilddrüsen-Autoantikörper _............................................. 39

2.2.3. Apparative Diagnostik ........................................................ 43

2.2.4. Diagnosekriterien ..................................................................... 46

2.2.5. Datenauswertung/Statistische Methoden ............................... 46

3. Ergebnisse ........................................................................................... 48

3.1. Patientencharakteristika

3.1.1. Alter 49

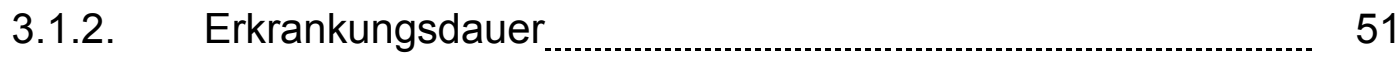


3.1.3. Lithiummedikation 52

3.2. Schilddrüsenhormonparameter $\ldots$

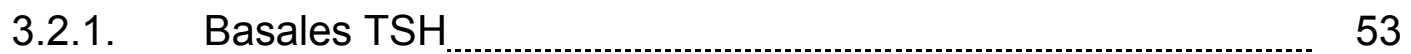

3.2.2. fT3 und fT4

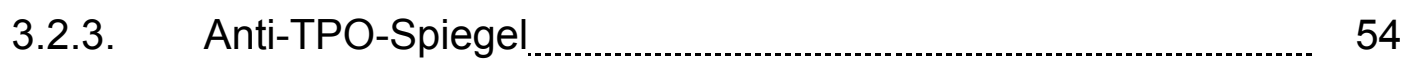

3.2.4. Korrelation von TSH und anti-TPO _..................................... 55

3.2.5. Anti-TG-Spiegel ..................................................................... 56

4. Diskussion 58

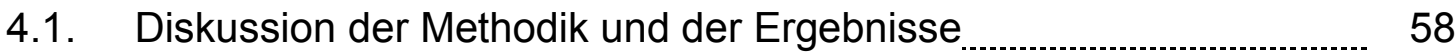

4.1.1. Geschlecht

4.1.2. Lithiummedikation _....................................................... 58

4.1.3. Basales TSH

4.1.4. Schilddrüsenhormonparameter ............................................. 59

4.1.5. Schilddrüsen-Autoantikörper $\quad$ S.............................................. 60

4.2. Autoimmunthyreoiditis (AIT) und affektive Störungen _..................... 61

5. Zusammenfassung

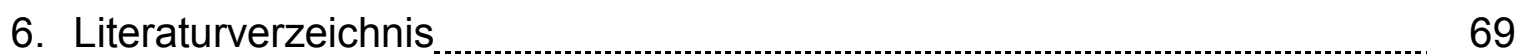




\section{ABBILDUNGSVERZEICHNIS}

Abbildung $1 \quad$ Schilddrüsen-Regelkreis/Feedbackmechanismen 3

Abbildung 2 Autoimmunologische Entstehungsmechanismen einer AIT .... 14

Abbildung $3 \quad$ Sonographische Darstellung der Schilddrüse …....................... 44

Abbildung $4 \quad$ Histologisches Übersichtspräparat einer typischen AIT .......... 45

Abbildung $5 \quad$ Vergrößerung eines histologischen Präparates

einer typischen AIT ................................................................. 46

Abbildung $6 \quad$ Diagnosegruppen AIT

Abbildung $7 \quad$ Negative Korrelation zwischen Alter und anti-TPO in beiden

Diagnosegruppen ................................................................ 50

Abbildung 8 Diagnosegruppen nach Erkrankungsdauer bis Studieneinschluss 51

Abbildung 9 Diagnosegruppen nach Erkrankungsdauer bis Studieneinschluss

Abbildung 10 Anti-TPO-Titer in Korrelation mit Lithiummedikation und Diagnose

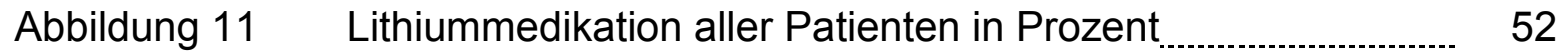

Abbildung $12 \quad$ TSH-basal-Spiegel einzelner Diagnosegruppen _.................... 53

Abbildung 13 Anti-TPO-Spiegel nach Diagnosegruppen und Geschlecht .... 54

Abbildung 14 Korrelation zwischen anti-TPO- und TSH-basal-Spiegeln aufgeteilt nach Diagnosegruppen

Abbildung 15 Signifikante Korrelation zwischen anti-TG- und anti-TPOSpiegel in beiden Diagnosegruppen 


\section{TABELLENVERZEICHNIS}

Tabelle 1

Tabelle 2

Tabelle 3

Tabelle 4

Tabelle 5

Tabelle 6

Tabelle 7

Tabelle 9
Übersicht Schilddrüsen-Dysfunktionen

4

Formen entzündlicher oder autoimmuner

Schilddrüsenerkrankungen

7

Prävalenzangaben unterschiedlicher Studien zum

Vorhandensein von Antikörpern gegen thyreoidale

Peroxidase und gegen Thyreoglobulin.

8

Ergebnisse der SHIP-Studie bzgl. der AIT 10

Schilddrüsenspezifische Antikörper und deren Funktion 11

Einteilung affektiver Störungen nach ICD-10. 27

Übersicht der Immun-Assays zur Bestimmung der

Schilddrüsenparameter 42

Patientenkollektiv nach Diagnosegruppen 48

Patientencharakteristik und Lithiummedikation nach

Diagnosegruppen 52 


\section{ABKÜRZUNGSVERZEICHNIS}

AIT

Ak

al.

bzw.

CTLA4

d

EEG

ELISA

fT3

fT4

HE

HLA

HVL

ICD-10

IL-1

IT

IU/I

$\mathrm{kg}$

KG

I

L-T4

MAO

$\mu \mathrm{g}$

$\mathrm{MHz}$

$\min$

$\mathrm{ml}$

mRNA

MS

$\mathrm{mU}$
Autoimmunthyreoiditis

Antikörper

alii = andere

beziehungsweise

Zytotoxisches T-Lymphozyten-Antigen 4

die $=$ Tag

Elektroenzephalogramm

Enzyme-linked Immunosorbent Assay

freies Triiodthyronin

freies Thyroxin

Hämatoxylin-Eosin

Human Leukocyte Antigen = humanes Leukozytenantigen

Hypophysenvorderlappen

International Classification of Diseases and related Health

Problems, 10th Revision = Internationale statistische Klassifikation

der Krankheiten und Gesundheitsprobleme, 10. Revision

Interleukin-1

Immunthyreopathie

Internationale Einheiten/ Liter

Kilogramm

Körpergewicht

Liter

Levo-Thyroxin

Monoaminoxidase

Mikrogramm

Megahertz

Minute

Milliliter

messenger- oder Boten- Ribonukleinsäure

Multiple Sklerose

Milliunits 
$\mathrm{n}$

ng

NIS

OR

$\mathrm{p}$

rho

RIA

rT3

SD

SHIP

SNRI

sog.

SPSS

SSRI

T3

T4

TG, Tg

TG-Ak

$\mathrm{TH} 1$

TNF-alpha

TPO

TPO-Ak

TRAK

TRH

TSH

TZA

U

vs

WHO

z.B.

ZNS

z.T. numerus $=$ Zahl

Nanogramm

Natrium-Jodid-Symporter

Odds Ratio

Signifikanzniveau (engl. probability)

Rangkorrelationskoeffizient

Radio Immuno Assay

Reverses Trijodthyronin

Schilddrüse

Study of Health in Pomerania, „Leben Gesundheit in Vorpommern“

Serotonin-Noradrenalin-Wiederaufnahmeinhibitoren

sogenannt

Statistical Package for the Social Sciences

Selektive Serotonin-Wiederaufnahmeinhibitoren

Trijodthyronin

Tetrajodthyronin $=$ Thyroxin

Thyreoglobulin

Thyreoglobulin-Antikörper

T-Helferzelle 1

Tumornekrosefaktor alpha

Thyreoidale Peroxidase

Antikörper gegen thyreoidale Peroxidase

TSH-Rezeptor-Antikörper

Thyreotropin Releasing Hormone $=$ Thyreoliberin

Thyreoidea-stimulierendes Hormon

Trizyklische Antidepressiva

Units = Einheiten

versus

World Health Organization $=$ Weltgesundheitsorganisation

zum Beispiel

Zentrales Nervensystem

zum Teil 


\section{EINLEITUNG}

\subsection{Thematik}

Seelische Vorgänge und endokrinologische sowie immunologische Funktionen zeigen beim Menschen eine multidimensionale Interaktion. Schilddrüsenhormone beeinflussen auf vielfältige Weise das zentrale Nervensystem (ZNS) und das psychische Erleben. Schon seit Beginn des letzten Jahrhunderts ist bekannt, dass Schilddrüsendysfunktionen komplex mit Veränderungen des Affektes assoziiert sind und Kognition sowie Vorgänge des Denkens nachhaltig beeinflussen können. Der lange bekannte Zusammenhang zwischen psychischen Veränderungen und hormonellen Störungen wird allgemein durch den Begriff des „endokrinen Psychosyndroms" beschrieben (Bleuler et al. 1983). Beispielsweise sind bei Hypothyreosen depressive Syndrome und schwere Antriebsstörungen, bei Hyperthyreosen maniforme Syndrome und Übererregbarkeit allgemein bekannt, jedoch nicht pathognomonisch im Sinne der thyreoidalen Dysfunktion (Heinrich und Grahm 2003, Abraham et al. 2005). Typischerweise bessern sich diese psychiatrisch-neurologischen Symptome bzw. Komplikationen durch eine Therapie der gestörten Schilddrüsenfunktion. Auch Immunthyreopathien, wie z.B. die Autoimmunthyreoiditis vom Typ Hashimoto (chronisch lymphozytäre Autoimmunthyreoiditis, AIT), können teilweise mit einer Reihe unterschiedlicher psychiatrischer Symptome einhergehen, da im Verlauf eine Dysregulation der Schilddrüsenfunktion auftreten kann (Degner et al. 2001).

In der Literatur werden zum Teil sehr heterogene Angaben zur Prävalenz von Immunthyreopathien (IT) bei Patienten mit affektiven Störungen gemacht. Bislang ist letztlich noch unklar, inwieweit psychiatrische Patienten hinsichtlich z.B. der Abklärung einer Autoimmunthyreoiditis und deren gezielter Diagnostik und Therapie konkret profitieren können. Zwar haben Erkenntnisse und Forschungsergebnisse über Autoimmunprozesse allgemein und beispielsweise über die HashimotoEnzephalopathie sowie über affektive Störungen in den letzten Jahren deutlich zugenommen, jedoch werden Häufigkeit und Relevanz einer AIT und deren potentielle klinische Folgen bei affektiven Störungen möglicherweise noch unterschätzt und umfassendere, wechselseitige Zusammenhänge noch nicht 
adäquat evaluiert. Es erscheint daher sinnvoll, diese komplexen und heterogenen Wechselwirkungen erneut wissenschaftlich zu untersuchen.

\subsection{Schilddrüse}

\subsubsection{Anatomie und Physiologie der Schilddrüse}

Die Schilddrüse ist anatomisch im ventralen Halsbereich unmittelbar vor der Luftröhre (Trachea) lokalisiert. Es handelt sich um eine phylo- und ontogenetisch komplex zusammengesetzte endokrine Drüse, die aus den eigentlichen Schilddrüsenzellen, den Thyreozyten, sowie den histologisch und funktionell davon unabhängigen Calcitonin produzierenden C-Zellen besteht. Das Calcitonin ist ein Hormon des Calciumstoffwechsels und spielt bezüglich der Schilddrüsenfunktion keine Rolle.

Die Hauptfunktion der Schilddrüse besteht in der Produktion der jodhaltigen Schilddrüsenhormone. Diese sichern den basalen, oxidativen Stoffwechsel sämtlicher Organe.

Jodid wird mittels des sog. Natrium-lodid-Symporters (NIS), gegen einen Konzentrationsgradienten in die Schilddrüsenzelle gepumpt (Jodination). Das Jodidion wird dann über den Transporter Pendrin direkt in das Follikellumen transportiert und dort durch das zellmembranständige Enzym Thyreoidale Peroxidase (TPO) oxidiert und an die Tyrosinreste des sog. Thyreoglobulins, ein ca. 660000 Dalton schweres Glykoprotein, gebunden (Jodisation).

Aus diesen durch die Jodisation entstandenen jodierten Tyrosinresten bestehen die Schilddrüsenhormone Tetrajodthyronin (T4) sowie Trijodthyronin (T3), die nach Freisetzung vom Thyreoglobulin die Zellmembran frei passieren und über das Blutgefäßsystem zu ihren Zielzellen gelangen können. Das im Blut freie, nicht gebundene T3 (fT3) weist gegenüber der gebundenen Form und dem T4 die größte biologische Aktivität auf. Hauptsächlich entsteht das fT3 durch periphere Konversion (z.B. im Plasma, in der Leber oder im ZNS) aus dem inaktiveren T4. Die Halbwertszeiten beider Hormone sind lang, für T4 werden 5 bis 8 Tage und für T3 werden 19 Stunden beschrieben (Hotze und Schumm-Draeger 2003). 
Die Schilddrüsenfunktion wird über die hypothalamisch-hypophysäre Achse gesteuert. Der Hypothalamus stimuliert als übergeordnetes Organ durch Bildung des Thyreotropin Releasing Hormon (TRH) den Hypophysenvorderlappen (HVL). Die Freisetzung von TRH wird unter anderem auch über einen durch die Serumkonzentration der Schilddrüsenhormone T3 und T4 abhängigen FeedbackMechanismus reguliert. Der Hypophysenvorderlappen wiederum steuert durch sein Thyreoidea-stimulierendes Hormon (TSH) die Synthese und Sekretion von SDHormonen (Nillni und Sevarino 1999). Das Hypophysenhormon TSH spielt eine zentrale Rolle innerhalb des endokrinen Systems und erfasst die Funktion des SDRegelkreises am sensitivsten (Zoephel et al. 1999).

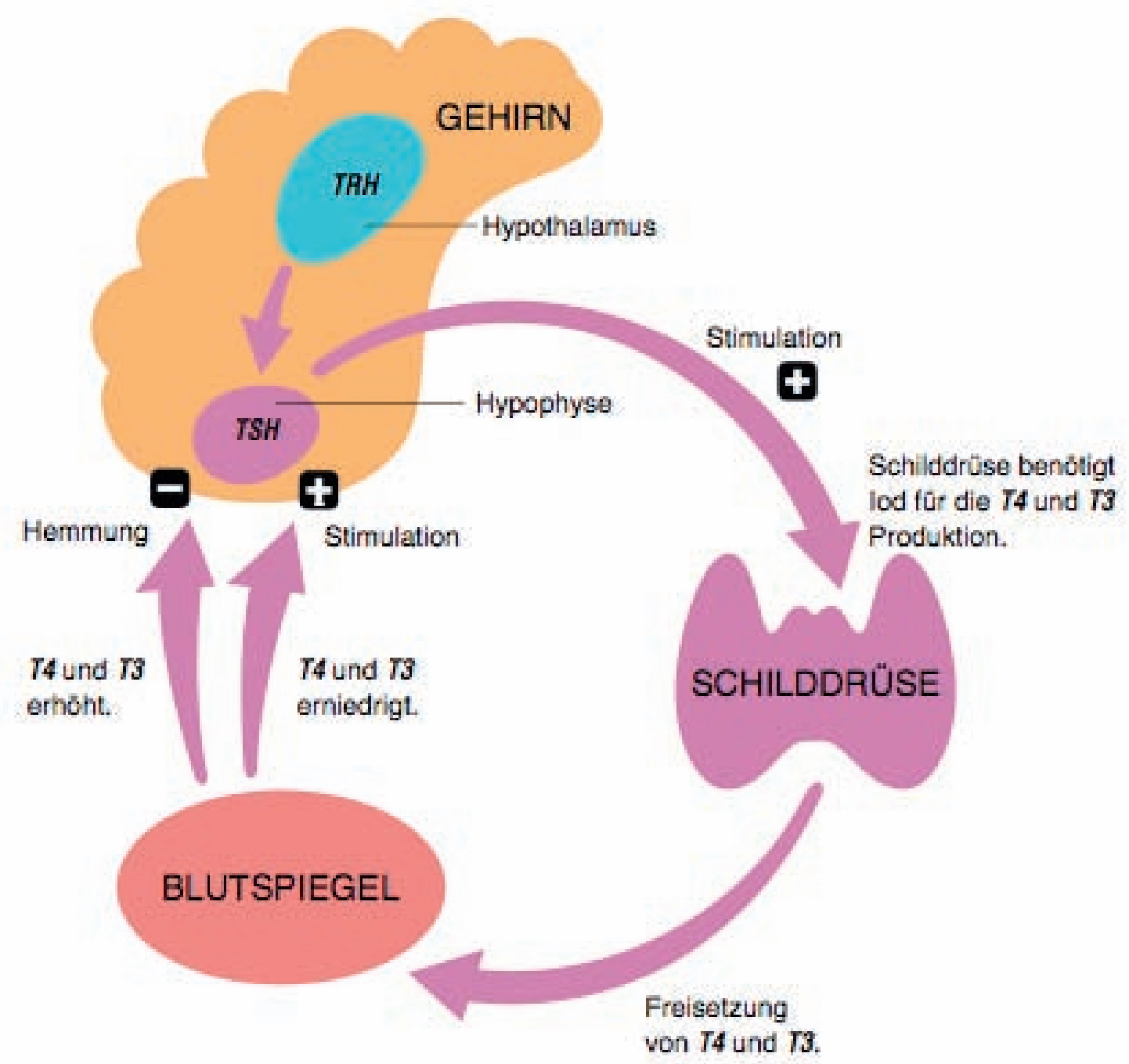

Abbildung 1 Schilddrüsen-Regelkreis/Feedbackmechanismen (modifiziert nach Hotze und Schumm-Draeger 2003, S. 33) 


\subsubsection{Schilddrüsen-Dysfunktionen}

Als wichtige Funktionsstörungen der Schilddrüse gelten eine Hyperthyreose und eine Hypothyreose. Beide Funktionsstörungen können manifest (mit klinischen Symptomen) oder latent (nur laborchemisch nachweisbar) auftreten.

Bei der Hyperthyreose handelt es sich um eine Überproduktion und/oder um die vermehrte Abgabe von T3 und T4 aus der Schilddrüse ins Blut mit konsekutiver Suppression der hypophysären TSH-Sekretion über den Feedbackmechanismus. Eine Hyperthyreose kann im Extremfall sogar zur lebensbedrohlichen Krise führen (Thyreotoxikose).

Die häufigsten Ursachen für eine Hyperthyreose sind unter anderem Immunthyreopathien und funktionelle Autonomien der Schilddrüse. Klinisch kommt es häufig zu einer Tachykardie, Gewichtsabnahme, motorischer Unruhe und Wärmeintoleranz, aber auch zu Haarausfall und einem Tremor.

Psychisch kann sich die Erkrankung unter anderem in Form von Gereiztheit, Konzentrationsstörungen, Schlafstörungen, Stimmungsschwankungen mit maniformen oder auch depressiven Symptomen und gelegentlich psychotischen Symptomen äußern (Hörmann 1998).

\begin{tabular}{|c|c|c|c|c|}
\hline \multirow{2}{*}{$\begin{array}{c}\text { SD- } \\
\text { Dysfunktionen }\end{array}$} & \multirow{2}{*}{ Hyperthyreose } & \multicolumn{3}{|c|}{ Hypothyreose } \\
\hline & & Primär & Sekundär & Tertiär \\
\hline Defekt & Hypophyse & Schilddrüse & Hypophyse & Hypothalamus \\
\hline \multirow{2}{*}{ Hormone } & $\downarrow$ TSH & 个TSH & $\downarrow \mathrm{TSH}$ & $\downarrow T R H, \downarrow T S H$ \\
\hline & 个T3/T4 & $\downarrow T 3 / T 4$ & $\downarrow T 3 / T 4$ & $\downarrow T 3 / T 4$ \\
\hline Test & & & TRH-Test neg. & TRH-Test pos. \\
\hline Ätiologie & $\begin{array}{l}\text { autoimmun, } \\
\text { funktionell, } \\
\text { neoplastisch, } \\
\text { iatrogen } \\
\text { (Jod, } \\
\text { Kontrastmittel) }\end{array}$ & $\begin{array}{c}\text { kongenital, } \\
\text { entzündlich, } \\
\text { autoimmun, } \\
\text { iatrogen } \\
\text { (medikamentös, } \\
\text { post-OP, } \\
\text { Radioiodtherapie) } \\
\text { neoplastisch, } \\
\text { idiopathisch }\end{array}$ & $\begin{array}{c}\text { Erkrankungen der } \\
\text { Hypophyse }\end{array}$ & $\begin{array}{l}\text { Erkrankung des } \\
\text { Hypothalamus }\end{array}$ \\
\hline
\end{tabular}


Eine Hypothyreose ist definiert als Folge des Mangels oder der unzureichenden Versorgung der Körperzellen mit Schilddrüsenhormonen. Sie lässt sich in eine primäre, sekundäre und tertiäre Hypothyreose unterteilen und resultiert fast immer aus einer Schädigung oder Insuffizienz des Schilddrüsengewebes.

Bei der primären Hypothyreose liegt die Störung in der Schilddrüse selbst. Als mögliche Ursache kommen in Betracht: Entzündungen, Neoplasien, Operation der Schilddrüse, Radioiodtherapie, perkutane Strahlentherapie (Schilddrüse im Strahlenfeld), Medikamente, angeborene Hypoplasien, oder aber auch Autoimmunprozesse (Autoimmunthyreoiditis vom Typ Hashimoto). Die meisten primären Hypothyreosen sind irreversibel und durch einen hohen TSH-Spiegel bei niedrigem T3- und T4-Spiegel gekennzeichnet. Die sekundäre Hypothyreose ist durch fehlende oder nicht ausreichende thyreotrope Stimulation der Schilddrüse bedingt. Bei der tertiären Hypothyreose bleibt infolge fehlender TRH-Freisetzung die Stimulation der Hypophyse und die damit verbundene TSH-Freisetzung aus (vgl. Tabelle 1).

Die typische klinische Symptomatik einer Hypothyreose geht mit Müdigkeit, Antriebslosigkeit, Leistungsminderung, Schwäche, Kälteintoleranz, Hypothermie, Gewichtszunahme bei geringem Appetit, Haarausfall, Bradykardie, Obstipation, Hyporeflexie, Libido- und Potenzabnahme einher. Eine seltene, lebensbedrohliche Exazerbation einer Hypothyreose stellt das hypothyreote Koma dar (Hörmann 1998).

Psychisch kann sich die Unterfunktion häufig in Form von Antriebsarmut, Apathie, Schläfrigkeit und auch kognitiven Einbußen mit Konzentrations- und Gedächtnisstörungen im Sinne eines depressiven Syndroms äußern. Eine depressive Symptomatik ist aber keinesfalls pathognomonisch für eine Hypothyreose. Meistens sind die psychischen Folgen psychopathologisch heterogener, da sich gelegentlich auch psychotische Symptome finden. 


\subsubsection{Immunthyreopathien}

Autoimmune Schilddrüsenerkrankungen sind die häufigsten Autoimmunerkrankungen des Menschen. Jeder zehnte Einwohner in Deutschland ist von einer Immunthyreopathie (IT) betroffen, somit zählt die IT auch zu der Gruppe der sogenannten Volkskrankheiten. Als IT im engeren Sinne betrachtet man die Autoimmunthyreoiditis (AIT), sowie die Immunogene Hyperthyreose. Letztere wird auch als Morbus Basedow bezeichnet. Seltenere Formen der autoimmunen Schilddrüsenerkrankungen sind die „silent Thyreoiditis“ (passagere Unterform der AIT mit mildem Verlauf) sowie iatrogen induzierte Formen und die PostpartumThyreoiditis. Die subakute Thyreoiditis de Quervain und die Riedel-Struma sind weitere Thyreoiditis-Formen, die mit einer hypothyreoten Stoffwechsellage einhergehen können, jedoch sehr selten sind, weswegen sie im Folgenden nicht weiter beschrieben werden (vgl. Tabelle 2).

Die AIT weist klinisch zwei Verlaufsformen, entweder mit einer Strumabildung (Hashimoto-Thyreoiditis) oder eine primäre Atrophie der Schilddrüse (atrophische AIT) auf, und kann mit einer Hypothyreose, einer Euthyreose und zum Teil auch initial mit einer hyperthyreoten Phase einhergehen. 
Autoimmunthyreoiditis (AIT, mit und ohne subklinische/manifeste Hypothyreose)

- mit Struma (Hashimoto-Thyreoiditis)

- ohne Struma

- $\quad$ atrophische Schilddrüse

Immunogene Hyperthyreose mit und ohne extrathyreoidaler Manifestation

- Endokrine Orbitopathie (Morbus Basedow)

- prätibiales Myxödem

Varianten autoimmunbedingter Thyreoiditiden

- postpartum Thyreoiditis

- schmerzlose Thyreoiditis

- subakute Thyreoiditis de Quervain

- invasiv-sklerosierende Riedel-Struma

Eitrige, bakterielle Thyreoiditis

Sonstige entzündliche/infiltrierende Schilddrüsenerkrankungen

- Lymphome

- Sarkoidose

- Strahlenthyreoiditis

Tabelle 2 Formen entzündlicher oder autoimmuner Schilddrüsenerkrankungen (nach Gaertner 2002, S. 636)

\subsubsection{Epidemiologie}

Der Wickham Survey von 1977 aus England (sowie die Follow-up-Studie von 1995) ist die größte bevölkerungsbasierte Verlaufsstudie, in der die Inzidenz und Prävalenz der AIT bei insgesamt 2779 Personen untersucht und über 20 Jahre nachverfolgt wurde (Tunbridge et al. 1977, Vanderpump et al. 1995). Es konnte gezeigt werden, dass:

- Bei $10 \%$ der Gesamtbevölkerung erhöhte Antikörper gegen thyreoidale Peroxidase (TPO-Ak) und/oder gegen Thyreoglobulin (Tg-Ak) im Serum nachweisbar sind,

- $7,5 \%$ eine subklinische Hypothyreose, 1,9\% eine manifeste Hypothyreose, $2 \%$ entweder eine subklinische oder manifeste Hyperthyreose haben,

- Frauen 8-10 mal häufiger von einer AIT betroffen sind als Männer. 
Die Prävalenz von TPO-Ak schwankt zwischen 4 und $14 \%$ in der Bevölkerung für Frauen. Bei Männern liegt die Prävalenz positiver Antikörper gegen die thyreoidale Peroxidase deutlich niedriger bei 2,5-3 \% (Bjoro et al. 2000, Bryhni et al. 1996, Lazarus et al. 1984, Roti et al. 1992, Tunbridge et al. 1977). Im Vergleich zu Antikörpern gegen thyreoidale Peroxidase liegt die Prävalenz von Antikörpern gegen Thyreoglobulin (Tg-Ak) um den Faktor 2 bis 3 niedriger. Hohe Joddosen haben einen noch ungeklärten permissiven Effekt, was sich in der Tatsache widerspiegelt, dass sich in Ländern mit hohem Jodkonsum die höchsten Prävalenzen für AIT finden. Im jodreichen Japan beträgt die Prävalenz von Schilddrüsenautoantikörpern 13,9 \% für Frauen und 6,5 \% für Männer (Konno et al. 1993). Die Untersuchung wurde in einer Stichprobe von 4110 Menschen aus Sapporo durchgeführt. Eine repräsentative Auswahl der Daten aus der Publikation mit Prävalenzangaben zum Vorhandensein von Schilddrüsenautoantikörpern gibt die Tabelle 3:

\begin{tabular}{cccccccc} 
Autor & Jahr & Land & $\mathbf{n}$ & $\begin{array}{c}\text { TPO-AK } \\
\text { Frauen }\end{array}$ & $\begin{array}{c}\text { TPO-AK } \\
\text { Männer }\end{array}$ & $\begin{array}{c}\text { TG-AL } \\
\text { Frauen }\end{array}$ & $\begin{array}{c}\text { TG-AK } \\
\text { Männer }\end{array}$ \\
\hline Bjoro et al. & 2000 & Norwegen & 942 aus 34744 & 13,9 & 2,8 & - & - \\
\hline Bryhni et al. & 1996 & Norwegen & 2551 & 8,5 & 3,6 & 3,5 & 2,0 \\
\hline $\begin{array}{c}\text { Tunbridge et } \\
\text { al. }\end{array}$ & 1977 & Großbritannien & 2771 & 10,3 & 2,7 & 3,1 & 0,9 \\
\hline $\begin{array}{c}\text { Konno et al. } \\
\text { Roti et al. }\end{array}$ & 1993 & Japan & 4110 & 8,4 & - & 4,5 & - \\
\hline Ro & Italien & 342 & 10,3 & 2,3 & - & - \\
\hline
\end{tabular}

Tabelle 3 Prävalenzangaben unterschiedlicher Studien zum Vorhandensein von Antikörpern gegen thyreoidale Peroxidase und gegen Thyreoglobulin

Die Wickham-Studie konnte weiterhin zeigen, dass die Prävalenz subklinischer Hypothyreosen mit höherem Lebensalter steigt:

Bei:

- $6 \%$ der Frauen unter 60 Jahren,

- 7-10 \% der Frauen über 60 Jahren,

- $20 \%$ der Frauen und $16 \%$ der Männer über 75 Jahren konnte ein entsprechender Nachweis erbracht werden.

Insgesamt sind Frauen etwa 8-10 mal häufiger an einer AIT erkrankt als Männer. Etwa ein Viertel der Kinder, von denen ein Elternteil an einer AIT leidet, hat erhöhte 
Autoantikörper. Etwa $5 \%$ der Frauen mit positiven Autoantikörpern und erhöhten TSH-Spiegeln werden innerhalb eines Jahres manifest hypothyreot, und 4 von 1000 Einwohnern entwickeln spontan eine Hypothyreose. Bei Nachweis von Antikörpern war dieses Risiko etwa 8fach höher bei Frauen und 44fach höher bei Männern.

In der sog. „SHIP“-Studie (Study of Health in Pomerania, „Leben Gesundheit in Vorpommern“, Voelzke et al. 2003) wurde in einem Zeitraum von Oktober 1997 bis März 2001 aus einer Gesamtpopulation von 212.157 Einwohnern Vorpommerns, einem ehemaligen Jodmangelgebiet, Daten von 3.941 Teilnehmern (20 - 79 Jahre) mit bislang nicht bekannter Schilddrüsenerkrankung analysiert.

Erhöhte TPO-Ak konnten alters- und geschlechtsabhängig bei 265 Teilnehmern nachgewiesen werden (Gesamt: 7,0\%, Männer: 4,2 \%, Frauen: 7,4 \%). Erhöhte TPO-Ak waren sowohl bei Frauen als auch in höheren Altersdekaden häufiger.

Ein inhomogenes Schilddrüsenechomuster wurde bei 1.389 Teilnehmern (Gesamt: $35,2 \%$, Männer: $28,2 \%$, Frauen: $42,0 \%$ ) diagnostiziert und wurde häufiger bei älteren Teilnehmern und bei Frauen nachgewiesen ( $p<0,05$; OR 2,1; $95 \%-\mathrm{Cl} 1,8$ $2,4)$.

Die Autoimmunthyreoiditis wurde mit Hilfe von Ultraschallcharakteristika (Inhomogenität, Echoarmut) und positiver Serum-TPO-Ak definiert. Anhand dieser Kriterien wurde eine AIT-Prävalenz von 1,2 \% (Gesamt: $n=47$; Männer: $n=2$; Frauen: $\mathrm{n}=45$ ) ermittelt (vgl. Tabelle 4). 
TPO-AK

$n=265: 7,0 \%(m: 4,2 \%, w: 7,4 \%)$

Inhomogen, echoarmes Ultraschallmuster

$n=1389: 35,2 \%$ (m: $28,2 \%, w: 42,0 \%)$

AIT-Prävalenz (inhomogen, echoarmes Ultraschallmuster plus TPO-AK)

$\mathrm{n}=47(\mathrm{~m}: 2, \mathrm{w}: 45): 1,2 \%$

\section{Funktion bei AIT}

- hypothyreot $(n=13): 27,7 \%$

- subklinisch hypothyreot $(n=3): 6,4 \%$

- euthyreot $(n=30): 63,8 \%$

- subklinisch hyperthyreot $(n=1): 2,1 \%$

Tabelle $4 \quad$ Ergebnisse der SHIP-Studie bzgl. der AIT

Zusammengefasst lag die Häufigkeit einer Hypothyreose je nach Studie zwischen 4,3\% und 9,5\%. Eine Hyperthyreose fand sich im Mittel bei 2,4 \% (Spannweite 1,2 \%- 4,7 \%). Das Vorkommen erhöhter TPO-Ak lag bei etwa $10 \%$.

\subsubsection{2. Ätiologie und Pathogenese}

Autoimmunerkrankungen beruhen auf einer pathologischen, chronischen Immunreaktion, die sich gegen körpereigene Antigene richtet (Kronenberg 1991). An der Pathogenese der AIT sind offenbar sowohl zelluläre als auch humorale Mechanismen beteiligt. Das gemeinsame histomorphologische Korrelat von Autoimmunerkrankungen der Schilddrüse ist die Infiltration des Organs mit dendritischen Zellen, Plasmazellen und Lymphozyten (sowohl B- als auch TLymphozyten) sowie die Entwicklung von Autoantikörpern gegen spezifische Antigene der Schilddrüse (vgl. Tabelle 5). 


\begin{tabular}{lll}
\hline Antigen & Antikörper & Funktion \\
\hline Thyreoglobulin & TG-Ak & Keine \\
\hline Thyreoidale Peroxidase & TPO-Ak & Wahrscheinlich zytotoxisch \\
\hline & & Je nach Epitop \\
TSH-Rezeptor & TRAK & $\bullet$ stimulierend \\
& & $\bullet$ blockierend \\
& T3-Ak & binden T3 Funktion \\
\hline Trijodthyronin (T3) & NIS-Ak & unklar \\
\hline Natrium-lodid-Symporter (NIS) & & \\
\hline
\end{tabular}

Tabelle 5 Schilddrüsenspezifische Antikörper und deren Funktion

Die Infiltrate bestehen überwiegend aus T-Zellen mit einem $\mathrm{CD}^{+}$(zytotoxisch/ Suppressor-)- und einem anteilmäßig etwas geringer vertretenem $\mathrm{CD}^{+}{ }^{+}$(T-Helfer-)Phänotyp (Bene et al. 1983, Jansson et al. 1983). T-Lymphozyten spielen die tragende Rolle in der Pathogenese der AIT. Im Tierversuch konnten aus Schilddrüseninfiltrat gewonnene $\mathrm{CD}^{+}$-Zellen eine Thyreoiditis auf gesunde Tiere übertragen (Romball und Weigle 1987). Es kann als sicher angenommen werden, dass Wechselwirkungen zwischen Thyreozyten, T-Zellen und Monozyten/ Makrophagen sowohl für die Induktion als auch für die Aufrechterhaltung des Autoimmunprozesses eine entscheidende Rolle spielen.

Die wichtigsten, insbesondere die AIT betreffenden Autoantikörper sind Thyreoglobulin-Antikörper (Tg-Ak) und Thyreoidale Peroxidase-Antikörper (TPO-Ak). Auch bei anderen Schilddrüsenerkrankungen sind erhöhte Serum-Spiegel für diese Autoantikörper zu finden, wenngleich häufig mit deutlich niedrigerem Ak-Titer. Die Autoantikörper sind nicht primär als Krankheitsauslöser, sondern vielmehr als Folgeerscheinung der Erkrankung zu sehen und wahrscheinlich teilweise für die klinische Manifestation der Erkrankung (z.B. Hypo- oder Hyperthyreose) mitverantwortlich.

In einer Arbeit an einem transgenen Mausmodell konnte erstmals gezeigt werden, dass ein bestimmtes Epitop der Thyreoidalen Peroxidase (TPO) von zytotoxischen TLymphozyten erkannt wird (Quaratino et al. 2004). Alle Mäuse entwickelten lymphozytäre Infiltrationen, einen Abfall der Serum-T4- und Serum-T3-Spiegel und Anstiege des TSH. Dies legt die Vermutung nahe, dass Teile der Thyreoidalen Peroxidase das Hauptepitop des Immunprozesses darstellen. Eine detaillierte 
Analyse der lymphozytären Infiltrate betroffener Patienten zeigt ein Th1-Zytokinprofil im Sinne einer zytotoxischen Immunreaktion (Heuer et al. 1996). Zelluläre Immunreaktionen gegen das Thyreoglobulin (TG), einem weiteren potenziellen schilddrüsenspezifischen Antigen, werden nach derzeitigem Kenntnisstand als immunologische Sekundärphänomene eingeordnet.

Eine große Rolle beim Verlust der Toleranz gegen Eigenantigene spielt offenbar eine genetische Prädisposition, die sich wiederum aus dem Zusammenspiel mehrerer Allele auf verschiedenen Genen ergibt (Vaidya et al. 2002). Ein „verantwortlicher“ Gen-Locus ist das HLA (Humanes-Leukozyten-Antigen) - System auf dem Chromosom 6p21. Die immunogene Hyperthyreose (M. Basedow) ist gehäuft gekoppelt mit dem Vorhandensein von u.a. HLA-DR3 und HLA-B8 (Tomer und Davies 1997). Die Assoziation bestimmter HLA mit der autoimmunen Hypothyreose scheint schwächer, aber auch vorhanden zu sein, u.a. mit HLA-DR3, -DR4, -DR5 (Vaidya et al. 2002, Boehm et al. 1993). Ein weiterer Genlocus ist das zytotoxische T-Lymphozyten-Antigen-4 (CTLA4) auf Chromosom 2q33. Das CTLA4 ist ein immunregulatorisches Molekül, das von aktivierten T-Lymphozyten exprimiert wird. Viele Untersuchungen zeigen, dass es ein Inhibitor der T-Zell-Aktivität ist. Drei CTLA4-Polymorphismen wurden bzgl. ihrer Verbindung zu Autoimmunerkrankungen, insbesondere zu Autoimmunerkrankungen der Schilddrüse, untersucht, eine spezifische Assoziation konnte gezeigt werden (Chistiakov und Turakulov 2003, Braun et al. 1998, Barbesino und Chiovato 2000, Guilherme et al. 1995, Gough 2000, Tait und Gough 2003, Vaidya et al. 2002). Polymorphismen in Genen, die für bestimmte Zytokine codieren, haben Einfluss auf das Auftreten von Autoimmunerkrankungen der Schilddrüse. Dazu gehören Gene für Interleukin-4 und Interleukin-12 (Hunt et al. 2000, Falcone und Sarvetnick 1999). Die Erhöhung der Empfindlichkeit gegenüber Zytokinen wie Interferon- $\mu$, IL-1 und TNF-alpha kann zur Verminderung der Produktion von Schilddrüsenhormonen bei der AIT beitragen. Dennoch müssen, wie eine Zwillingsstudie (Brix et al. 2000) zeigte, offenbar zusätzlich nicht-genetische Faktoren eine große ätiologische Rolle für die Auslösung einer AIT spielen. Hierzu gehören unter anderem virale und bakterielle Infektionen, Sexualhormonstörungen (z.B. nach Schwangerschaften oder perimenopausal), Selen-Mangel, immunstimulierende Medikamente (z.B. Th1-Zytokine wie Interferon- 
alpha, Interleukin 2), eine Strahlen-Exposition der Schilddrüse, Toxine oder auch sog. „negativer Stress“ (Weetman 2000).

Durch psychische Faktoren werden die Synthese und Ausschüttung von Neurotransmittern, Hormonen und Zytokinen aktiviert, die die immunologische Funktion regulieren und steuern. Auf diese Weise können seelische Aspekte, wie z.B. Stress, das Immunsystem alterieren und möglicherweise zu einer Entstehung von Autoimmunerkrankungen, z.B. auch der Hashimoto-Thyreoiditis beitragen. Umweltfaktoren wurden ebenfalls als prädisponierend für eine AIT beschrieben. Hierzu zählen das Rauchen und eine hohe Jodversorgung. Die genannten Faktoren können sämtlich mit einer erhöhten Inzidenz einer AIT einhergehen (Laurberg et al. 1998).

Die Triggerfaktoren verursachen durch eine Zerstörung thyreoidaler Zellen eine Freisetzung von Thyreoidase-spezifischem Material. Antigen-präsentierende Zellen präsentieren diese Peptide auf ihrer Zelloberfläche und wandern in die drainierenden Lymphknoten. Hier können sie aufgrund der gestörten Immuntoleranz B- und TZellen aktivieren, die dann in die Schilddrüse einwandern. Die von Plasmazellen produzierten Antikörper (Ak) richten sich gegen verschiedene Bestandteile der Zellen der Schilddrüse, meist gegen die Thyreoidale Peroxidase (TPO) und gegen das Thyreoglobulin (TG), seltener gegen das Zytoplasma oder den Rezeptor für Thyreoidea-stimulierendes Hormon (TRAK). Fascillin-vermittelt, kommt es zu einer Apoptose der Thyreozyten (Chistiakov 2005). 
Genetische Disposition + virale Infektion, Stress, Umweltfaktoren u.a.

$\downarrow$

Aktivierung dendritischer Zellen

$\downarrow$

IFN- - -Produktion

$\downarrow$

Aktivierung der Thyreozyten

$\downarrow$

MHC-Klasse-II-Präsentation auf der Thyreozytenoberfläche (und später auch MHC-Klasse-I-Präsentation)

$\downarrow$

Aktivierung von CD4-T-Zellen durch weitere Faktoren

(wie ICAM-1 und LFA-1 und Kofaktoren wie B7, CD28 und CTLA-4)

$\downarrow$

Bindung von CD4-T-Zellen und NK-Zellen an Thyreozyten

Komplement-Aktivierung, Zytokinbildung, etc.

$\downarrow$

a) Funktionsstörung bzw. Zerstörung der Thyreozyten

b) B-Zell-Aktivierung in der Schilddrüse, Lymphknoten und Knochenmark

(durch dendritische Zellen und ihrerseits durch schon aktivierte

T-Lymphozyten sowie durch IL-6 und IL-13)

$\downarrow$

Antikörperproduktion (TPO-Ak, TG-Ak)

Abbildung 2 Autoimmunologische Entstehungsmechanismen einer AIT (modifiziert nach Weetman und McGregor 1994, S. 798)

\subsubsection{Verlauf und klinisches Bild}

Das Erkrankungsbild wurde erstmals 1912 von Hakaru Hashimoto (1881-1934) klinisch beschrieben (Hashimoto 1912). Erst 1956 wurde durch Campbell et al. ihre autoimmune Pathogenese erforscht (Campbell et al. 1956). In ihrer klassischen Form führt die Hashimoto-Thyreoiditis zu einer Struma mit fortschreitender Funktionseinbuße (hypothyreote Struma) (Hotze und Schumm-Draeger et al. 2003). Demgegenüber führt die atrophe Variante zu einer progredienten Zerstörung von 
Schilddrüsengewebe. Sie ist mit $80 \%$ die häufigste Schilddrüsenentzündung überhaupt und bedingt eine der jeweiligen Progression entsprechende Hypothyreose mit allmählich nachlassender Schilddrüsenhormonsynthese bis hin zur Entwicklung eines primären Myxödems (Heufelder und Hofbauer 1998). Im Rahmen des lymphozytären Destruktionsprozesses kann die hypertrophe Hashimoto-Thyreoiditis sekundär in eine atrophische Verlaufsform übergehen. Die Autoimmunthyreoiditis tritt vorwiegend bei Frauen in der 4. bis 5. Lebensdekade auf. Oft stammen diese Frauen aus Familien, die bereits gehäuft andere Schilddrüsenerkrankungen aufweisen.

Ähnlich wie andere organspezifischen Autoimmunerkrankungen zeigt die AIT einen klinisch-variablen, schubhaften Verlauf. Manchmal kommt es in der frühen Phase der Erkrankung zu einer spontanen Ausheilung. Eine initiale Hyperthyreose wird durch eine Destruktionshyperthyreose mit verstärkter Freisetzung präformierten Schilddrüsenhormons aus den zerstörten Schilddrüsenfollikeln im Rahmen der lymphozytären Infiltration erklärt.

Zunächst kann die Konzentration der freien Hormone (fT3, fT4) noch im Normalbereich liegen, während das Thyroidea-stimulierende Hormon (TSH) bereits leicht erhöht ist (subklinische Hypothyreose). Etwa 3-5\% der Patienten mit AIT entwickeln pro Jahr eine solche subklinische Hypothyreose, die dann häufig mit einer Atrophie der Schilddrüse einhergeht. Später kann trotz erhöhtem TSH nicht mehr genügend T3 und T4 freigesetzt werden, die Hypothyreose wird laborchemisch manifest. Diese Hypothyreose ist aufgrund der Zerstörung des Parenchyms irreversibel, so dass eine langfristige Substitutionstherapie mit L-Thyroxin als Mittel der Wahl anzusehen ist.

Viele AIT-Patienten sind allerdings klinisch asymptomatisch. Bei diesen Patienten wird die Diagnose häufig zufällig gestellt.

\subsubsection{Diagnostik}

In der Anamneseerhebung sollte eine familiäre Prädisposition erfragt werden. Eine positive Anamnese bezüglich weiterer Autoimmunerkrankungen kann hinweisend für eine IT sein, ebenso wie Symptome der Schilddrüsenfunktionsstörungen. 
Bei jeder klinischen Untersuchung sollte die Schilddrüse durch Palpation beurteilt werden. Im Falle einer AIT ist sie eher weich, kann entweder vergrößert, normal groß oder verkleinert sein.

Neben einem Nachweis von Antikörpern ist die sensitivste Methode zum Nachweis einer AIT eine Ultraschalluntersuchung der Schilddrüse. Das Schilddrüsenparenchym bei einer AIT ist typischerweise inhomogen und diffus echoarm im Gegensatz zu Gesunden, die ein homogenes Schilddrüsenparenchym und eine normale Echogenität aufweisen. Eine diffus vergrößerte, echoarme Schilddrüse, multiple kleine fokale echoarme Infiltrate oder eine kleine, echoarme Schilddrüse wie bei der atrophischen Verlaufsform sind nahezu beweisend für das Vorliegen einer AIT und haben eine Spezifität und Sensitivität von etwa $95 \%$ (Pedersen et al. 2000). Zeigt die Schilddrüse ein völlig normales Binnenecho des Parenchyms, so ist eine AIT meistens auszuschließen.

Eine Schilddrüsenszintigraphie zeigt in der Regel einen verminderten ${ }^{99 \mathrm{~m}}$ Tc-Uptake sowie ein inhomogenes Speichermuster und ist außer in Fällen mit sonographisch nachweisbaren Knoten zum Ausschluss oder Nachweis einer Autonomie bzw. funktionell inaktiver Knoten, nur bei der initial hyperthyreoten Phase zur Abgrenzung der AIT von einer Immunogenen Hyperthyreose hilfreich (Sahlmann et al. 2004).

Eine Feinnadelpunktion zur histologischen Einordnung der Befunde und zum Ausschluss maligner Erkrankungen kann insbesondere bei untypischen Befunden indiziert sein. Sie ist beweisend durch den Nachweis einer lymphozytären Thyreoiditis. Seit der allgemein zugänglichen, hochauflösenden Sonographie kann auf eine Feinnadelbiopsie als zusätzliches diagnostisches Hilfsmittel weitestgehend verzichtet werden.

Die Serum-TSH-Konzentration spiegelt indirekt die aktuelle Hormonsekretion und damit die Versorgung peripherer Organe mit Schilddrüsenhormon wider. In vielen Fällen ist daher die alleinige Bestimmung des basalen TSH-Wertes zur Einschätzung der Schilddrüsenfunktion ausreichend. Für eine Bestimmung der Schilddrüsenhormone im Serum sollten die freien Hormone herangezogen werden, 
weil nur diese die Versorgung der Körperperipherie weitgehend unbeeinflusst widerspiegeln.

\subsubsection{Autoantikörper}

In etwa 80 bis $90 \%$ der Fälle finden sich laborchemisch TPO-Ak, bei etwa 40 bis $70 \%$ der Patienten mit einer AIT sind zudem Ak gegen Thyreoglobulin (Tg-AK) nachweisbar (Pfannenstiel et al. 1997; Dietlein et al. 1999). Die Spezifität der TPOAk zur Diagnose der AIT liegt bei über 90 \%. Die Höhe der Titer korreliert nicht mit der Schwere der klinischen Symptomatik (Gutekunst et al. 1989) und kann im Verlauf der Erkrankung in Abhängigkeit von der Aktivität des Immunsystems stark schwanken. Eine Verlaufsbeobachtung der Titer ist daher nicht notwendig, wenn einmal die Diagnose gestellt wurde. In einer Studie von Meller et al. konnten pathologische TRAK-Werte im DYNOtest TRAKhuman bei $22,5 \%$ (9 von 40 Patienten) der hypothyreoten Patienten mit einer AIT nachgewiesen werden (Meller et al. 2000b). Dies lässt darauf schließen, dass die funktionsblockierenden TRAK bei der Pathogenese der AIT möglicherweise eine größere Rolle spielen, als dies bislang angenommen wurde (vgl. Tabelle 5).

\subsubsection{Therapie}

Eine kausale Therapie der AIT ist nicht möglich, da es sich um eine Störung der Immunregulation handelt. Sie kann derzeit nur symptomatisch behandelt werden. Solange eine euthyreote Stoffwechsellage vorliegt, kann eine Behandlung mit Selen versucht werden, bislang ist die Datenlage allerdings nicht ausreichend (Gaertner und Duntas 2008).

Bei einer manifesten Hypothyreose mit erhöhtem TSH basal und erniedrigtem fT4 ist eine L-Thyroxin-Substitution notwendig. Nachdem gezeigt werden konnte, dass subklinische Funktionsstörungen im Verlauf klinisch symptomatisch werden können (Kalmijn et al. 2000, McDermott und Ridgway 2001), empfiehlt sich eine frühzeitige Substitution bei noch normalen peripheren Schilddrüsenhormonwerten. Eine Substitution mit Jod kann den Autoimmunprozess ungünstig beeinflussen und aggravieren (Reinhardt et al. 1998). 
Bei manifester initialer Hyperthyreose infolge einer AIT, kann die Einleitung einer thyreostatischen Therapie z.B. mit Thiamazol oder Propylthiouracil, notwendig werden. Die Indikation ist allerdings von der klinischen Situation abhängig, da die initiale Phase der AIT in der Regel selbstlimitierend ist und spontan in eine normale oder eine Unterfunktion übergehen kann.

\subsubsection{Assoziierte Autoimmunerkrankungen}

In etwa einem Drittel der diagnostizierten Fälle einer AIT zeigt sich eine Koinzidenz mit anderen Autoimmunerkrankungen (Karni und Abramsky 1999, Morita et al. 1995). Häufig beschrieben ist eine Assoziation mit Rheumatoider Arthritis, SjögrenSyndrom, Systemischem Lupus erythematodes, Myasthenia gravis, Diabetes mellitus Typ I und perniziöser Anämie. Seltener sind Multiple Sklerose, Vitiligo, Alopecia areata, Zöliakie und Primär biliäre Zirrhose (Chistiakov 2005). $45 \%$ aller Patienten mit AIT haben positive Parietalzellantikörper, umgekehrt haben etwa $14 \%$ der Patienten mit perniziöser Anämie auch eine AIT. Etwa $25 \%$ der Patienten mit AIT leiden an einer Rheumatoiden Arthritis. Jeder 5. Patient mit Diabetes mellitus Typ I leidet auch an einer AIT und bei etwa einem Drittel der Patienten mit AIT lassen sich antinukleäre Antikörper gegen Kernantigene (ANA) nachweisen (Weetman 2000). Meller et al. konnten 1999 in einer Studie mit 200 nicht selektierten Patienten mit Autoimmunthyreopathien eine bis zu 12fach höhere Prävalenz für weitere Autoimmunerkrankungen aufzeigen (Meller et al. 2000a). Daher sollte bei uncharakteristischen Beschwerden oder nicht zueinander passenden Laborbefunden und Beschwerden an die Möglichkeit anderer Autoimmunkrankheiten gedacht werden. Diese lassen sich in den meisten Fällen durch die Bestimmung spezifischer Antikörper nachweisen.

\subsubsection{Hashimoto-Enzephalopathie}

Unter dem Begriff Hashimoto-Enzephalopathie versteht man eine Kombination aus einer Autoimmunthyreoiditis und dem Auftreten persistierender oder fluktuierender neurologischer, neuropsychologischer bzw. psychiatrischer Defizite. Das Krankheitsbild der Hashimoto-Enzephalopathie wurde erstmals im Jahr 1966 von Brain et al. beschrieben, wobei bislang weder Ätiologie noch Pathogenese der Hashimoto-Enzephalopathie bekannt sind (Brain et al. 1966). Als mögliche Ursache 
werden neben einem vaskulitisartigen Geschehen auch eine immunologische Genese durch erhöhte autoimmune Antikörper, eines noch unbekannten gemeinsamen Antigens von Schilddrüse und Gehirn oder ein toxischer Effekt erhöhter TRH-Spiegel und des TSH auf das zentrale Nervensystem im Rahmen einer Schilddrüsendysfunktion mit hypothyreoter Stoffwechsellage diskutiert (Hussain et al. 2005, Contreras et al. 2004, Bertoni et al. 2003, Nolte et al. 2000, Forchetti et al. 1997, Henchey et al. 1995, Jordan et al. 1978, Canton et al. 2000, Latinville et al. 1985, Claussmann et al. 1994, Kothbauer-Margreiter et al. 1996).

Da sie auch bei euthyreoten Patienten bzw. nach Korrektur einer Hypothyreose auftritt, kann diese als Ursache der klinischen Symptomatik weitestgehend ausgeschlossen werden (Thrush und Boddie 1974, Shein et al. 1986). In den meisten Fällen lassen sich Antikörper gegen die thyreoidale Peroxidase (TPO-Ak) und seltener gegen das Thyreoglobulin (Tg-AK) laborchemisch nachweisen. Die Höhe der Antikörper weist jedoch keinen Zusammenhang zu Symptomschwere oder Verlauf der Enzephalopathie auf (Kothbauer-Margreiter et al. 1996). Auch bleibt die Symptomatik unbeeinflusst von einer Korrektur der Schilddrüsenhormone (Brain et al. 1966, Mauriac 1982, Shein et al. 1986).

Eine Therapie der Hashimoto-Enzephalopathie mit Kortikoiden, z.T. auch mit anderen Immunsuppressiva, führte jedoch in den meisten Fällen zu einer deutlichen Besserung oder sogar zum Abklingen der neurologischen bzw. psychiatrischen Symptome. Dies spricht für eine autoimmune Genese, wie auch eine Assoziation der Hashimoto-Enzephalitis mit anderen Autoimmunerkrankungen (Becker und McConahey 1963, Mulhern et al. 1966). 


\subsection{Psychische Störungen}

\subsubsection{Definition, Epidemiologie}

Die Psyche umfasst im weiteren Sinn alle bewussten und unbewussten seelischen Vorgänge und wird als dualistischer Gegenbegriff zum Biologisch-Körperlichen des Menschen gesehen.

Psychische Erkrankungen zählen weltweit zu den häufigsten Erkrankungen in der Allgemeinbevölkerung, welche die Prävalenzraten somatischer Erkrankungen überschreiten. Psychische Störungen sind nicht nur mit einer erheblichen Belastung des psychosozialen Wohlbefindens, der allgemeinen Lebenszufriedenheit und Lebensqualität verbunden, sondern führen häufig zu massiven Einschränkungen der Alltagsbewältigung, der Lebensgestaltung und der Arbeitsproduktivität (Lin et al. 1997). Die psychosozialen Beeinträchtigungen werden dabei als schwerwiegender beurteilt als die bei chronischen somatischen Leiden wie z.B. Diabetes mellitus, Arthritis, kardialen oder pulmonalen Erkrankungen (Spitzer et al. 1995).

Unter den psychischen Erkrankungen haben die affektiven Störungen eine besondere Bedeutung, weil sie weltweit zu den häufigsten psychischen Leiden in der Allgemeinbevölkerung zählen. Die Weltgesundheitsorganisation (WHO) berichtete in ihrem Weltgesundheitsbericht 2001, dass unter Berücksichtigung aller psychischen und somatischen Erkrankungen affektive Störungen die dritthäufigste Erkrankung in den Industrienationen darstellen. Ein möglicher weiterer Anstieg innerhalb der nächsten Jahre wird trotz der zur Verfügung stehenden Antidepressiva und wirksamer psychotherapeutischer Interventionen erwartet, so dass Schätzungen zufolge affektive Störungen bis zum Jahr 2020 den zweiten Rangplatz nach den kardiovaskulären Erkrankungen einnehmen sollen (Murray und Lopez 1996, WHO 2001).

\subsubsection{Affektive Störungen}

\subsubsection{Definition, Klassifikation}

Die affektive Störung ist eine der häufigsten Erkrankungen des psychiatrischen Formenkreises. Sie beinhaltet hauptsächlich pathologische Änderungen der Stimmung, der Aktivität und des Antriebs. Sie kann sich in polar entgegengesetzten 
Formen äußern, als Depression oder als Manie, die in zeitlich abgesetzten Phasen auftreten und in der Regel vollständig remittieren. In diesen beschwerdefreien Intervallen zeigen betroffene Patienten keine Persönlichkeitsveränderungen. Dies ist ein deutliches Unterscheidungsmerkmal z.B. zur Schizophrenie. Man unterscheidet üblicherweise unipolare von bipolaren Verlaufsformen sowie einzelne Episoden von rezidivierenden Verläufen. Nach der "International Classification of Diseases” (DIMDI 2000) werden einzelne manische Episoden, bipolar-affektive Störungen, einzelne depressive Episoden, rezidivierende depressive Störungen sowie anhaltende affektive Störungen, wie z.B. die Dysthymia oder die Zyklothymia, klassifiziert.

\subsubsection{Depressionen}

\subsubsection{Historie}

Depressionen sind seit mehreren tausend Jahren bekannt. Schon Hippokrates untersuchte physiologische Grundlagen der Erkrankung und bezeichnete sie als Melancholia. Die Ursache sah er in einem relativen Überschuss an „schwarzer Galle“ gegenüber den drei anderen Körpersäften Blut, Schleim und gelber Galle (Vie und Baruk 1990).

\subsubsection{Epidemiologie}

Erstmanifestationen von Depressionen findet man am häufigsten im Alter von 20 bis 29 und von 50 bis 59 Jahre (Brunnhuber und Lieb 2000). Das durchschnittliche Erstmanifestationsalter liegt bei $50 \%$ der Patienten vor dem 32. Lebensjahr (Jacobi et al. 2004), für Männer bei 26 und für Frauen bei 23 Jahren (Spaner et al. 1994). Frauen erleiden etwa doppelt so oft Depressionen wie Männer, wobei die Lebenszeitprävalenz für Frauen bei etwa $16 \%$ und für Männer bei $7 \%$ liegt (Wittchen et al. 1999, Brunnhuber und Lieb 2000).

Der 1998 durchgeführte Bundes-Gesundheits-Survey zeigte eine Lebenszeitprävalenz von $18 \%$ für sämtliche depressive Störungen in Deutschland (Wittchen und Jacobi 2001). Die Häufigkeit einer schweren behandlungsbedürftigen Depression zeigte eine Punktprävalenz von ca. $6 \%$ der Bevölkerung bezogen auf die letzten 4 Wochen auf (Jacobi et al. 2004). Nach Angaben des Statistischen Bundesamtes beliefen sich dabei die direkten Krankheitskosten für eine Depression 
in Deutschland im Jahre 2002 auf insgesamt 4 Milliarden Euro. Die indirekten Kosten werden um ein Vielfaches höher geschätzt. Die Bedeutung dieser Erkrankung wird auch dadurch sichtbar, dass in Deutschland die Depressionsbehandlung kürzlich als 6. Nationales Gesundheitsziel festgelegt wurde (www.gesundheitsziele.de).

\subsubsection{Symptome}

Die Patienten sind niedergeschlagen, leiden unter Interessenverlust, Konzentrationsschwäche, Durchschlafstörungen, gedrückter Stimmung bis hin zur Anhedonie, Antriebsminderung, Grübelzwang und Schuldgefühlen. Mitunter kommt es auch zu suizidalen Gedanken mit zum Teil konkreten Suizidabsichten. Diese Symptome halten länger als zwei Wochen an. Bei schweren Verlaufsformen können stimmungskongruente Wahnvorstellungen hinzukommen (z.B. Verarmungswahn). Beim „somatischen Syndrom“ kommen Beschwerden wie Appetit- und Libidoverlust, Gewichtsabnahme und Früherwachen hinzu. Die Häufigkeit und Anzahl der Symptome bestimmen die Einschätzung des Schweregrades der Depression. Man unterscheidet leichte depressive Episoden (F32.0), mittelgradige depressive Episoden (F32.1), schwere depressive Episoden ohne psychotische Symptome (F32.2), schwere depressive Episoden mit psychotischen Symptomen (F32.3) und sonstige depressive Episoden (F32.8).

\subsubsection{4. Ätiologie}

Die Genese der Depression ist multifaktoriell (Ebel und Beichert 2002). Eine erhöhte Konkordanz bei monozygoten Zwillingen (50 \%) im Vergleich zu dizygoten Zwillingen (20 \%) spricht für eine genetische Prädisposition der Erkrankung (Marneros 1999). Als Auslöser ("Trigger") von Depressionen werden häufig psychosoziale Belastungsfaktoren wie Verlust oder Tod einer Bezugsperson, angegeben (Huber 1999, Tölle 1999). Auch eine körperliche Erkrankung kann Auslöser einer Depression sein (Ebel und Beichert 2002). Auf biochemischer Ebene gibt es mindestens drei Theorien, die die Ursachen dieser affektiven Störung zu erklären versuchen. Die Aminhypothese besagt, dass die Ursache einer Depression im Mangel bzw. der Dysbalance biogener Amine wie Serotonin und Noradrenalin im postsynaptischen Spalt zu finden sei. Die Tatsache, dass trizyklische Antidepressiva und Monoaminooxidase-(MAO)-Hemmer, die funktionell zu Verfügung stehenden 
Transmitter erhöhen, die Symptome bessern, unterstützt diese Theorie (Axelrod et al. 1961, Schildkraut 1965, Coppen 1967). In neueren Untersuchungen konnte tatsächlich nachgewiesen werden, dass depressive Erkrankungen mit einer Verminderung der Neurotransmitter Serotonin und Noradrenalin einhergehen (Maes und Meltzer 1995, Trivedi 2006).

Die Rezeptor-Supersensitivitäts-Hypothese besagt, dass eine Interaktion zwischen noradrenergem und serotonergem System besteht, welche die Integrität des jeweils anderen Systems bedingt (Sulser et al. 1983). Janowsky et al. haben 1972 ausgehend von ihren Studien die Transmitter-Hypothesen um ein weiteres Modell bereichert, indem sie eine Dysbalance von Acetylcholin zuungunsten des Noradrenalins nachweisen konnten (Janowsky et al. 1972). Weiterhin konnte gezeigt werden, dass bei depressiven Patienten Veränderungen innerhalb der Hypothalamus-Hypophysen-Nebennieren-Achse bestehen, die durch eine CortisolHypersekretion (Sachar et al. 1970) und geringere Response auf den Dexamethason-Hemmtest (Carroll et al. 1981) gekennzeichnet sind. Loosen et al. konnten 1980 zeigen, dass es nach Stimulation mit Thyreotropin-Releasing-Hormon (TRH) zu einer verringerten Thyreotropin-Antwort in der Hypothalamus-HypophysenSchilddrüsen-Achse kommt (Loosen et al. 1980).

\subsubsection{Therapie}

Erste klinische Beobachtungen einer pharmakologischen Therapie von Depressionen wurden von dem schweizer Psychiater Kuhn 1957 gemacht. Er entdeckte die Wirksamkeit von Imipramin, welche als Grundlage für die Entwicklung weiterer sog. "trizyklischer Antidepressiva" wie Amitryptilin, Clomipramin oder Desipramin diente (Morris und Beck 1974). Trizyklische Antidepressiva (TZA) waren lange Zeit die am häufigsten eingesetzten Antidepressiva. Wesentliche, insbesondere anticholinerge Nebenwirkungen umfassen Mundtrockenheit, Obstipation, Akkomodationsstörungen, Dysurie, Schwindel, Tachykardie und ein erhöhtes Glaukomrisiko. Überdosierungen dieser Medikamente können kardiale Leitungsstörungen, ventrikuläre Arrhythmien, Delirien, cerebrale Krampfanfälle, bzw. eine Blasen- oder Darmatonie nach sich ziehen (Nierenberg und Cole 1991, Richelson 1991, Settle 1992, Small 1991). Monoaminooxidase-(MAO)-Hemmer sind ebenfalls wirksame Antidepressiva. Eine Hemmung der MAO erhöht die Konzentration von Noradrenalin und Serotonin im 
synaptischen Spalt. MAO-Hemmer haben u.a. anticholinerge Nebenwirkungen wie Hypertonie, Unruhe, Erregung oder Verwirrtheit.

Eine Weiterentwicklung der Antidepressiva stellten die selektiven SerotoninRückaufnahme-Hemmer (SSRI) dar. Die Medikamente beeinflussen das serotonerge System und besitzen eine den trizyklischen Antidepressiva vergleichbare therapeutische Wirksamkeit (Freisleder und Schmauß 1996).

Heute gehören die meisten erhältlichen Antidepressiva zu den Substanzgruppen der NaSSA (noradrenerge und spezifisch serotonerge Antidepressiva), den trizyklischen und tetrazyklischen Antidepressiva, Monoaminooxidase-Hemmer, SSRI oder SNRI (Serotonin-Noradrenalin-Wiederaufnahme-Inhibitoren). Zusätzlich können gegebenenfalls Hypnotika, Benzodiazepine oder ( - niedrigdosiert - ) Antipsychotika gegeben werden.

Weitere somatische Therapieverfahren sind:

- Schlafentzugsbehandlung

- Lichttherapie

- Elektrokrampftherapie (bei therapierefraktären Depressionen)

- Vagusstimulation

- Psychotherapeutische Verfahren wie beispielsweise Verhaltenstherapie, Kognitive Verhaltenstherapie, Interpersonelle Psychotherapie oder in Einzelfällen eine tiefenpsychologisch fundierte Psychotherapie.

\subsubsection{Manie}

\subsubsection{Symptome}

Die manische Episode definiert sich als deutlich abgrenzbare Veränderung der Stimmung und des Antriebes im Sinne einer gehobenen, reizbaren Stimmung und/ oder Antriebssteigerung für einen definierten Zeitraum. Die Patienten weisen motorische Ruhelosigkeit und das Gefühl der körperlichen und seelischen Leistungsfähigkeit auf. Wie die unipolare Depression wird die Manie nach der ICD10-Klassifikation (DIMDI 2000) eingeteilt. Man unterscheidet die Manische Episode (F30), die Hypomanie (F30.0), Manie ohne psychotische Symptome (F30.1), Manie 
mit psychotischen Symptomen (F30.2), sonstige manische Episoden (F30.8) und nicht näher bezeichnete manische Episoden (F30.9).

\subsubsection{Therapie}

Ziel der medikamentösen Behandlung ist es, Stimmung, Antrieb und Schlaf-WachRhythmus zu regulieren sowie evtl. begleitende psychotische Symptome zu unterdrücken. Die Medikamentenauswahl richtet sich nach der vorliegenden Erkrankungsphase und dem Nebenwirkungsspektrum. Neben Antipsychotika und Benzodiazepinen, die als Mittel der ersten Wahl zur Behandlung akuter manischer Phasen eingesetzt werden, sind Lithiumsalze ein probates Mittel in der Akuttherapie von Manien und darüber hinaus zur Phasenprophylaxe bipolar affektiver Störungen geeignet. Bei Unverträglichkeit oder fehlendem Ansprechen auf Lithium können Valproat, Lamotrigin, Carbamazepin oder neuere Antikonvulsiva als Mood-Stabilizer alternativ zu oder in Kombination mit den Standardtherapien zur Behandlung der akuten Manie wie auch zur Phasenprophylaxe erwogen werden.

\subsubsection{Bipolare affektive Störungen}

\subsubsection{Einteilung, Ätiologie und Epidemiologie}

Die bipolar affektive Störung zählt nosologisch zu den affektiven Störungen und ist von den organischen Psychosen eindeutig abzugrenzen. Huber beschreibt die bipolar affektiven Störungen als „unmotivierte Verstimmungen depressiv-gehemmter oder manisch-erregter Art“, deren Verlauf sich in Phasen gestaltet (Huber 1994). Zwischen den einzelnen Phasen kommt es in der Regel zu einer kompletten Remission der psychischen Verfassung. Die Genese bipolarer affektiver Störungen ist geprägt durch genetische Faktoren und Dysregulationen im neuronalen Transmitterhaushalt.

Die Lebenszeitprävalenz beträgt etwa 0,5-1,5 \% (Craddock und Jones 1999). Eine Geschlechtspräferenz ließ sich bislang nicht beobachten, Männer und Frauen erkranken dabei etwa gleich häufig. Das Alter bei Ersterkrankung erstreckt sich über die gesamte Erwachsenenperiode, d.h. von der Pubertät bis zum 70. Lebensjahr. Das Mittel liegt bei etwa 30-35 Jahren (Angst 1980). Man unterscheidet zwischen Bipolar I und Bipolar II Erkrankungen. Bipolar I Erkrankungen sind Erkrankungen mit 
mindestens einer manischen Episode neben depressiven Phasen. Bei Bipolar II Erkrankungen handelt es sich um Episoden, bei denen neben depressiven Episoden nicht Manien, sondern nur leichte, sog. Hypomanien, auftreten. Eine detailliertere Differenzierung der Diagnose ist der ICD-10-Klassifikation (F31.0 bis F31.7) (DIMDI 2000) zu entnehmen (vgl. Tabelle 6).

Depressive Phasen beginnen meist eher schleichend, während sich manische Phasen häufig schon innerhalb von Stunden oder wenigen Tagen entwickeln. Im Laufe des Lebens müssen Betroffene im Mittel mit dem Auftreten von ca. sechs Krankheitsepisoden rechnen. Mit zunehmender Krankheitsdauer kommt es oft zu einer Verkürzung des beschwerdefreien Intervalls, d.h. manische und depressive Episoden treten in kürzer werdenden Abständen auf. Trotzdem kommt es nach jeder manischen oder depressiven Episode in der Regel zur einer Vollremission. Die Erkrankung hinterlässt keine gravierenden Persönlichkeitsveränderungen.

\subsubsection{Therapie}

Nach dem klinischen Erscheinungsbild und der jeweiligen Phase der affektiven Störung wird ein Therapieschema zur Behandlung einer Depression bzw. einer manischen Phase durchgeführt, welches weiter oben ausführlicher erörtert wurde.

Seit der Erstbeschreibung durch Cade im Jahre 1949 findet Lithium Anwendung in der Psychiatrie (Cade 1949). Eine mögliche unerwünschte Arzneimittelwirkung der Lithiumsalze ist eine Schilddrüsenvergrößerung unter anderem durch eine Interaktion mit der intrathyreoidalen Proteolyse und der Hormonfreisetzung (Gaitan 1980). Erste Zusammenhänge zwischen der gehäuft auftretenden Struma und einer Lithiumtherapie wurden von Fieve und Platman (1968) und Jensen et al. nachgewiesen (Fieve und Platman 1968, Jensen et al. 1968).

Standardmäßig werden - zumindest in Europa - Antipsychotika eingesetzt. Dem Vorteil einer raschen Sedierung stehen jedoch häufig unerwünschte Nebenwirkungen (insbesondere des Extrapyramidal-motorischen Systems) gegenüber, sodass derzeit vermehrt atypische Antipsychotika zum Einsatz kommen. 


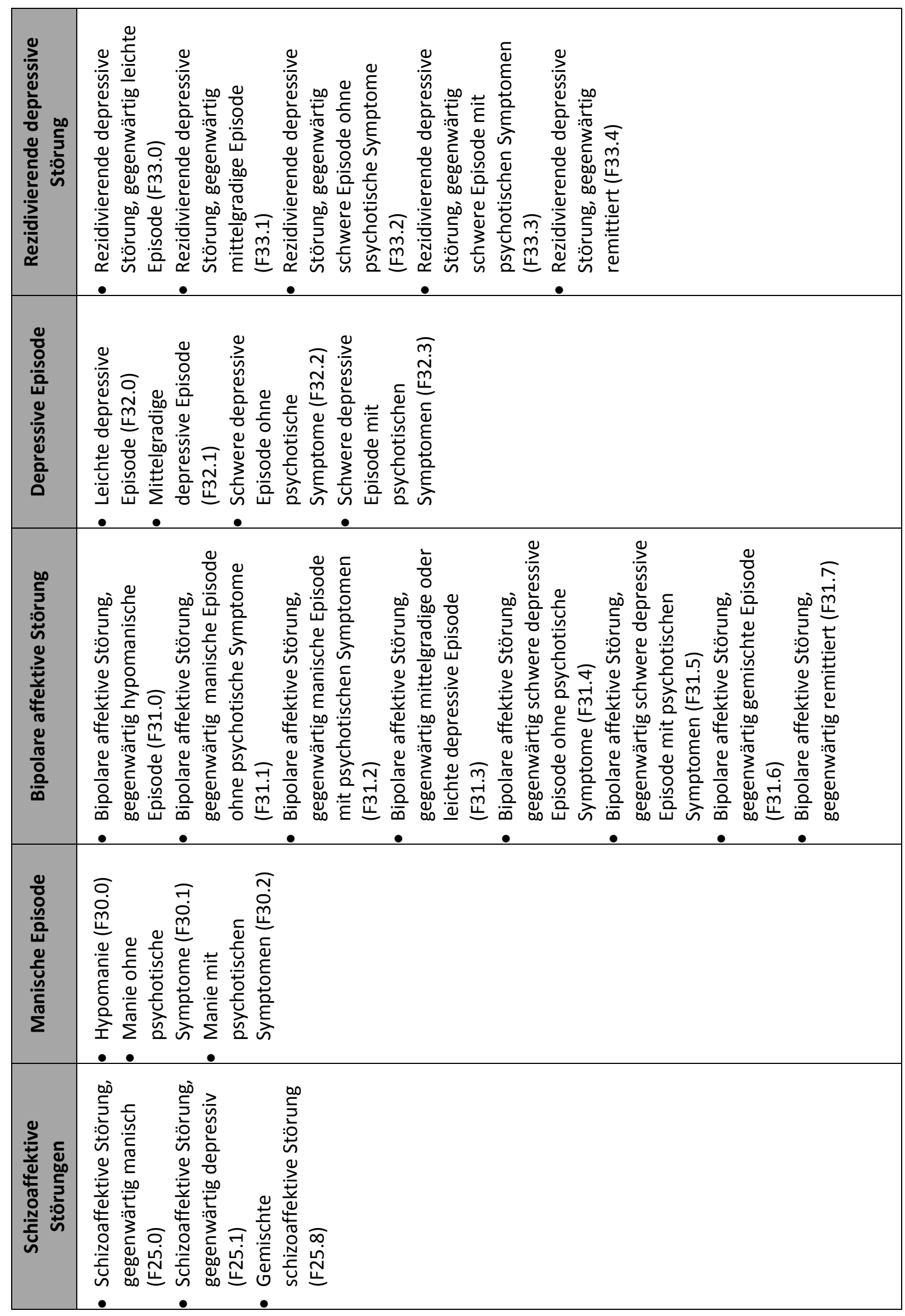

Tabelle 6 Einteilung affektiver Störungen nach ICD-10 (DIMDI 2000) 


\subsubsection{Schizophrenie}

\subsubsection{Historie, Einteilung und Symptome}

Erstbeschreiber der Schizophrenie war Emil Kraepelin 1899, der jedoch noch den Begriff der "Dementia praecox" für diese psychiatrische Störung benutzte. Neben Emil Kraepelin beschäftigten sich Eugen Bleuler (1911) und Kurt Schneider (1939) vor allem mit der Beschreibung der Symptomatik und der Klassifikation der Schizophrenie, die zum Teil noch heute Gültigkeit hat (Kraepelin 1899; Bleuler 1911; Schneider 1939). Die schizophrene Erkrankung bietet ein sehr heterogenes Erscheinungsbild: Formale Denkstörungen, Wahn, Halluzinationen, Ich-Störungen, Störungen der Affektes, Störungen des Willens und der Psychomotorik sowie Störungen des Trieb- und Sozialverhaltens. Die Ausprägung der unterschiedlichen Symptomatik ist dabei individuell verschieden. Die Symptome der Schizophrenie werden auch in Positiv- und Negativsymptomatik eingeteilt (Zubin 1985). In den 90er Jahren machte man weitere Fortschritte in der Erforschung der Schizophrenie mit verbesserten bildgebenden Untersuchungsmethoden wie der funktionellen Magnetresonanztomographie, der Single-Photon-Emission-Computertomography und der Positronen-Emissions-Tomographie (Roth und Prinz 1996; Kandel und Jessell 1995).

Die Einteilung der Schizophrenie erfolgt nach der ICD-10-Klassifikation psychischer Erkrankungen der WHO (DIMDI 2000). Sie orientiert sich in den diagnostischen Leitlinien an der Einteilung der Symptome des 1. und 2. Ranges nach Kurt Schneider (Schneider 1957). In der WHO-Klassifikation werden zusätzlich schizoaffektive Störungen (F25), die gegenwärtig manisch (F25.0), depressiv (F25.1) oder gemischt sind, unterschieden.

\subsubsection{2. Ätiologie}

Wie bei den affektiven Störungen geht man bei den schizophrenen Störungen von einer multifaktoriellen Ätiopathogenese aus. Zahlreiche Familien-, Zwillings- und Adoptionsstudien haben gezeigt, dass bei der Entstehung schizophrener Erkrankungen genetische Komponenten eine Rolle spielen (Haefner 1993). Bei zunehmendem Verwandtschaftsgrad mit einem Schizophrenen, steigt das Risiko, ebenfalls zu erkranken. Maier et al. beschreiben die Wahrscheinlichkeit einer polygenetischen Transmission (Maier et al. 1999). 
Durch computertomographischen und magnetresonanztomographischen Bildgebung konnten bei Schizophrenen strukturelle Veränderungen des Gehirns gezeigt werden. Insbesondere fielen eine Erweiterung der Hirnventrikel und Verlust der grauen Substanz mit Atrophien auf (Illowsky et al. 1988; Michels und Marzuk 1993). In Studien am Sektionsgut schizophrener Patienten konnte eine gestörte Cytoarchitektur und eine Hypoplasie temporo-limbischer Strukturen nachgewiesen werden (Jeste und Lohr 1989, Beckmann und Jakob 1994). Die Dopaminhypothese ist eine der zentralen Hypothesen der Schizophrenieforschung. Ausgehend von der Tatsache, dass Dopaminagonisten (z.B. Amphetamine) schizophrenieähnliche Psychosen hervorrufen können und Dopaminantagonisten wie Antipsychotika, stark antipsychotische Wirkung haben, geht man von einem Zusammenhang der Aktivität des dopaminergen Systems mit der Erkrankung aus. In ihrer ursprünglichen Form postuliert die Dopaminhypothese eine allgemeine Überfunktion dopaminerger Strukturen (Davis et al. 1991). Eine weitere Theorie geht von der Annahme aus, dass eine Virusinfektion während der Fetalperiode eine wichtige Voraussetzung für die spätere Entwicklung einer Schizophrenie darstellen könnte, wobei eine Virämie im 2. Schwangerschaftstrimenon zu einer Schädigung der Neuronenmigration führen könnte (Mednick et al. 1988).

\subsubsection{Therapie}

Entscheidende Fortschritte in der Therapie erzielte man mit der Entdeckung des ersten Antipsychotikums (Chlorpromazin) durch Delay et al. (Delay et al. 1952). In der Folgezeit wurde eine Reihe sogenannter typischer, konventioneller und später sogenannter atypischer Antipsychotika (Prototyp Clozapin) entwickelt. Schwerpunkt der heutigen pharmakologischen Therapie von Schizophrenien sind weiterhin Antipsychotika. Ihre Wirkung kann durch Benzodiazepine und bei gleichzeitigen depressiven Symptomen durch Antidepressiva ergänzt werden (Lehman et al. 2004). Mit dem Zurückdrängen der akuten psychotischen Symptome und der damit verbundenen wachsenden Gesprächs- und Kooperationsmöglichkeit des Patienten werden zunehmend mehr psycho- und soziotherapeutische Maßnahmen eingesetzt. 


\subsection{Schilddrüse und Psyche}

Schilddrüsenhormone haben eine zentrale Bedeutung für die Regulation der Entwicklung, des Wachstums und der Funktion des Organismus. Für die Hirnfunktion ist der stimulierende Effekt des Schilddrüsenhormons Trijodthyronin (T3) von besonderer Bedeutung (Sullivan et al. 1997). An der Zellmembran stimuliert T3 die Aufnahme von Glukose und von Aminosäuren in die Zelle. Die metabolischen Funktionen der Schilddrüsenhormone erklären die vielfältigen psychischen und psychophysiologischen Veränderungen im Rahmen von Schilddrüsenfunktionsstörungen. Neben häufigen Symptomen einer Hypothyreose mit Apathie, Müdigkeit, Affektlabilität, psychomotorischer Verlangsamung, Merkfähigkeits- und Gedächtnisstörungen sowie vegetativen Symptomen wie Kälteempfinden sind eine Vielzahl weiterer psychiatrischer Manifestationsformen der Hypothyreose beschrieben worden:

Das am häufigsten auftretende Symptom sind depressive Verstimmungen. Sie können bei bis zu 40 \% der Patienten mit einer manifesten Hypothyreose beobachtet werden (Heinrich und Grahm 2003). König et al. 1999 bezeichnen eine relevante Hypothyreose deshalb als Risikofaktor für eine Depression. Andererseits zeigt jedoch im Gesamtkollektiv der an einer Depression Erkrankten nur eine Minderheit eine Schilddrüsenunterfunktion (Heinrich und Grahm 2003).

Asher prägte 1949 den Begriff der "myxedema madness" als Bezeichnung für eine symptomatische Psychose mit psychotischen (paranoid-halluzinatorischen) Störungen sowie affektiven (manisch-depressiven) Krankheitsmanifestationen im Zusammenhang mit einer Hypothyreose (Asher 1949, Hall et al.1982, Heinrich und Grahm 2003). Eine Studie von Hall zeigte, dass 5 bis $15 \%$ aller Myxödem-Patienten eine Psychose entwickeln (Hall 1983).

Eine weitere psychiatrische Manifestationsform der Hypothyreose sind kognitive Störungen bis hin zur Demenz (Heinrich und Grahm 2003). Sie zeigen sich mit Symptomen wie Verwirrtheit, Konzentrationsstörungen, Gedächtnisstörungen, Schläfrigkeit, Wortfindungsstörungen und Delir.

Einige Autoren (Matsuoka et al. 2000, Blume und Grabow 1969) beschreiben das Auftreten von Nausea, Vertigo, zerebellärer Ataxie und anderen Kleinhirnsymptomen 
wie Nystagmus, Gleichgewichtsverlust, Koordinationsstörungen und selten auch Dysarthrie bei einer Hypothyreose. Auch epileptische Krampfanfälle (Bryce und Poyner 1992) sind beschrieben worden, wobei keine pathognomonischen EEGVeränderungen für eine Hypothyreose existieren.

Im Extremfall ( $<1 \%)$ kann eine Hypothyreose zum lebensbedrohlichen Zustand des sogenannten "Myxödem-Koma“ führen. Symptome sind ein veränderter mentaler Status (Desorientierung, extreme Lethargie, Verwirrung) sowie Hypothermie, epileptische Anfälle und Atemdepression. Fakultativ werden komatöse Zustände der betroffenen Patienten beschrieben (Fliers und Wiersinga 2003).

Typische psychiatrische Manifestationen einer Hyperthyreose sind Hyperaktivität, psychomotorische Unruhe, Emotionslabilität, Schlaflosigkeit, Euphorie und Tremor, etc. (Abraham et al. 2005). Patienten mit einem paranoiden Syndrom (Steinberg 1994), depressiven oder Angstsymptomen (Demet et al. 2002) und verminderter Konzentrations- und Gedächtnisleistung (Stern et al. 1996) sind beschrieben worden. Im Allgemeinen sind dementielle Symptome aber seltener und weniger stark ausgeprägt als bei einer hypothyreoten Stoffwechsellage (Leigh und Kramer 1984). Fälle von Hyperthyreose mit meist generalisierten Krampfanfällen wurden publiziert (Kahaly et al. 1989, Jabbari und Huott 1980). 60 \% der hyperthyreoten Patienten haben EEG-Veränderungen mit generalisierter slow-wave-Aktivität, gelegentlichen Spikes oder einer erhöhten alpha-Frequenz. Jedoch existieren keine spezifischen EEG-Veränderungen für die Hyperthyreose (Skanse und Nyman 1956). Im Extremfall kann es bei einer thyreotoxischen Krise zu einer Bewusstseinstrübung kommen (Ghobrial und Ruby 2002). Bei älteren Patienten kann eher das Bild des „apathetic hyperthyroidism“ mit Apathie, Depression und Antriebslosigkeit (Bailes 1999) auftreten.

Die neurologisch-psychiatrischen Symptome, die bislang in Zusammenhang mit einer Autoimmunthyreoiditis gebracht wurden, zeigen meist das klassische Bild einer Hypothyreose (Pfannenstiel et al. 1997). Psychiatrisch können dabei zwei Manifestationsformen unterschieden werden: zum einen eine chronische, schleichende Persönlichkeitsveränderung mit psychischer Labiliät, Angst und sozialem Rückzug, zum anderen eine langsam fortschreitende depressive 
Symptomatik (Hall et al. 1982). Außerdem kann sich das Krankheitsbild der „myxedema madness“ (s.o.) manifestieren mit extremer Unruhe, Desorientiertheit, Erregtheit sowie visuellen und akustischen Halluzinationen. Alle genannten Symptome können auftreten, lange bevor eine auffällige Veränderung der Schilddrüsenparameter messbar ist (Hall et al. 1982).

Zusammenfassend kann gesagt werden, dass periphere Schilddrüsendysfunktionen nahezu jedes psychiatrische Symptom oder Syndrom hervorrufen können. Keine Schilddrüsenerkrankung führt jedoch zu diagnostisch eindeutigen psychiatrischen Symptomen. Eine Hypothyreose kann zu einem bunten, nicht diagnosespezifischen Muster an psychiatrischen Symptomen aus fast allen Diagnosebereichen führen. Die Ausprägung der entsprechenden psychischen Symptome ist offenbar von Schweregrad und Progredienz der endokrinen Grunderkrankung sowie möglicherweise von der jeweiligen psychischen und auch genetischen Disposition abhängig. Unter den häufig vorkommenden Symptomen dominieren Krankheitsbilder, die oft an depressive, aber - mindestens genauso häufig - auch an schizophrene Erkrankungen erinnern können.

Insgesamt werden Schilddrüsenfunktionsstörungen nahezu immer von psychischen Veränderungen begleitet. Andererseits ist jedoch auch eine Induktion schon manifester psychiatrischer Erkrankungen selbst durch eine latente Schilddrüsendysfunktion möglich. So findet sich bei Patienten mit einer subklinischen Hypothyreose beispielsweise eine dreimal höhere Lebenszeitprävalenz (56\%) für Depressionen gegenüber euthyreoten Personen (18\%) (Haggerty und Prange 1995). Erhöhte schilddrüsenspezifische Antikörper finden sich bei depressiven Patienten mit einer Prävalenz von 9 bis $25 \%$, in der Normalbevölkerung dagegen von $10 \%$ (Gold et al. 1982, Joffe 1987, Haggerty et al. 1997). Insgesamt zeigen Frauen mit erhöhten Antikörpertitern gegen thyreoidale Peroxidase (TPO-Ak) auch eine erhöhte Vulnerabilität für Depressionen (Pop et al. 1998).

Bei euthyreoten depressiven Patienten zeigen sich trotz der bestehenden Euthyreose eine Reihe von Auffälligkeiten im Schilddrüsenhormonhaushalt (Jackson und Asamoah 1999):

- Ein verminderter Anstieg von TSH auf TRH-Stimulation bei 25 bis $30 \%$ der depressiven Patienten. Dieses Phänomen ist noch nicht vollständig aufgeklärt 
und tritt auch bei anderen Erkrankungen, z.B. Alkoholismus und Akromegalie auf. Die klinische Besserung der Depression geht dabei mit der Normalisierung der TSH-Antwort einher.

- Ein Anstieg von T4 bzw. fT4 innerhalb der Normwerte während einer Depression und Abfall bei erfolgreicher Therapie der Depression.

- Eine Autoimmunthyreoiditis bei $15 \%$ der depressiven Patienten. Bei Patienten mit Rapid Cycling, einer speziellen bipolaren Verlaufsform mit mehr als 4 Phasen pro Jahr, sogar in 50 \% der Fälle.

- Eine Veränderung der zirkadianen Rhythmik des TSH mit Ausfall des nächtlichen TSH-Anstiegs. Schlafentzug führt dann zum Wiedereintritt des nächtlichen TSHAnstiegs und Erhöhung der T3- und T4-Spiegel.

Bei einem Teil der Patienten mit Depressionen wurden erhöhte T4- bzw. fT4-Werte gemessen, während die T3-Spiegel im Normbereich lagen (Bauer und Whybrow 1990a). Dies scheint im Widerspruch zu dem bisher angenommenen Zusammenhang zwischen Hypothyreose und Depression zu stehen. Dieser scheinbare Gegensatz erklärt sich wahrscheinlich dadurch, dass es zur verstärkten Bildung von reversem Trijodthyronin (rT3) kommt, welches ein starker Inhibitor des Enzyms ist, das im Gehirn T4 zu T3 umbaut. Da außerdem T3 das hauptsächlich aktive Hormon ist, stellt eine Erhöhung von T4 höchstwahrscheinlich nur eine Reaktion auf die verminderte Umwandlung von T4 zu T3 dar (Henley und Koehnle 1997). Das Gehirn scheint Schilddrüsenhormone anders zu nutzen als alle anderen Organe. Als einziges Organ hat es die Möglichkeit die Konversion von T4 zu T3 lokal zu steuern, was vermuten lässt, dass die Spiegel der Schilddrüsenhormone hier spezifisch reguliert werden können.

Die Behandlung depressiver Störungen mit Schilddrüsenhormon-Präparaten war bis in die 70er Jahre des letzten Jahrhunderts üblich und wird in den letzten Jahren, mit z.T. kontroversen Ergebnissen, in der Therapie schwerer therapierefraktärer Depressionen vermehrt wieder eingesetzt. Eine Studie, die eine alleinige Gabe von T3 zur Therapie von Depressionen untersuchte, zeigte zunächst positive Ergebnisse, musste dann aber wegen thyreotoxischer Nebenwirkungen abgebrochen werden (Prange et al. 1976). In einer doppelblinden, placebokontrollierten Studie zeigte sich bei der Kombination von T3 mit trizyklischen Antidepressiva (TZA) eine Ansprechrate 
von $54 \%$ im Vergleich zu einer Kombination Placebo + TZA mit einer Ansprechrate von $19 \%$ (Joffe et al. 1993). Depressive Patienten, deren T4-Serumspiegel im unteren Normbereich liegen, sprechen offenbar besser auf die kombinierte Gabe von Schilddrüsenhormonen und TZA an, als solche, deren T4-Serumspiegel im mittleren oder oberen Normbereich liegen (Nakamura und Nomura 1992). Die überlegene Stellung von T3 in der Augmentationstherapie gegenüber T4 wird heute weiterhin angenommen. Hatzinger und Holsboer-Trachsler empfehlen z.B. den Einsatz von 2550 mg T3/Tag ergänzend zur Basistherapie (Antidepressiva mit verschiedenen Wirkmechanismen, ggf. auch in Kombinationen) (Hatzinger und Holsboer-Trachsler 1999). Von anderen Therapiestudien ist bekannt, dass die Gabe von Schilddrüsenhormonen die zentrale 5-Hydroxytryptamin-Aktivität erhöhen soll und auf diese Weise depressive Symptome vermindern kann (Sullivan et al. 1997). Besonders im höheren Lebensalter ist eine latente oder sogar manifeste Hypothyreose differentialdiagnostisch auszuschließen. Schon bei einer latenten Hypothyreose sollte bei diesen Patienten ein Therapieversuch mit Levothyroxin eingeleitet werden, da es unter dieser Medikation häufig zu einer deutlichen Rückbildung der neurologisch-psychiatrischen wie auch der körperlichen Symptome kommen kann.

Wenn auch bei depressiven Patienten eine Hypothyreose insgesamt nicht sehr häufig ist (2 bis $5 \%$ ), so ist doch bei therapieresistenten Depressionen und insbesondere bei bipolaren depressiven Störungen an das Vorliegen einer latenten oder manifesten Hypothyreose zu denken. Das Auftreten einer subklinischen Hypothyreose im Umfang von maximal $15 \%$ bei stationär behandlungsbedürftigen Depressiven ist sowohl in englischsprachigen als auch in deutschsprachigen Arbeiten repliziert worden (Haggerty und Prange 1995, König 1998). Erhöhte Schilddrüsen-Autoantikörper werden hingegen bei 10 bis $52 \%$ aller Patienten mit affektiven Störungen beobachtet und können längerfristig zu einer manifesten Schilddrüsenunterfunktion führen. Diese ist wahrscheinlich als Risikofaktor für depressive Syndrome und für Therapie-Nonresponder anzusehen. Insofern empfiehlt sich im höheren Alter, bei rezidivierenden depressiven Episoden und bei therapierefraktärer Depression neben einer kostengünstigen Bestimmung von basalem TSH zum Ausschluß einer Schilddrüsenfunktionsstörung im Einzelfall durchaus die Bestimmung von Schilddrüsenautoantikörpern. 
Bezüglich des klinischen Benefits einer Levothyroxin-Substitutionstherapie für affektiv gestörte Patienten mit erhöhten TPO-Ak Titern liegen bislang keine ausreichend gesicherten Erkenntnisse vor. Es ist fraglich, ob durch frühzeitige Diagnostik von Schilddrüsenautoantikörpern bei psychiatrischen Patienten therapiemodifizierende Faktoren gefunden werden können. Weiterhin bleibt zu diskutieren, ob Patienten mit einer affektiven Störung und positiven TPO-Ak unabhängig von der jeweiligen SD-Stoffwechsellage von einer Therapie mit Schilddrüsenhormon-Präparaten wirklich profitieren. Inwieweit eine Erweiterung eines Laborscreenings um die Bestimmung von TPO-Ak sinnvoll ist, soll im Diskussionsteil dieser Dissertation kritisch hinterfragt werden.

\subsection{Zielsetzung}

Ziele der Arbeit waren, Zusammenhänge zwischen der Autoimmunthyreoiditis und affektiven Störungen (Depressionen, uni- bzw. bipolare Formen) bei ambulanten Patienten zu erfassen, zu korrelieren und mit der nationalen und internationalen Literatur zu vergleichen. Dazu wurde die Häufigkeit einer AIT bei affektiven Störungen hinsichtlich psychiatrischer Diagnosegruppen (ICD-10-Klassifikation) (DIMDI 2000), Alter und Geschlecht der Patienten durch serologische Untersuchungen bezüglich der Schilddrüsen-Hormonparameter und der SDAutoantikörper ermittelt und durch apparative Diagnostik verifiziert. Als Vergleich diente zusätzlich eine alters- und geschlechtsgematchte Kontrollgruppe ambulanter schizophrener Patienten. Die Medikation der Patienten wurde ebenfalls berücksichtigt, insbesondere Lithium sowie Antidepressiva. Die statistische Untersuchung erfolgte mittels einer logistischen Regressionsanalyse zur Analyse der unterschiedlichen Zielparameter. 


\section{MATERIAL UND METHODEN}

Die in der vorliegenden Arbeit verwendeten Daten und Laborparameter wurden im Zeitraum von Februar 2002 bis Januar 2005 ausschließlich im Routinebetrieb in der Poliklinik der Klinik für Psychiatrie und Psychotherapie der Universitätsmedizin Göttingen an 71 konsekutiven Patienten (36 Männer, 35 Frauen, Durchschnittsalter 44,8 Jahre) erhoben und lagen zum Zeitpunkt der Auswertung der Arbeit in einer Datenbank vor. In diese Datenbank waren die Daten der ambulanten Patienten eingefügt und jedem Patienten eine fortlaufende Identifikationsnummer zugeordnet worden, die keine Rückschlüsse auf Namen, Alter, Geschlecht sowie Art und Schwere der Erkrankung zuließ. Diese Nummer ersetzte den Namen der Patienten. Bei auffälligen Schilddrüsenlaborwerten war den entsprechenden Patienten eine Vorstellung in einer für Schilddrüsenuntersuchungen spezialisierten Abteilung angeraten worden.

\subsection{Psychiatrischer Teil}

In die Studie wurden Patienten einbezogen, bei denen eines der folgenden Kriterien eindeutig nachweisbar war (ICD-10-Kriterien):

- depressive Episode (F 32)

- rezidivierende depressive Störung (F 33)

- bipolare affektive Störung

- gegenwärtige depressive Episode (F 32.2 und 32.3)

- Schizophrenie (F 20).

Nach der „International Classification of Diseases” (DIMDI 2000) erfolgt die Differenzierung der einzelnen Erscheinungsbilder anhand einer multikategorialen Diagnostik nach Schweregrad, Mindestdauer, Polarität und Rezidivhäufigkeit. Dieser Unterscheidung folgt neben der ICD-10 auch das Diagnostische und Statistische Manual Psychischer Störungen (DSM-IV) der American Psychiatric Association, auf dem mittlerweile die meisten Forschungsvorhaben und Publikationen gründen, da es in vielen Punkten den aktuellen empirischen Wissensstand vergleichsweise gut repräsentiert (Sass et al. 2003). Dieses Manual umfasst eine multiaxiale Beurteilung des Patienten in fünf Achsen und bedient sich bei der Definition der Krankheitsbilder 
und der Erstellung einer Diagnose einer strikten Operationalisierung klinischer Kriterien. Durch die multiaxiale Klassifikation sollen verschiedene für Diagnostik, Prognose und Therapie relevante Informationsbereiche getrennt erfasst werden.

Patienten, die die ICD-10-Kriterien (DIMDI 2000) nicht eindeutig erfüllten oder unter einer manifesten Hyper- oder Hypothyreose litten, wurden aus der Studie ausgeschlossen.

Im Gegensatz zu anderen Autoimmunerkrankungen ist eine Autoimmunthyreoiditis nicht gehäuft mit einer Schizophrenie assoziiert, weshalb diese Patienten als zusätzliches Kontrollkollektiv untersucht wurden (Eaton et al. 2006).

Unter Zuhilfenahme eines selbst erstellten Fragebogens wurden folgende Daten erfasst und dann wie oben beschrieben in die Datenbank eingegeben:

- Biographische Daten des Patienten

- Gesamtdauer der psychiatrischen Erkrankung

- Psychiatrische bzw. organische Komorbiditäten

- Sämtliche vom Patienten eingenommene psychopharmakologische und internistische Medikamente.

\subsection{Endokrinologischer Teil}

Im Rahmen eines klinischen Routinesettings, welches als Screeningverfahren bei Patienten mit affektiven Störungen standardmäßig eingesetzt wird, wurden sämtliche Schilddrüsenhormonparameter sowie weiter unten aufgelistete Schilddrüsenautoantikörper bestimmt. Als Probenmaterial wurde Humanserum verwendet. Die Blutentnahmen erfolgten in der Poliklinik der Abteilung für Psychiatrie und Psychotherapie der Universitätsmedizin Göttingen an nüchternen Patienten.

\subsubsection{Schilddrüsenhormonparameter}

\subsubsection{Bestimmung des freien Triiodthyronins (fT3)}

Zur Bestimmung der fT3-Konzentration kam der ADVIA Centaur fT3-Test der Firma Bayer Diagnostics (Bayer Vital GmbH Geschäftsbereich Diagnostics, Fernwald, 
Deutschland) zum Einsatz. Hierbei handelte es sich um einen kompetetiven Immunassay unter Anwendung der direkten Chemilumineszenz-Technologie. FT3 im Patientenserum konkurriert mit einem T3-Analogon, das kovalent an paramagnetische Partikel gebunden ist, um eine begrenzte Menge mit Acridiniumester markiertem, monoklonalem Maus-anti-T3-Antikörper.

Zwischen der Menge an freiem T3 in der Patientenprobe und den vom System erfassten relativen Lichteinheiten (RLUs) besteht ein umgekehrt proportionales Verhältnis.

Der Normbereich von fT3 liegt laut Testanleitung des ADVIA Centaur bei 1,8 - 4,2 $\mathrm{ng} / \mathrm{l}$.

\subsubsection{Bestimmung der Konzentration an freiem Thyroxin (fT4)}

Die Menge an fT4 im Patientenserum wurde mit dem ADVIA Centaur FrT4-Test der Firma Bayer Diagnostics (Bayer Vital GmbH Geschäftsbereich Diagnostics, Fernwald, Deutschland), einem kompetitiven Immunassay unter Anwendung der direkten Chemilumineszenz-Technologie, gemessen. FT4 in der Patientenprobe konkurriert mit dem Acridiniumester markierten T4 im sog. Lite-Reagenz um eine begrenzte Menge an polyklonalem Kaninchen-anti-T4-Antikörper, der kovalent an paramagnetische Partikel in der Festphase gebunden ist (Chen und Sperling 1989).

Der Normbereich von fT4 liegt bei 8,0-19,0 ng/l.

\subsubsection{Basales, Thyreoidea-stimulierendes Hormon (TSHbasal)}

Die TSH-Bestimmung der Patientenproben erfolgte mit dem kommerziell erhältlichen ADVIA Centaur-TSH-Assay der Firma Bayer Diagnostics (Bayer Vital GmbH Geschäftsbereich Diagnostics, Fernwald, Deutschland) mit einer analytischen Sensitivität von 0,010 mIU/l. Es handelt sich um ein nach der Sandwichmethode an zwei Stellen ansetzendes Immunoassay mit direkter ChemilumineszenzTechnologie, bei dem jeweils konstante Mengen zweier Antikörper eingesetzt werden. Der erste Antikörper ist ein monoklonaler Maus Anti-TSH-Antikörper, markiert mit Acridiniumester. Der zweite Antikörper ist ein polyklonaler Schaf-AntiTSH-Antikörper, der kovalent an paramagnetische Partikel gebunden ist (FernandezUlloa und Maxon 1989). 
Der Normbereich liegt bei diesem Assay zwischen 0,43 und 3,2 $\mu \mathrm{U} / \mathrm{ml}$. Patienten mit Werten $<0,1 \mu \mathrm{U} / \mathrm{ml}$ wurden als supprimiert betrachtet. Werte $>3,2 \mu \mathrm{U} / \mathrm{ml}$ wurden als erhöht angesehen.

\subsubsection{Schilddrüsen-Autoantikörper (AK)}

Antikörper gegen Antigene können durch verschiedene Messmethoden bestimmt werden. Nachweisverfahren für Auto-Antikörper gegen Thyreoglobulin beispielsweise können in Form von einfachen Niederschlagstests und Haemagglutinationen oder Immunfluoreszenz bis hin zu Enzym- oder Radioimmunassays durchgeführt werden. Anti-TPO-Antikörper können ebenfalls durch Immunfluoreszenz-Assays oder ELISAVerfahren bestimmt werden. Bei den üblicherweise angewendeten Test-Verfahren handelt es sich um Immunoassays. Dieser TPO-Assay wird gegen einen WHOStandard geeicht. Eine Kalibrierung gegen die international anerkannte WHO Standard-Präparation für Anti-TPO-Antikörper in humanem Serum wird genutzt, um eine Kalkulationskurve für Antikörper-Werte in der Einheit „international units per millilitre" (IU/mL) zu erstellen, welche wiederum als Referenz zur Konzentrationsbestimmung des Kalibrators verwendet wird.

TSH-Antikörper-Nachweis-Verfahren sind deutlich aufwendiger. Man benutzt sog. Bioassays von Mäusen, Messungen der Thymidin-Aufnahme thyreoidaler Zellen bzw. Messung der Inhibition der TSH-Bindung an Schilddrüsenzellen bzw. membranen. Es wird ein sog. Standardisierungsverfahren zur Bestimmung von Antikörper durchgeführt, um Messfehler zu vermeiden. TG-Assays werden, unter Zuhilfenahme von international standardisiertem "Certified Reference Material“ in ähnlicher Weise geeicht.

\subsubsection{Bestimmung der TSH-Rezeptor-Antikörper (TRAK)}

Zur Bestimmung der TRAK-Konzentration wurde der „LUMItestTRAK human“ der Firma Brahms, Berlin, Deutschland verwendet. Bei diesem Lumineszenzrezeptorassay wird ein „Coated Tube System“ verwendet, bei welchem die Teströhrchen mit humanen, rekombinanten TSH-Rezeptoren beschichtet wurden. Tracer bei diesem Reagenzansatz ist Lumineszenz-markiertes TSH vom Rind. Das Assayprinzip erfolgt in mehreren Phasen: Der erste Schritt besteht aus der Inkubation der Patientenprobe im Teströhrchen. Als nächstes folgt die Zugabe des 
markierten TSH, welches die restlichen TSH- Rezeptoren besetzt. Durch einen Waschschritt wird das ungebundene TSH entfernt und das gebundene markierte TSH kann anschließend im Luminometer bestimmt werden. Die Stärke des Messsignals ist umgekehrt proportional zu der Menge der vorhandenen TRAK (Meller J et. al. 2000b). Der Normbereich für TRAK liegt bei $<1,0-1,5 \mathrm{mlU} / \mathrm{ml}$.

\subsubsection{Nachweis von Autoantikörpern gegen Thyreoglobulin (Tg)}

Tg-Ak sind nur in 40 bis $70 \%$ aller Patienten mit einer Autoimmunthyreoiditis nachweisbar. Auch sie sind nicht pathognomonisch für diese Erkrankung, sondern lassen sich ebenso bei anderen autoimmunen und nichtautoimmunen Thyreopathien nachweisen. Die Bestimmmung von Tg-Ak zusätzlich zur Bestimmung von TPO-Ak erlaubt nur in seltenen Fällen eine zusätzliche Aussage und ist daher in der Regel entbehrlich. Sie ist dann indiziert, wenn trotz negativer TPO-Titer weiterhin der Verdacht auf das Vorliegen einer Autoimmunthyreoiditis besteht (z.B. bei Patienten mit echoarmem Muster in der Schilddrüsensonographie oder bei Patienten mit einer unklaren Hypothyreose). Zusätzlich können Tg-Ak und besonders TSH-Rezeptor-AK hilfreich sein, wenn eine Autoimmunthyreoiditis gegenüber einem Morbus Basedow abgegrenzt werden soll (Saller et al. 1993)

Antikörper gegen Thyreoglobulin wurden mit dem ADVIA Centaur anti-Tg-Test der Firma Bayer Diagnostics (Bayer Vital $\mathrm{GmbH}$ Geschäftsbereich Diagnostics, Fernwald, Deutschland) bestimmt. Es handelt sich dabei um ein direktes Chemilumineszenzverfahren, bei dem humane Anti-Tg-Antikörper mit festphasenfixierten polyklonalen Ziege-anti-Human-Antikörpern um AE-markiertes Humanthyreoglobulin konkurrieren. Die funktionelle Sensitivität wird mit $30 \mathrm{U} / \mathrm{ml}$ angegeben. Normalwerte liegen bei Werten unter $60 \mathrm{U} / \mathrm{ml}$ vor.

\subsubsection{Nachweis von Autoantikörpern gegen die thyreoidale Peroxidase (TPO)}

Die wichtigsten Antikörper bei dem Nachweis einer AIT sind gegen die Schilddrüsenperoxidase (Thyreoidale Peroxidase $=$ TPO) gerichtete Autoantikörper, die allerdings eher blockierend auf die Thyreoidale Peroxidase wirken, während die 
Destruktion der Follikelzellen bei der AIT primär durch zytotoxische Antikörper vermittelt wird (Bogner et al. 1990). Die TPO ist ein 103.000 Dalton schweres, membranständiges Protein der apikalen Zellmembran der Thyreozyten und spielt eine Schlüsselrolle bei der Schilddrüsenhormon-Synthese. Das Molekül besteht aus einer Polypeptidkette von 933 Aminosäuren mit einem großen N-terminalen extrazellulären Teil von 845 Aminosäuren, einem transmembranären und einem intrazellulären Anteil (Banga et al. 1991).

Die bei Immunthyreopathien der Schilddrüse nachweisbaren Autoantikörper sind gegen den extrazellulären Anteil der TPO gerichtet. Bisher sind zwei Epitope auf der TPO identfiziert worden, an die TPO-AK binden, und zwar „C2“, das die Aminosäuren 590 bis 675 umspannt und „C21“, das sich über die Aminosäuren 651 bis 750 erstreckt. Zur Initiierung des Autoimmunprozesses ist es erforderlich, dass die TPO die apikale Zelloberfläche bzw. das Follikellumen verlässt und für das Immunsystem zugänglich wird. Auf welche Weise dies geschieht, ist bislang nicht sicher geklärt (Scherbaum 1993).

TPO-Ak werden heute mit quantitativen Verfahren (RIA, ELISA) nachgewiesen. Als Antigen wird in diesem Testverfahren rekombinante humane SchilddrüsenPeroxidase eingesetzt. Bei diesen Testverfahren zum Nachweis von TPO-Ak erfolgt eine Quantifizierung der Messwerte in internationalen Einheiten (IU/I). Bei Patienten mit Autoimmunthyreoiditis lassen sich in über 80 bis $90 \%$ der Fälle TPO-Ak nachweisen. Häufig liegen sehr hohe Antikörpertiter vor, allerdings fehlt eine Korrelation der Titerhöhe mit dem klinischen Schweregrad der Erkrankung bzw. der Prognose (Gutekunst et al. 1989).

Der Nachweis von TPO-Ak ist außerdem nicht spezifisch für die Autoimmunthyreoiditis. Positive Ak-Titer finden sich auch in $70 \%$ der Patienten mit einem floriden Morbus Basedow. Auch bei Patienten mit anderen Autoimmunerkrankungen, mit nichtimmunogenen Schilddrüsenerkrankungen und auch bei "gesunden“ Kontrollpersonen sind in bis zu $20 \%$ der Fälle TPO-Ak nachweisbar (Tunbridge et al. 1977, Roti et al. 1992). 
Die Menge an Anti-TPO im Patientenserum wurde mit dem ADVIA Centaur AntiTPO-Test der Firma Bayer Diagnostics (Bayer Vital GmbH Geschäftsbereich Diagnostics, Fernwald, Deutschland), einem kompetetiven Immunassay unter Anwendung der direkten Chemilumineszenz, bestimmt. Die in der Patientenprobe enthaltenen Autoantikörper gegen TPO konkurrieren mit monoklonalen Maus-antiTPO-Antikörpern um eine begrenzte Menge Human TPO, das an mit Arcidiniumester markierte monoklonale Maus-anti-TPO-Antikörper gebunden ist (Kaczur et al. 1997). Der Normbereich von anti-TPO liegt bei $<60-100 \mathrm{U} / \mathrm{ml}$.

\begin{tabular}{|c|c|c|c|c|c|c|}
\hline Parameter & Zeitraum & Hersteller & Gerät & Methode & Normbereich & Einheit \\
\hline TSH & $\begin{array}{l}11 / 99- \\
03 / 05\end{array}$ & Bayer & $\begin{array}{l}\text { ADVIA } \\
\text { Centaur }\end{array}$ & Chemilumineszenz & $0,45-3,20$ & $\mu \mathrm{IU} / \mathrm{ml}$ \\
\hline fT4 & $\begin{array}{l}11 / 99- \\
03 / 05\end{array}$ & Bayer & $\begin{array}{l}\text { ADVIA } \\
\text { Centaur }\end{array}$ & Chemilumineszenz & $0,77-1,53$ & $\mathrm{ng} / \mathrm{dl}$ \\
\hline fT3 & $\begin{array}{l}11 / 99- \\
03 / 05\end{array}$ & Bayer & $\begin{array}{l}\text { ADVIA } \\
\text { Centaur }\end{array}$ & Chemilumineszenz & $2,00-4,20$ & $\mathrm{pg} / \mathrm{ml}$ \\
\hline aTPO & $\begin{array}{l}\text { 08/01- } \\
03 / 05\end{array}$ & Bayer & $\begin{array}{l}\text { ADVIA } \\
\text { Centaur }\end{array}$ & Chemilumineszenz & $<60-100$ & $\mathrm{U} / \mathrm{ml}$ \\
\hline aTG & $\begin{array}{l}\text { 08/01- } \\
03 / 05\end{array}$ & Bayer & $\begin{array}{l}\text { ADVIA } \\
\text { Centaur }\end{array}$ & Chemilumineszenz & $<60$ & $\mathrm{U} / \mathrm{ml}$ \\
\hline
\end{tabular}

Tabelle 7 Übersicht der Immun-Assays zur Bestimmung der Schilddrüsenparameter (Hormonlabor der Abteilung für Nuklearmedizin der Universitätsmedizin Göttingen) 


\subsubsection{Apparative Diagnostik}

\subsubsection{Sonographie der Schilddrüse}

Bei erhöhten anti-TPO-Titern (cut off $>60 \mathrm{U} / \mathrm{ml}$ ) wurde den Patienten eine Vorstellung in einer Spezialambulanz für Schilddrüsendiagnostik empfohlen. Die Sonographie wurde nach der Methode nach Brunn et al. durchgeführt (Brunn et al. 1981). Durch die Sonographie wird das Volumen bzw. die Größe der Schilddrüse, ihre Lage und Form sowie die Binnenstruktur ihres Gewebes untersucht. Die Binnenstruktur des Schilddrüsengewebes wird hinsichtlich der Echogenität (echonormal/echoarm) und der Homogenität (homogen/inhomogen) beschrieben. Die Echogenität wird bestimmt durch die Zahl und Größe der Schilddrüsenfollikel, die ihrerseits vom Kolloidgehalt und dem Funktionszustand der Schilddrüse abhängen. Die Homogenität beschreibt die Verteilung des Echomusters. Als Referenz zur Beurteilung werden echonormale Schallmuster der gesunden Schilddrüse bzw. die umgebende Muskulatur verwendet, die im Vergleich zum normalen Schilddrüsengewebe echoarm (d.h. dunkel) ist. Bei der Autoimmunthyreoiditis vom Typ Hashimoto findet sich typischerweise eine auffällige Echoarmut, die entweder diffus oder fleckförmig verteilt auftreten kann und mit einer Sensitivität und Spezifität von etwa $95 \%$ nahezu beweisend für das Vorliegen einer AIT ist (Pedersen et al. 2000). In typischen Fällen (atrophische Form) ist auch das Gesamtvolumen verkleinert, wobei formal kein Referenzwert für die Kleinheit der Schilddrüse vorliegt.

Wesentliche Vorteile der Schilddrüsensonographie sind die einfache Durchführbarkeit und die Tatsache, dass die Schilddrüse aufgrund ihrer oberflächlichen Lage einer Ultraschalluntersuchung sehr gut zugänglich ist. Die heute zur Verfügung stehenden Geräte besitzen eine hohe Detailauflösung und erlauben den Nachweis auch diskreter Veränderungen. Die Schilddrüsensonographie ist damit ein probates, im Rahmen der Schilddrüsendiagnostik bevorzugt einzusetzendes, bildgebendes Verfahren. 

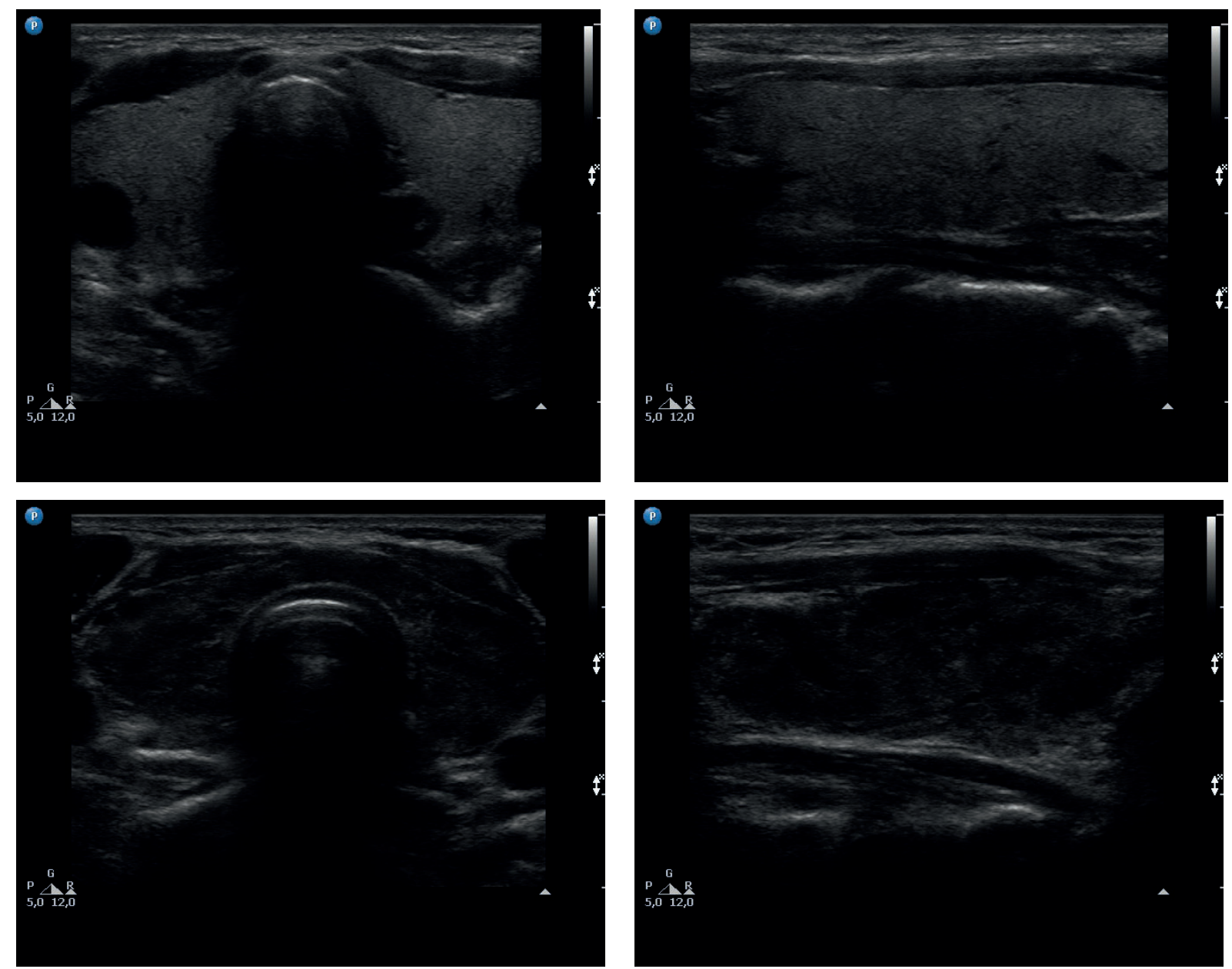

Abbildung 3 Sonographische Darstellungen der Schilddrüse (gesund vs. AIT)

Oben: Echonormale, normal große Schilddrüse einer Frau, $13,5 \mathrm{ml}$ Volumen (normal bis $18 \mathrm{ml}$ ), transversales Bild (links) und sagittales Bild (rechts). Unten: Inhomogen echoarme, normal große Schilddrüse einer Frau mit AIT, $15 \mathrm{ml}$ Volumen (normal bis $18 \mathrm{ml}$ ), transversales Bild (links) und sagittales Bild (rechts). Verwendet wurde jeweils ein variabler 5-12 $\mathrm{MHz}$ Ultraschallkopf, Philips HD11-XE Ultraschallsystem (Philips Healthcare, Best, Niederlande); (mit freundlicher Überlassung durch Prof. Dr. J. Meller, Abteilung Nuklearmedizin der Universitätsmedizin Göttingen).

\subsubsection{Farbkodierte Dopplersonographie}

Bei der farbkodierten Dopplersonographie wird die Bewegung der Erythrozyten in den Blutgefäßen farbig dargestellt und so das Durchblutungsmuster der Schilddrüse sichtbar gemacht. Bei der Autoimmunthyreoiditis vom Typ Hashimoto zeigt die farbkodierte Duplexsonographie typischerweise eine globale oder fokale Hypovaskularisation. 


\subsubsection{Szintigraphie}

Die Szintigraphie der Schilddrüse ist eine Funktionsuntersuchung. Ihre Domäne ist der Nachweis einer Autonomie der Schilddrüse sowie funktionell inaktiver, nicht speichernder Knoten, weshalb sie bei der Diagnostik der Autoimmunthyreoiditis nur eine untergeordnete Rolle spielt. Die Indikation für eine Schilddrüsenszintigraphie ist bzgl. der AIT nur zur Differenzierung zwischen einer initial hyperthyreoten Phase einer AIT und einer Immunogenen Hyperthyreose gegeben, allerdings waren Patienten mit einer manifesten Hyperthyreose ausgeschlossen worden.

\subsubsection{Feinnadelpunktion}

Die einfach durchzuführende und komplikationsarme Feinnadelpunktion mit Gewinnung einer Aspirationszytologie stellt das wichtigste diagnostische Hilfsmittel zur Dignitätsbeurteilung von Schilddrüsenknoten dar und dient ebenso dem zytologischen Nachweis einer Autoimmunthyreoiditis mit lymphozytärer Infiltration.

Die Feinnadelpunktion wird nur bei unklaren Fällen zur Sicherung der Diagnose angewendet. Bei typischem sonographischem Befund und positivem Antikörpernachweis ist sie verzichtbar.

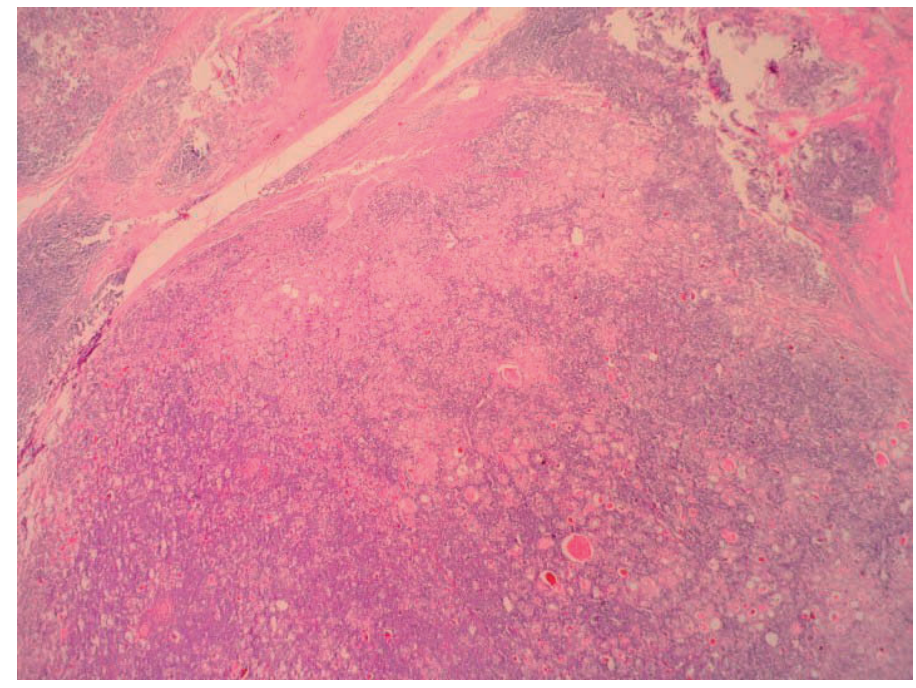

\section{Abbildung 4 Histologisches Übersichtspräparat einer typischen AIT}

HE-Färbung; lymphozytäre Infiltration mit typischer mikrofollikulärer Struktur (mit freundlicher Überlassung durch Prof. L. Füzesi, ehemals Abteilung Gastroenteropathologie der Universitätsmedizin Göttingen). 


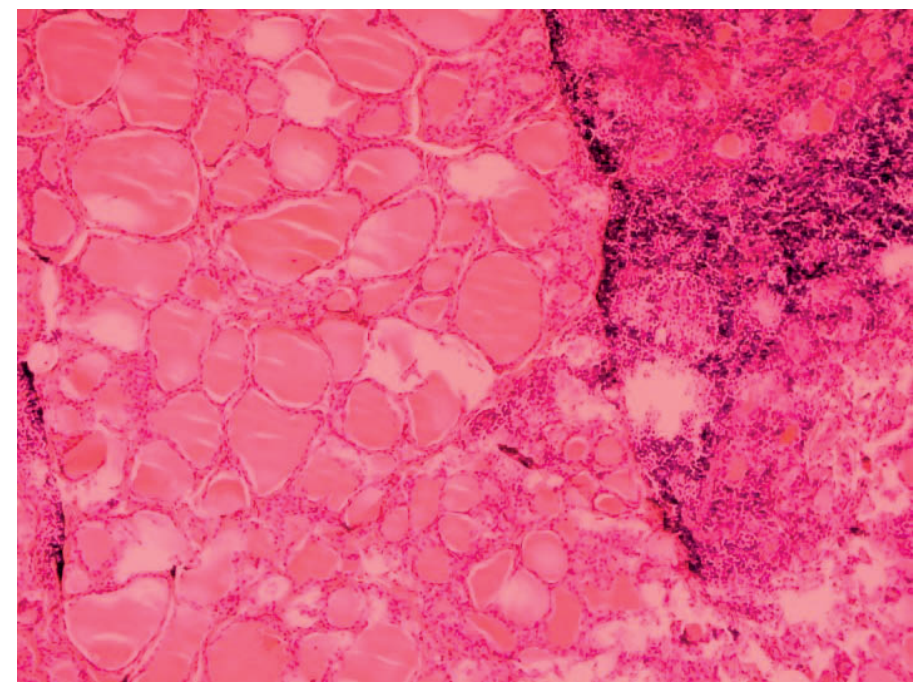

Abbildung 5 Vergrößerung eines histologischen Präparates einer typischen AIT

HE-Färbung; in der linken Bildhälfte finden sich überwiegend normale Follikel, während in der rechten Bildhälfte klassische lymphozytäre Infiltrate imponieren (mit freundlicher Überlassung durch Prof. L. Füzesi, ehemals Abteilung Gastroenteropathologie der Universitätsmedizin Göttingen).

\subsubsection{Diagnosekriterien}

Diagnosekriterien für die Autoimmunthyreoiditis sind:

- Erhöhte anti-TPO-Werte + Echoarmut in der Sonographie und/oder

- Erhöhte anti-TPO-Werte + (subklinische) Hypothyreose und/oder

- Positive Feinnadelbiopsie.

\subsubsection{Datenauswertung/Statistische Methoden}

Die Gruppen wurden in einer vergleichenden Statistik einschließlich MultivariaterAnsätze hinsichtlich unterschiedlicher Parameter (u.a. Diagnosegruppe, Alter, Geschlecht, Medikation) ausgewertet. Die anti-TPO-Spiegel wurden, sofern sie mehrfach bei Patienten vorhanden waren, mit Hilfe des Mittelwertes aggregiert. Eine Dichotomisierung der anti-TPO-Titer wurde mit $>60 \mathrm{U} / \mathrm{ml}$ als Grenzwert durchgeführt. Aufgrund der fehlenden Normalverteilung der anti-TPO-Werte wurden nichtparametrische Verfahren wie Chi-Quadrat-Test, Mann-Whitney-U und Spearman-Korrelationen verwendet. Für Gruppenunterschiede des basalen TSHWertes konnten parametrische Tests (z.B. t-Test für unabhängige Stichproben) angewendet werden. Neben einer Geschlechtsstratifikation wurde eine logistische Modellierung mit Geschlechts- und Altersadjustierung durchgeführt. 
Der anti-TPO-Spiegel diente dabei als unabhängige Variable, die Diagnosegruppe als abhängige Variable. Außerdem wurden die Odds Ratio (OR) bestimmt (Ramm et al. 1976, Weiss 2001).

Geschlecht, Alter und Dauer der Erkrankung sowie die eingenommenen Medikamente wurden in einem Erhebungsbogen festgehalten.

Alle statistischen Tests waren zweiseitig, ein Signifikanzniveau von $p=0,05$ wurde verwendet. Alle Berechnungen wurden mit Hilfe des Statistikpaketes SPSS ${ }^{\mathrm{TM}}$ für Windows (SPSS Inc., Chicago, IL/USA) durchgeführt. 


\section{ERGEBNISSE}

\subsection{Patientencharakteristika}

Insgesamt wurden 52 Patienten mit einer affektiven Störung (28 weiblich, 24 männlich, Durchschnittsalter 46,1 Jahre) eingeschlossen. Bei 16 Patienten (30,8\%, 12 weiblich, 4 männlich) fand sich eine klinisch, sonographisch und laborchemisch gesicherte AIT. In der Kontrollgruppe der schizophrenen Patienten ( $n=19,7$ weiblich, 12 männlich; Durchschnittsalter: 43,2 Jahre) nur bei 2 Patienten $(10,5 \%, 1$ weiblich, 1 männlich). Im Vergleich zu den Werten in der Allgemeinbevölkerung und bei der statistischen Analyse mit dem Kontrollkollektiv zeigte sich eine statistisch signifikante Erhöhung des Risikos einer AIT bei Patienten mit einer affektiven Störung.

\begin{tabular}{llccccccc}
\hline ICD-10 & Psychiatrische Diagnosen & $\mathbf{n}$ & Frauen & Männer & $\begin{array}{c}\text { Alter } \\
\text { (Median) }\end{array}$ & AIT (n) & AIT (\%) \\
\hline & Affektive Störungen & 52 & 28 & 24 & 46,1 & 16 & 30,8 \\
\cline { 2 - 8 } & Unipolare Depressionen & & & & & & \\
\cline { 2 - 8 } F 33 & Rez. depressive Störung & 34 & 17 & 17 & 49,9 & 10 & 29,4 \\
\cline { 2 - 8 } F 32 & Depressive Episode & 5 & 4 & 1 & 29,0 & 2 & 40,0 \\
\cline { 2 - 8 } & Bipolare Depression & & & & & 4 & \\
\cline { 2 - 8 } F 31 & Bipolare affektive Störung & 13 & 7 & 6 & 42,8 & 4 & 30,8 \\
\hline F 20 & Schizophrenie & $\mathbf{1 9}$ & $\mathbf{7}$ & $\mathbf{1 2}$ & $\mathbf{4 3 , 5}$ & $\mathbf{2}$ & $\mathbf{1 0 , 5}$ \\
\hline
\end{tabular}

Tabelle 8 Patientenkollektiv nach Diagnosegruppen 


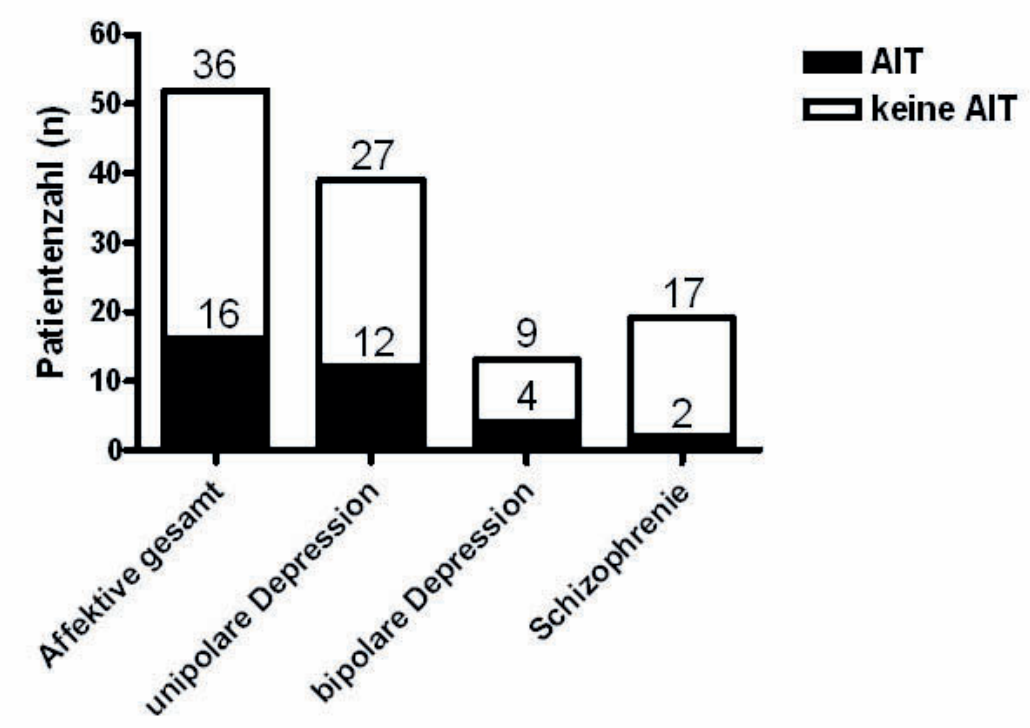

Abbildung 6 Diagnosegruppen AIT

\subsubsection{Alter}

Es gab keine signifikante Korrelation zwischen dem Alter und anti-TPO (Spearmans $r h o=-0,14 ; p=0,265)$. Dies war konsistent für sämtliche psychiatrische Diagnosegruppen (Schizophrenie und Depression).

In einer geschlechts- und altersadjustierten logistischen Regression mit dem antiTPO-Spiegel als abhängige Variable (dichotomisiert: erhöht oder nicht erhöht) und der Diagnosegruppe als unabhängige Variable war das Odds Ratio (OR) von unibzw. bipolar depressiven Patienten verglichen mit schizophrenen Patienten zehnfach erhöht $(95 \% \mathrm{Cl}=1,2-85,3)$. 

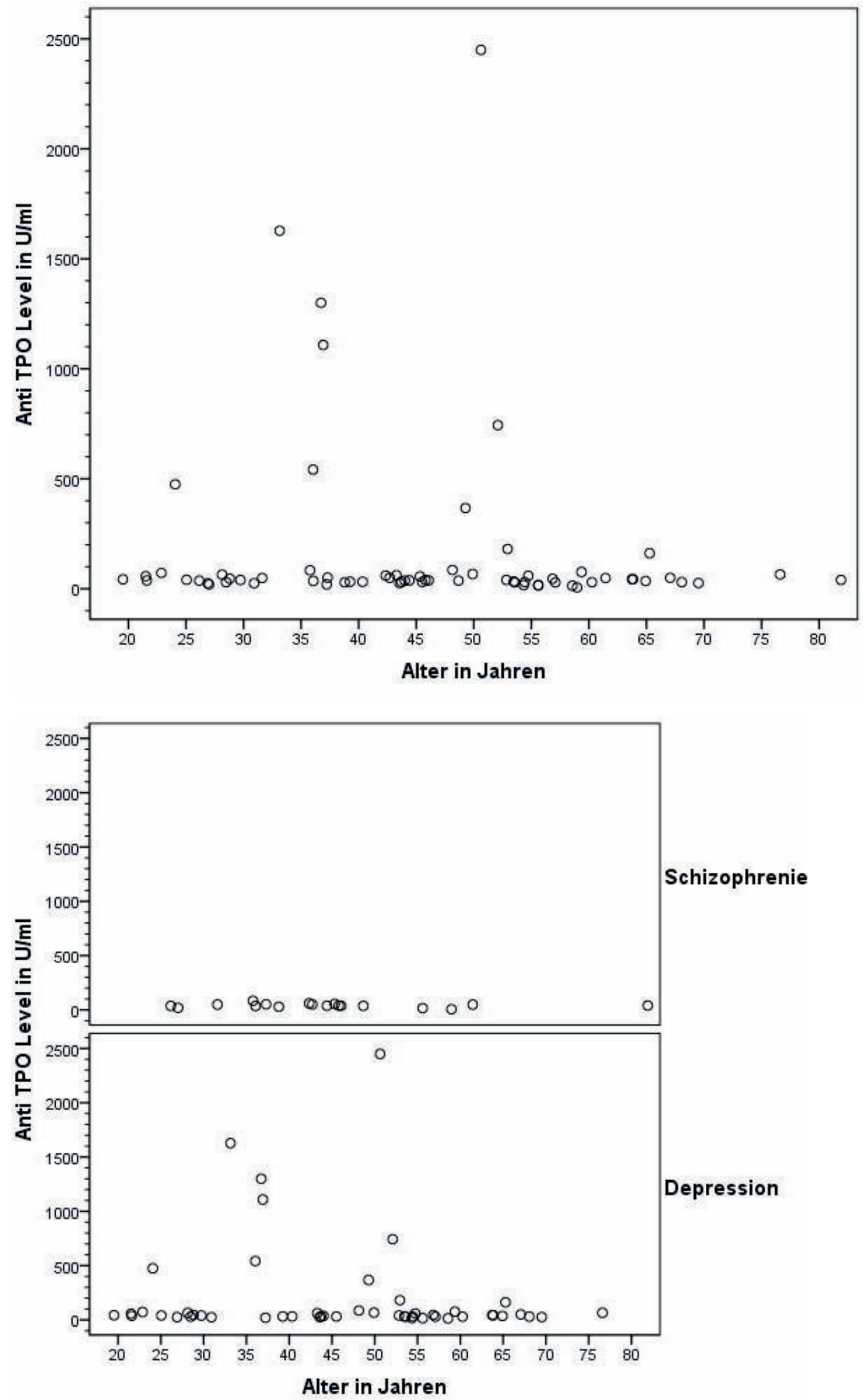

Abbildung 7 Negative Korrelation zwischen Alter und anti-TPO in beiden Diagnosegruppen 


\subsubsection{Erkrankungsdauer}

In einer Subgruppenanalyse hinsichtlich der Erkrankungsdauer der Patienten zeigte sich, dass bei der überwiegenden Anzahl der Patienten die Diagnosestellung innerhalb des letzten Jahres vor der Untersuchung erfolgt war (bei Patienten mit Schizophrenie zu 94,7\%, mit unipolarer Depression zu 56,4\%, mit bipolarer Depression zu 46,2\%). Die Dauer der Erkrankung spielte somit keine Rolle hinsichtlich des anti-TPO-Spiegels ( $r h o=-0,065 ; p=0,600$ ).

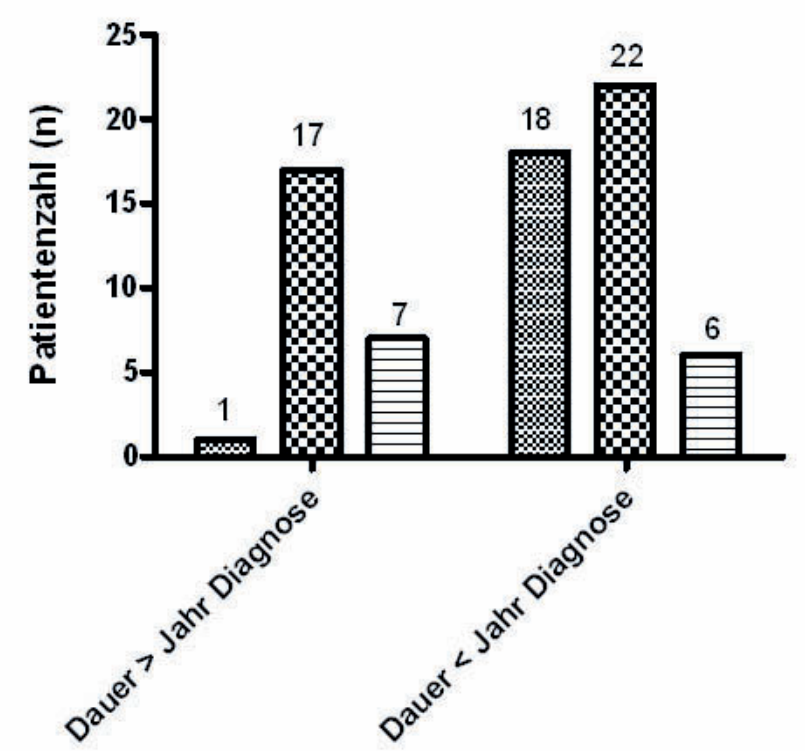

Abbildung 8 Diagnosegruppen nach Erkrankungsdauer bis Studieneinschluss $(n=71)$

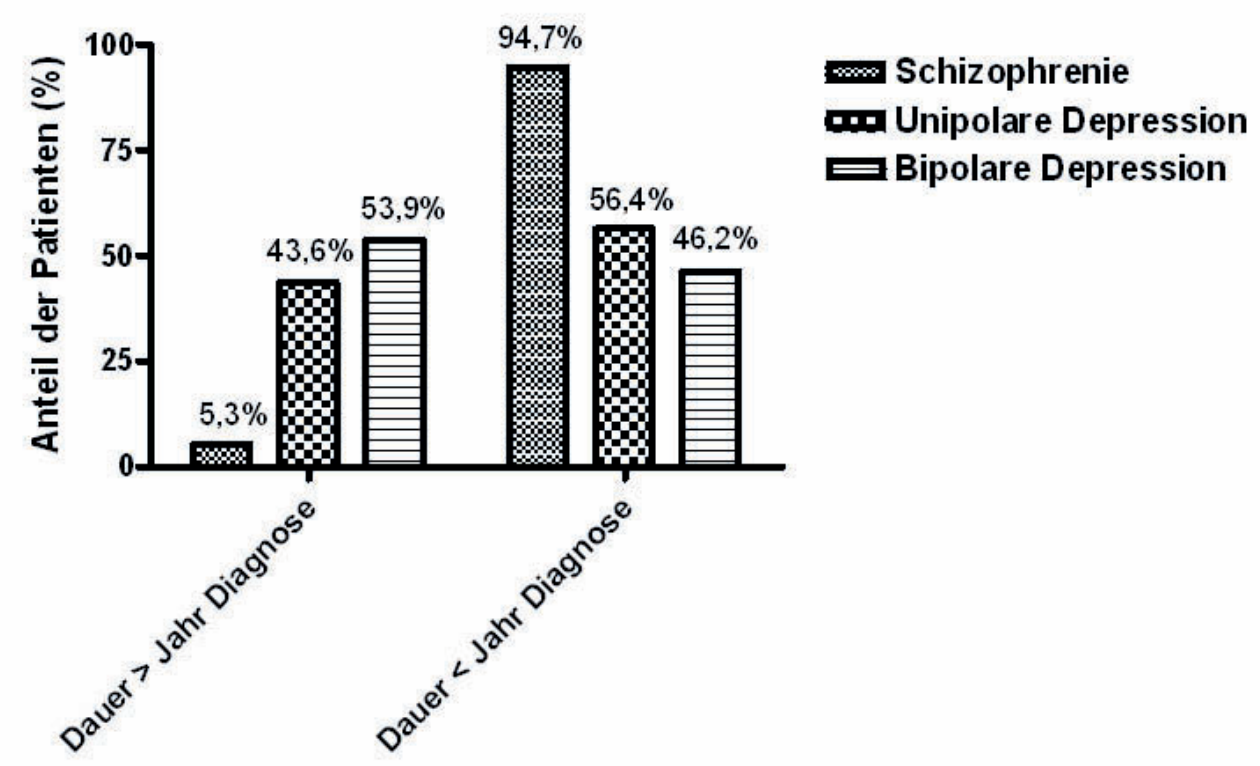

Abbildung 9 Diagnosegruppen nach Erkrankungsdauer bis Studieneinschluss (Angaben in Prozent) 


\subsubsection{Lithiummedikation}

Die Gabe von Lithium bei unipolar bzw. bipolar depressiven Patienten hatte keine Relevanz für den anti-TPO-Spiegel (Mann-Whitney-U, $Z=-1,1, p=0,271$ ). Somit ließ sich statistisch kein Zusammenhang zwischen der Einnahme von Lithiumsalzen und einer Hashimoto-Thyreoiditis feststellen. Es konnte weiterhin keine spezifische antidepressive Medikation (trizyklische Antidepressiva, SSRI, SNRI oder MAOHemmer) mit den anti-TPO-Spiegeln in Verbindung gebracht werden.

\begin{tabular}{cccc} 
& Schizophrenie & Unipolare Depression & Bipolare Depression \\
\hline $\begin{array}{c}\text { Durchschnittsalter } \\
\text { (Standardabweichung) }\end{array}$ & $43,5(13,4)$ & $46,7(14,9)$ & $42,8(14,7)$ \\
\hline $\begin{array}{c}\text { Patientenzahl, } \\
\text { Geschlecht (m/w) }\end{array}$ & $19(12 \mathrm{~m} / 7 \mathrm{w})$ & $39(18 \mathrm{~m} / 21 \mathrm{w})$ & $13(6 \mathrm{~m} / 7 \mathrm{w})$ \\
\hline $\begin{array}{c}\text { Lithiummedikation } \\
\text { in \% der Fälle }\end{array}$ & $0,0 \%$ & $10,3 \%$ & $61,5 \%$ \\
\hline $\begin{array}{c}\text { Erstdiagnose } \\
\text { < ein Jahr vor } \\
\text { Studieneinschluss }\end{array}$ & $94,7 \%$ & $56,4 \%$ & $46,2 \%$ \\
\hline
\end{tabular}

Tabelle 9 Patientencharakteristik und Lithiummedikation nach Diagnosegruppen

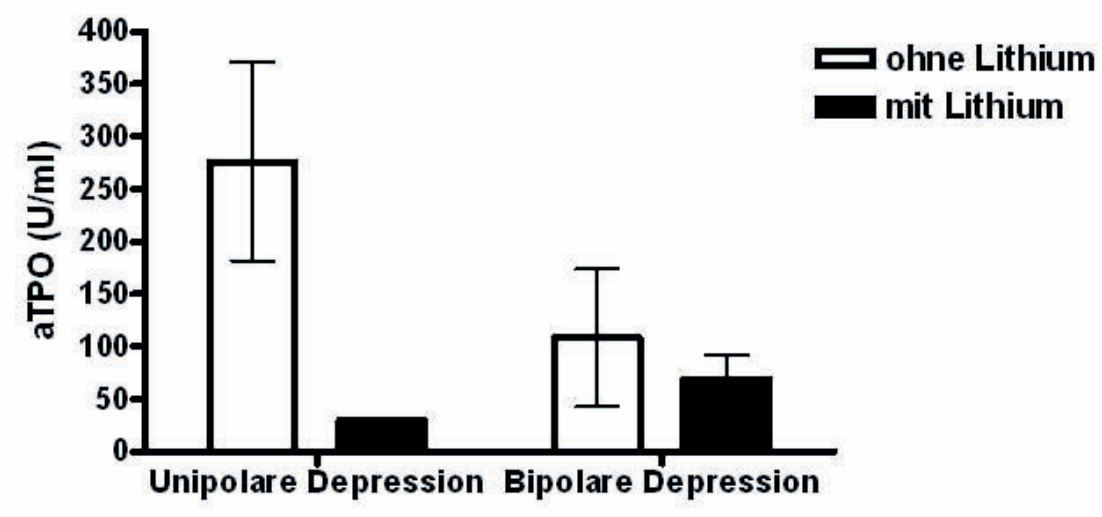

Abbildung 10 Anti-TPO-Titer in Korrelation mit Lithiummedikation und Diagnose

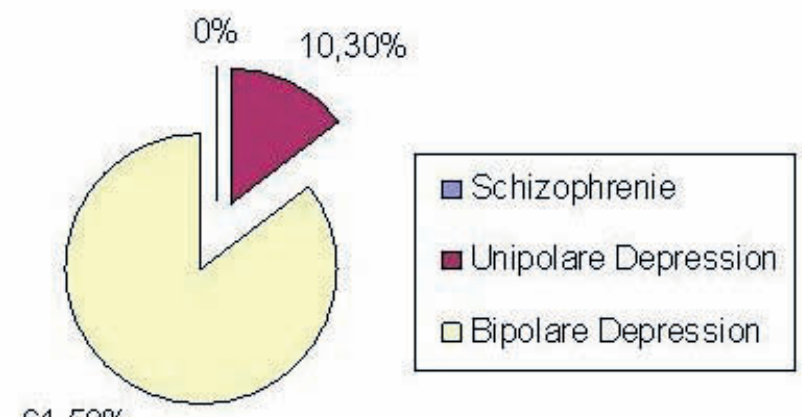

$61,50 \%$

Abbildung 11 Lithiummedikation aller Patienten in Prozent 


\subsection{Schilddrüsenhormonlabor}

\subsubsection{Basales TSH}

Der TSH-basal-Spiegel (Normalbereich 0,4-4,0 $\mu \mathrm{lU} / \mathrm{ml}$ ) unterschied sich nicht zwischen schizophrenen und uni- bzw. bipolar depressiven Patienten (1,6 $\mu \mathrm{lU} / \mathrm{ml}$ (SD $1,5)$ vs. $1,6 \mu \mathrm{lU} / \mathrm{ml}$ (SD 1,5); T-0-09, $p=0,926)$. Weibliche Patienten $(1,89 \mu \mathrm{lU} / \mathrm{ml}$; SD 1,61) hatten einen höheren TSH-basal-Spiegel als männliche Patienten $(1,30 \mu \mathrm{lU} / \mathrm{ml} ; \mathrm{SD} 0,89)$, allerdings war dieser Unterschied nicht signifikant $(T=-$ 1,875, $p=0,065)$.

In einer Subgruppenanalyse hinsichtlich der Patienten mit affektiven Störungen war der TSH-basal-Spiegel bei unipolar depressiven Patienten im Vergleich zu Patienten mit einer bipolaren Erkrankung erhöht, jedoch ebenfalls nicht signifikant (1,71 (SD $1,62)$ vs. 1,26 (SD 0,76$) ; T=-0,984 ; p=0,330)$.
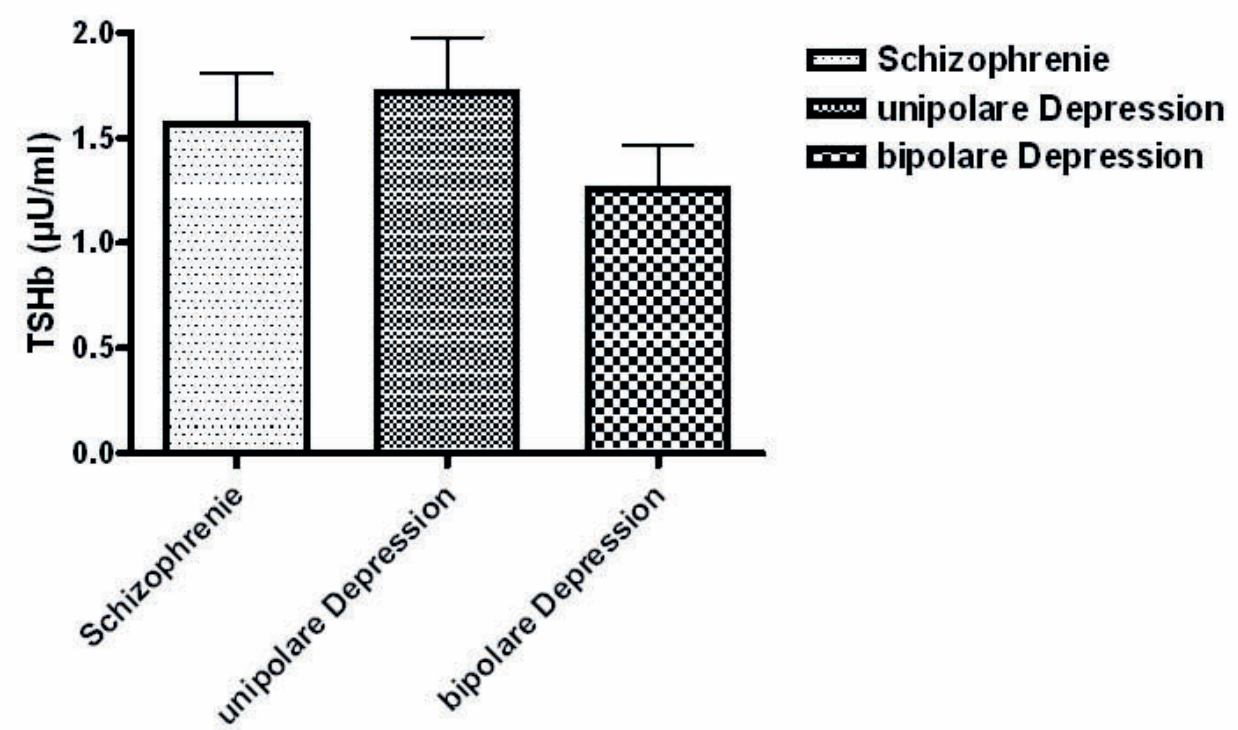

bipolare Depression

Abbildung 12 TSH-basal-Spiegel einzelner Diagnosegruppen 


\subsection{2. fT3 und fT4}

Die Schilddrüsenwerte fT3 (Normbereich 2,0-4,2 pg/ml) und fT4 (Normbereich 0,77$1,53 \mathrm{ng} / \mathrm{dl}$ ) lagen bei allen Patienten im Normbereich. Der Mittelwert des fT3 lag bei $3,1 \mathrm{pg} / \mathrm{ml}$ bei einer Standardabweichung von $0,38 \mathrm{pg} / \mathrm{ml}$, der Mittelwert des fT4 lag bei $1,2 \mathrm{ng} / \mathrm{ml}$ bei einer Standardabweichung von $0,21 \mathrm{ng} / \mathrm{dl}$.

\subsubsection{Anti-TPO-Spiegel}

Die Verteilung der erhöhten anti-TPO-Spiegel war signifikant unterschiedlich zwischen schizophrenen (5,3\%) und uni- bzw. bipolar depressiven Patienten $(32,7 \%)$ (Chi-Quadrat Test, $\left.X^{2}=5,53, p=0,019\right)$. Diese unterschiedliche Verteilung war nicht im Zusammenhang mit erniedrigten TSH-Spiegeln zu sehen.

Nach Risikostratifikation bezüglich des Geschlechts als Confoundervariable, war diese unterschiedliche Verteilung nur bei Patientinnen signifikant $\left(x^{2}=5,17\right.$; $p=0,023)$.

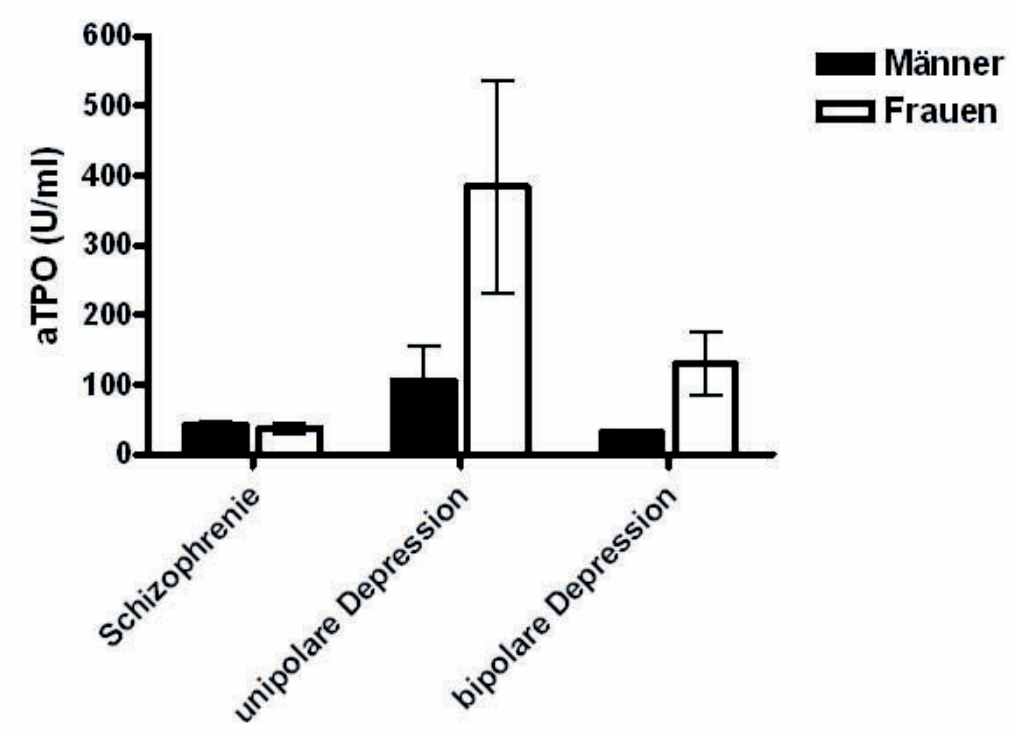

Abbildung 13 Anti-TPO-Spiegel nach Diagnosegruppen und Geschlecht 


\subsubsection{Korrelation von TSH und anti-TPO}

Es konnte keine signifikante Korrelation zwischen den anti-TPO-Spiegeln und den TSH-basal-Spiegeln festgestellt werden (Spearmans $r h o=0,175 ; p=0,153$ ). Interessanterweise unterschieden sich die Korrelationskoeffizienten deutlich, wenn für die Diagnosegruppen (Schizophrenie ICD-10: F20; depressive Episode F32; rezidivierende depressive Störung F33; bipolare affektive Störung, gegenwärtig depressive Episode F32.2 und F32.3) getrennt gerechnet wurde. Eine positive und signifikante Korrelation konnte dagegen bei depressiven Patienten beobachtet werden $(r h o=0,356 ; p=0,011)$. Eine negative Korrelation bestand bei schizophrenen Patienten zwischen anti-TPO und TSH-basal-Spiegel ( $r h o=-0,341$; $p=0,166)$.

a)

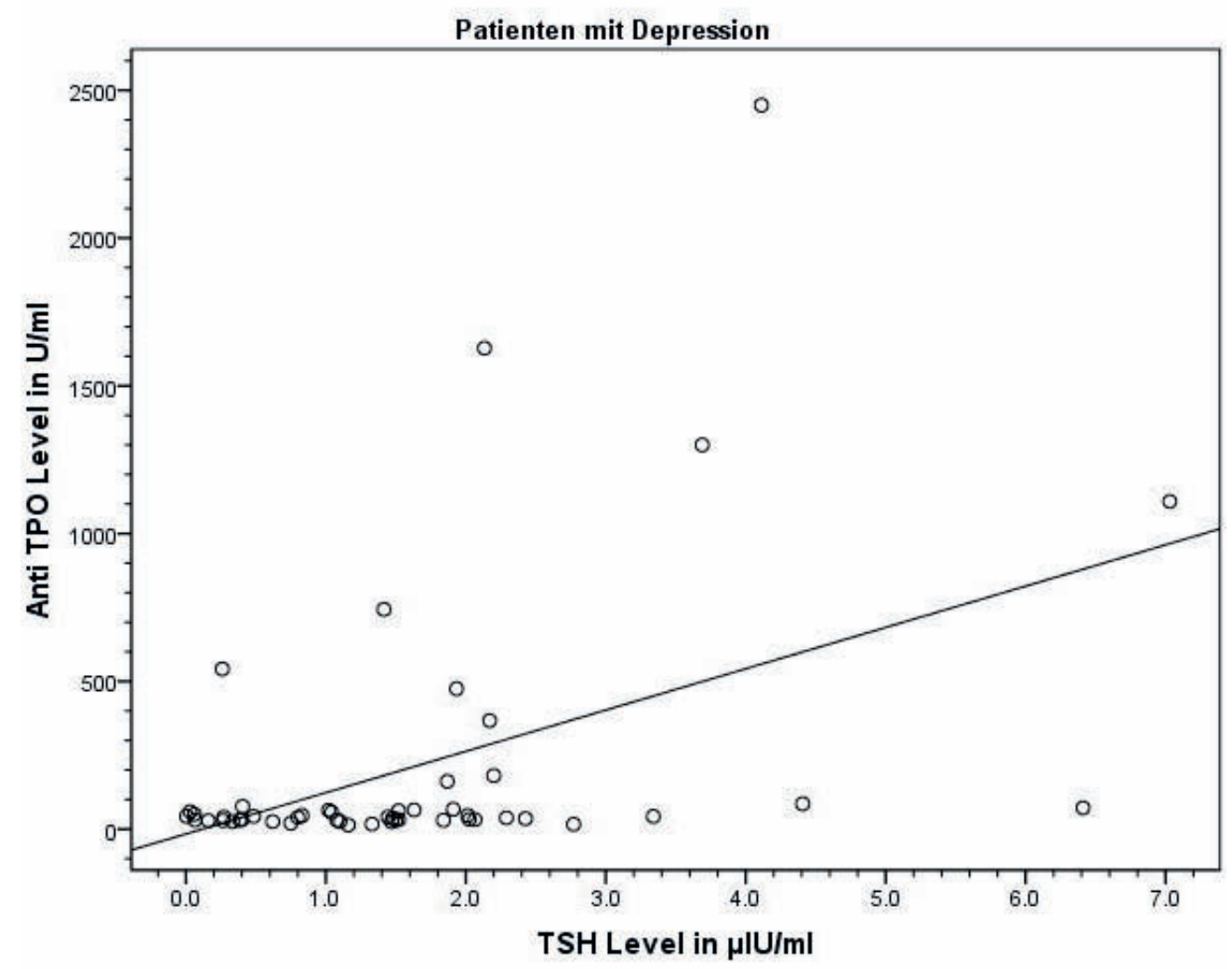


b)

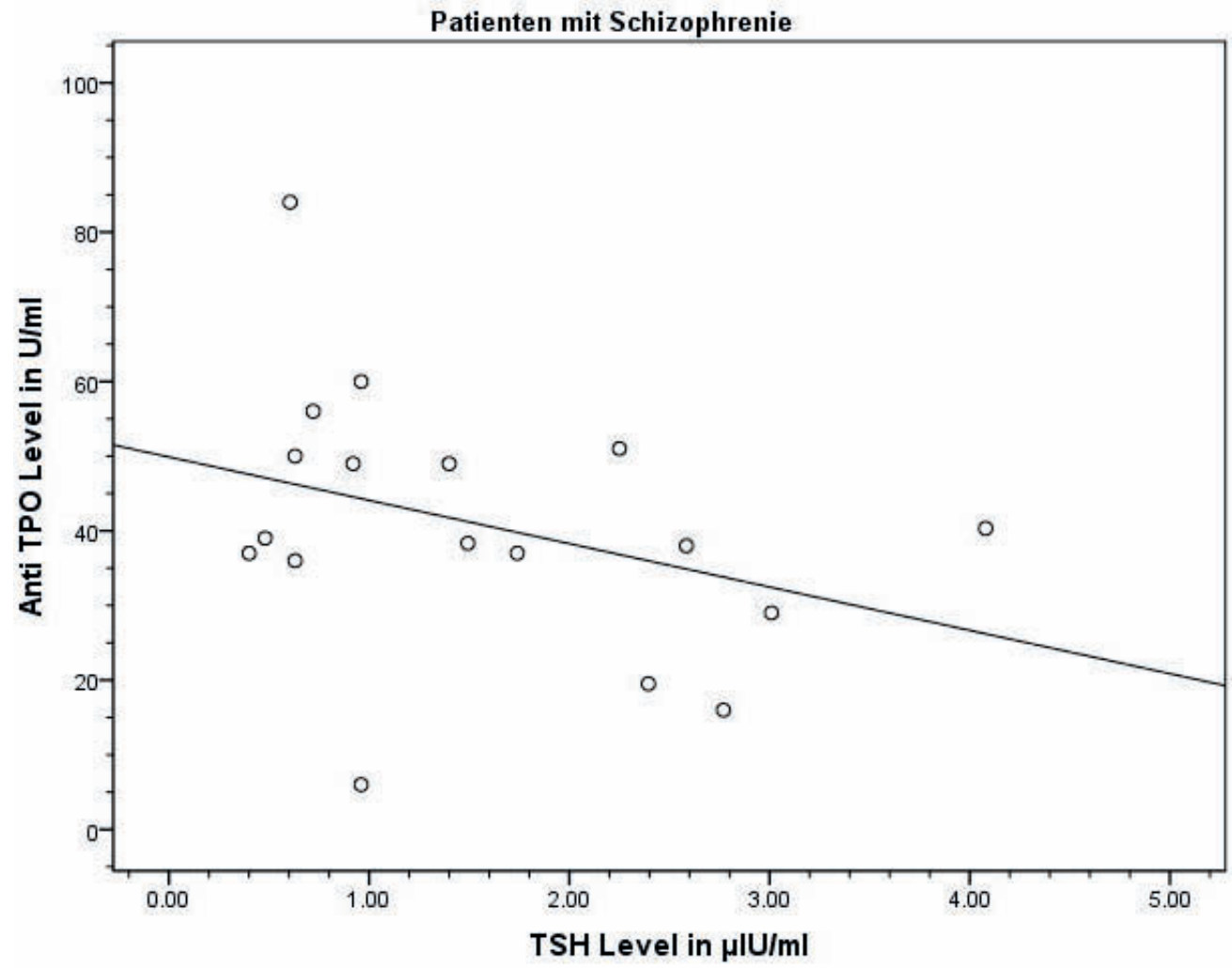

Abbildung 14 Korrelation zwischen anti-TPO- und TSH-basal-Spiegeln aufgeteilt nach Diagnosegruppen (a: signifikant, b: nicht signifikant)

\subsubsection{Anti-TG-Spiegel}

Der anti-TG-Spiegel (Normbereich $<40 \mathrm{U} / \mathrm{ml}$ ) war signifikant mit dem anti-TPOSpiegel korreliert $(r h o=0,502 ; p<0,001)$. Diese Beobachtung konnte bei allen Patienten unabhängig von der psychiatrischen Diagnose (Depression oder Schizophrenie) bestätigt werden. 

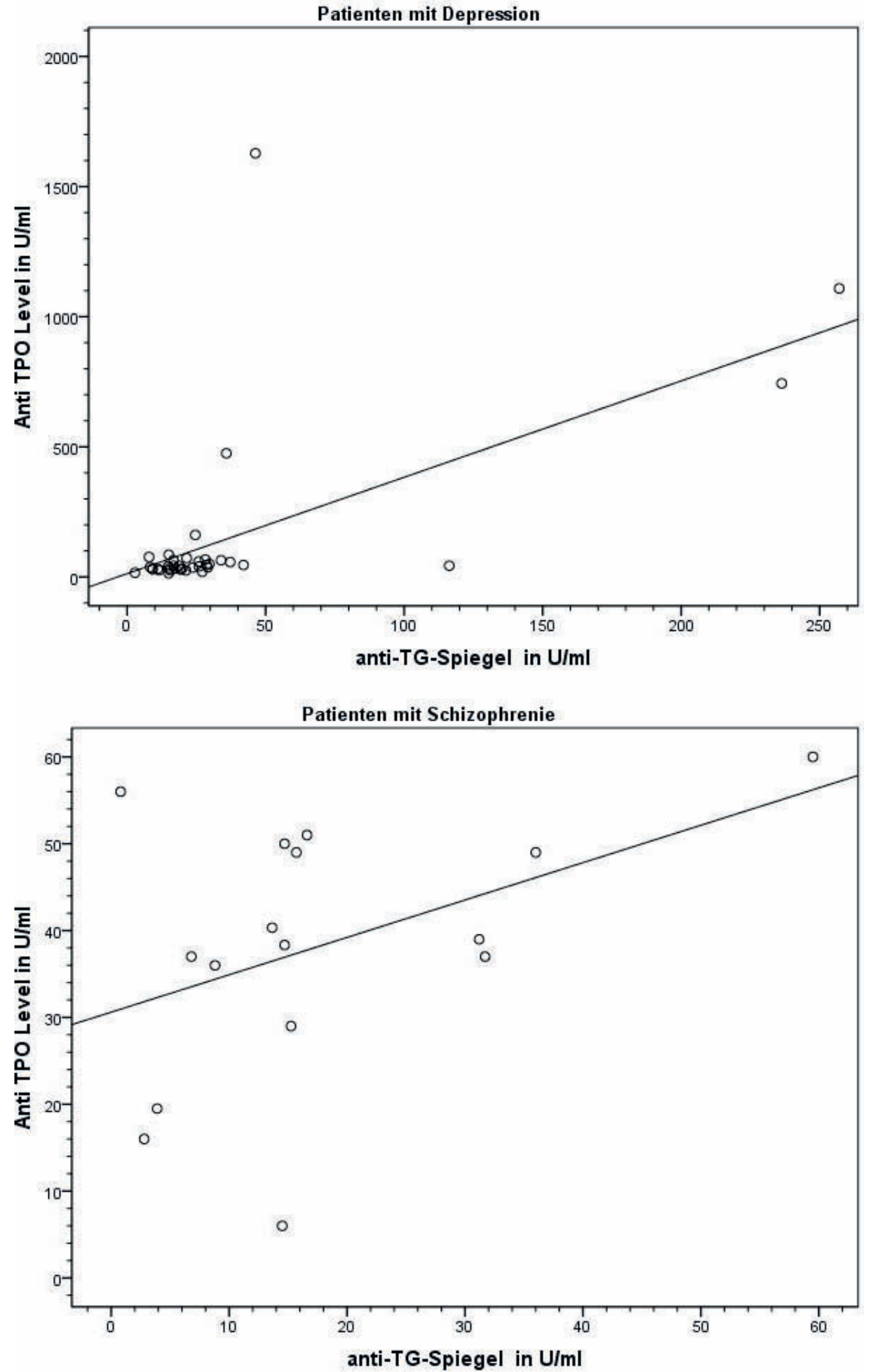

Abbildung 15 Signifikante Korrelation zwischen anti-TG- und anti-TPO-Spiegel in beiden Diagnosegruppen 


\section{DISKUSSION}

\subsection{Diskussion der Methodik und der Ergebnisse}

\subsubsection{Geschlecht}

Pop et al. konnten mit ihren Untersuchungen zeigen, dass Frauen mit erhöhten AntiTPO-Werten ein höheres Risiko als Männer haben, an einer Depression zu erkranken (Pop et al. 1998). In der Bevölkerung liegt die Prävalenz für eine Autoimmunthyreoiditis (AIT) bei Frauen zwischen 2 und $12 \%$ und bei Männern zwischen 2,5 und 3 \% (Bjoro et al. 2000, Bryhni et al. 1996, Dos Remedios et al. 1980, Lazarus et al. 1984, Roti et al. 1992, Tunbridge et al. 1981). Diese Beobachtung deckt sich mit den vorliegenden Daten dieser Arbeit.

Es besteht allgemeines Einvernehmen darüber, dass eine depressive Störung multifaktorielle Ursachen hat. Die genauen ätiologischen Mechanismen sind jedoch weiterhin unbekannt. Es gibt allerdings Hinweise, dass neben biologischen Faktoren, psychologische Aspekte oder aber auch Umweltfaktoren wie das Auftreten sog. „life events" oder der Familienhintergrund möglicherweise eine ähnlich hohe Relevanz besitzen (Gelder et al. 1994).

\subsubsection{Lithiummedikation}

Ebenso wie Kupka et al., Bocchetta et al. und Haggerty et al. konnte die vorliegende Arbeit keinen Zusammenhang zwischen der Einnahme von Lithium und Autoimmunthyreoitiden feststellen (Kupka et al. 2002, Bocchetta et al. 2001, Haggerty et al. 1997). Diese Ergebnisse stehen im Gegensatz zu anderen Arbeitsgruppen (Hassmann und McGregor 1988, Myers et al. 1985, Wilson et al. 1991). Dennoch haben Patienten, die Lithiumsalze einnehmen müssen, ein potentiell höheres Risiko eine pharmakologisch induzierte Hypothyreose zu entwickeln (Kleiner et al. 1999). Dabei scheinen eine thyreoidale Autonomie und die Lithiumeinnahme zwei unabhängige Risikofaktoren bei affektiven Störungen zu sein, die sich gegenseitig potenzieren. Der Versuch einer Identifikation von Risikopatienten über den Nachweis von Schilddrüsenautoantikörpern erscheint nicht sinnvoll, da hier keine immunologische Verbindung zu bestehen scheint. 


\subsubsection{Basales TSH}

Poirier et al. konnten einen signifikanten Zusammenhang zwischen erniedrigten basalen TSH-Werten und der Schwere einer Depression bei affektiv erkrankten Patienten feststellen, wobei zur TSH-Bestimmung ein ähnliches Nachweisverfahren wie in der vorliegenden Arbeit benutzt wurde (Poirier et al. 1995). Die Größe der Gruppe der untersuchten Patienten entsprach ebenfalls dem hier untersuchten Patientenkollektiv. Die Ergebnisse von Poirier et al. sind gut mit denen anderer Arbeitsgruppen vergleichbar (Goldstein et al. 1980, Kjellman et al. 1984, Rubin et al. 1987, Joffe 1990). Trotz ähnlichem Studiendesign konnte in der vorliegenden Arbeit jedoch keinen Zusammenhang zwischen erniedrigtem TSH-Spiegel im Vergleich zwischen Gesunden und Patienten mit einer depressiven Störung festgestellt werden, womit die Ergebnisse von Kasper et al. sowie Joffe et al. bestätigt werden (Kasper et al. 1988, Joffe et al. 1992). Die Höhe der TSH-basal-Spiegel unterschied sich nicht zwischen schizophrenen und unipolar bzw. bipolar depressiven Patienten.

Die Ursache für die abweichenden Ergebnisse könnte darin begründet liegen, dass bei den unterschiedlichen Studien die Hormonwerte der jeweiligen psychiatrischen Populationen in unterschiedlichen Laboren mit unterschiedlichen Messmethoden bestimmt wurden. Für eine eindeutige Aussage über diesen Teilaspekt sind weitere Untersuchungen mit einer größeren Patientenzahl unter stringent standardisierten Versuchsbedingungen notwendig.

In der vorliegenden Untersuchung zeigte sich darüber hinaus eine negative Korrelation zwischen den anti-TPO- und TSH-Spiegeln schizophrener Patienten sowie eine positive und signifikante Korrelation bei depressiven Patienten.

In einer Subgruppenanlyse hinsichtlich der Patienten mit affektiven Störungen war der TSH-Spiegel bei unipolar depressiven Patienten im Vergleich zu Patienten mit bipolaren Erkrankungen zwar erhöht, dies war jedoch nicht signifikant.

\subsubsection{Schilddrüsenhormonparameter}

Mehrere Autoren konnten durch ihre Untersuchungen leicht erhöhte T4- bzw fT4Werte bei sogenannten "mixed psychiatric inpatients" oder auch sog. "endogen" depressiven Patienten feststellen (Baumgartner et al. 1988). Diese Abweichung der 
Werte gegenüber Gesunden fiel allerdings so diskret aus, dass diese kaum als Ursache für eine psychiatrische Erkrankung wahrscheinlich wäre.

Die vorliegende Arbeit kann die Ergebnisse von Joffe et al. sowie Brouwer et al. bestätigen, dass auch die Serumkonzentration von T3 bzw. fT3 bei Patienten mit bipolaren Störungen unauffällig im Vergleich zur Kontrollgruppe waren (Joffe et al. 1992, Brouwer et al. 2005). Ebenso waren die fT4-Werte unauffällig.

\subsubsection{Schilddrüsen-Autoantikörper}

Antikörper gegen die thyreoidale Peroxidase finden sich mit einer Prävalenz von 80$90 \%$ bei Patienten mit Autoimmunthyreoiditiden (Gutekunst et al. 1989). Darüberhinaus finden sich mit einer Prävalenz von 40-70\% zusätzlich Thyreoglobulin-Antikörper, die dabei eng mit den TPO-Ak-Spiegeln korrelieren (Pfannenstiel et al. 1997, Dietlein et al. 1999). Im Rahmen der vorliegenden Arbeit konnte diese Korrelation bei Patienten mit Schizophrenien und affektiven Störungen bestätigt werden.

Im klinischen Alltag ist die Bestimmung von TPO- und TG -Auto-Antikörpern eine sichere und unerlässliche Methode für den Nachweis einer AIT. Da jedoch einige Patienten zwar niedrige Antikörper-Titer und dennoch keine AIT haben, reicht ihre Bestimmung als alleiniges Testverfahren nicht aus. Deswegen wird z.B. in der Abteilung für Nuklearmedizin der Universitätsmedizin Göttingen zur Diagnosestellung weiterhin eine Bestimmung von $\mathrm{TSH}$, der peripheren Schilddrüsenhormone und Ultraschalluntersuchungen durchgeführt.

TSH-Rezeptor-Antikörper weisen eine hohe Spezifität für Immunthyreopathien, insbesondere für den Morbus Basedow mit einer Prävalenz von 70-100 \% auf (Meller et al. 2000b). Im Falle einer Autoimmunthyreoiditis zeigt sich nur eine geringe Prävalenz (0-7 \%) für diesen Antikörper. Es ist allerdings bekannt, dass ein Morbus Basedow spontan in eine Autoimmunthyreoiditis übergehen kann. Der umgekehrte Weg ist ebenfalls möglich und selbst wiederkehrende Zyklen beider Krankheitsbilder treten in seltenen Fällen auf (Kaplan 1999). So ist es nicht ungewöhnlich, dass bei Patienten mit Autoimmunthyreoiditis TRAK nachweisbar sind. Zum Ausschluss eines Morbus Basedow, wurde in der vorliegenden Untersuchung bei allen Patienten 
zusätzlich eine TRAK-Bestimmung durchgeführt. Die TRAK-Titer aller Patienten lagen im Normbereich.

Die Sensitivität und Spezifität einzelner Nachweisverfahren sind allerdings nicht einheitlich (Bird und Stephenson 1973). Aus diesem Grund sind Kontrollgruppen, wie sie in unserem Studiendesign untersucht wurden, unerlässlich.

\subsection{Autoimmunthyreoiditis (AIT) und affektive Störungen}

Bislang vorliegende Studien bezüglich erhöhter Antikörper-Titer bei affektiven Störungen kommen teilweise zu sehr unterschiedlichen Ergebnissen. In 0 bis $43 \%$ konnten Antikörper nachgewiesen werden. Die erhöhten Ak-Werte werden zum Teil mit der Einnahme von Lithium in Verbindung gebracht (Bartalena et al. 1990, Bocchetta et al. 2001, Calabrese et al. 1985, Haggerty et al. 1997, Hornig et al. 1999, Leroy et al. 1988, Lazarus et al. 1981, Lazarus et al. 1986, Myers et al. 1985, Rapaport 1994, Wilson et al. 1991). Die Diskrepanzen zwischen den einzelnen Studien sind auf unterschiedliche Diagnosegruppen und Größen der untersuchten Patientengruppen, unterschiedliche Geschlechter-Verhältnisse, eingenommene Medikamente bzw. auf den Einsatz verschiedener Antikörper-Nachweisverfahren zurückzuführen. In Untersuchungen, die eine Kontrollgruppe eingeschlossen hatten (Haggerty et al. 1990, 1997, Wilson et al. 1991), und in drei weiteren ohne Kontrollgruppen (Bartalena et al. 1990, Hornig et al. 1999, Rapaport 1994) konnten erhöhte Schilddrüsen-Auto-Antikörper bei affektiv Erkrankten, insbesondere bei Depressiven nachgewiesen werden. König et al. fanden heraus, dass erhöhte Schilddrüsen-Auto-Antikörper mit einem schlechteren Ansprechen der Patienten auf Antidepressiva korrelieren (König et al. 1999). Kupka et al. konnten in ihrer breit angelegten Untersuchung zeigen, dass erhöhte Schilddrüsen-Auto-Antikörper eher mit bipolaren als mit unipolaren affektiven Störungen assoziiert sind (Kupka et al. 2002). $17 \%$ aller Patienten mit bipolaren Störungen litten darüber hinaus an einer manifesten Hypothyreose.

Es ist bekannt, dass Schilddrüsen-Auto-Antikörper bei 9-20\% der Patienten mit Depressionen oder anderen affektiven Störungen erhöht sind (Gold et al. 1982, Nemeroff et al. 1985, Reus et al. 1986, Haggerty et al. 1997), im Vergleich zu 2-12 \% in der Gesamtbevölkerung (Tunbridge et al. 1977, Okamura et al. 1987). Aus dieser Beobachtung wurde abgeleitet, dass Schilddrüsendysfunktionen möglicherweise ein 
Risikofaktor für die Entwicklung affektiver Störungen sind. Weiterhin können die Schilddrüsen-Auto-Antikörper als prädiktiver Marker insbesondere der subklinischen Hypothyreose dienen, wenn Serum-Schilddrüsenhormonwerte und basales TSH keine eindeutigen Ergebnisse aufzeigen (Gold et al. 1982, Nemeroff et al. 1985, Reus et al. 1986, Haggerty et al. 1987).

1997 konnten Haggerty et al. in einer Folgestudie von 1990 den Trend des Befundes erhöhter Auto-Antikörper-Titer bei bipolar depressiven bzw. bei bipolar "gemischt" ("mixed") Erkrankten bestätigen, jedoch nicht bei bipolar manischen Patienten (Haggerty et al. 1997).

In der hier vorliegenden prospektiven Untersuchung konnte ein wahrscheinlicher Zusammenhang zwischen einer Autoimmunthyreoiditis und depressiven Störungen anhand deutlich erhöhter anti-TPO-Ak gegenüber dem ausgewählten Kontrollkollektiv aufgezeigt werden.

Die Verteilung der erhöhten anti-TPO-Spiegel war signifikant unterschiedlich zwischen schizophrenen (10,5\%) und unipolar sowie bipolar depressiven Patienten $(30,8 \%)$. Damit konnten die Ergebnisse aus der Arbeitsgruppe von Kupka et al. bestätigt werden, die bei bipolaren Patienten eine erhöhte Prävalenz von TPO-Ak $(28,3 \%)$ fanden (Kupka et al. 2002). Die häufige Koinzidenz der AIT mit affektiven Störungen impliziert, dass affektive Erkrankungen wie Depressionen möglicherweise Störungen des Immunsystems hervorrufen oder dass es sich bei affektiven Störungen tatsächlich um eine eigenständige Autoimmunerkrankung handeln könnte (Carta et al. 2004). Diese Ergebnisse bestätigen auch die Daten von Eaton et al., die ebenfalls zeigen konnten, dass eine Schizophrenie nicht mit einer höheren Prävalenz von Autoimmunthyreoiditiden einhergeht (Eaton et al. 2006).

Die Ergebnisse der Studie zeigen eine Assoziation zwischen der Entwicklung affektiver Störungen und dem Auftreten von anti-TPO-Ak. Thyreoidale Antikörper sind prädiktive Marker für die Entwicklung einer subklinischen Hypothyreose, welche wiederum eine Ursache für eine affektive Störung über bis jetzt unbekannte Mechanismen darstellen könnte. Bauer et al. sowie Cowdry et al. konnten in ihren Untersuchungen zeigen, dass Patienten, die an einer sog. „Rapid-Cycling“-Störung im Rahmen einer affektiven Störung leiden, die einer gemischten bipolaren Störung 
ähnelt, häufig auch an einer subklinischen Hypothyreose leiden (Bauer et al. 1990, Cowdry et al. 1983).

Alternativ wäre es grundsätzlich möglich, dass es einen immunologischen Zusammenhang zwischen der Prädisposition für eine bipolare Störung und der Prädisposition für eine Autoimmunthyreoiditis geben könnte. So konnten Schiffer et al. beispielsweise zeigen, dass affektive Störungen und Autoimmunerkrankungen wie die Multiple Sklerose (MS) assoziiert sind (Schiffer et al. 1988). Zudem konnten Niederwieser et al. eine signifikant höhere Prävalenz der AIT bei männlichen Patienten mit MS (9,4 \%) gegenüber 1,9 \% im Kontrollkollektiv (männliche Patienten mit Lumbalgien oder Cephalgien jedoch ohne chronisch-entzündliche neurologische Erkrankung) nachweisen (Niederwieser et al. 2003).

Psychiatrische Störungen und autoimmune Reaktionen scheinen ihren Ausgang von ein und derselben Dysfunktion des immunologisch-endokrinen Systems zu nehmen. Die Pathogenese beider Erkrankungen, affektiver Störungen und Autoimmunerkrankungen, könnte möglicherweise durch eine allgemeine neuroendokrinologische Dysregulation mit Beteiligung insbesondere der Zytokine zu erklären sein. Gegenwärtige Studien lassen vermuten, dass die thyreoidale Autoimmunität über die Hypothalamus-Hypophysen-Achse durch ein Gleichgewicht pro- und antiinflammatorischer Zytokine beeinflusst werden kann (Elenkov und Chrousos 2002, Chistiakov und Turakulov 2003).

Möglicherweise sind auch Krankheitsverlauf und Behandlungserfolg der Depression vom Schilddrüsenfunktionsstatus abhängig. Die additive Gabe von Schilddrüsenhormon-Präparaten (insbesondere T3) zusätzlich zu einer Therapie mit Antidepressiva ist eine gut dokumentierte Behandlungsoption im therapeutischen Management von Patienten mit therapierefraktären Depressionen (Fountoulakis et al. 2006). In der Literatur finden sich zunehmend Hinweise, dass Antidepressiva die "Schilddrüsenachse" möglicherweise in differenzierter Weise beeinflussen. Baumgartner et al. berichteten neben weiteren Arbeitsgruppen (Baumgartner et al. 1988, Brady und Anton 1989, Joffe 1990) von einem Absinken der T4-, fT4 und rT3Serumspiegel unter tri- bzw. tetrazyklischen Antidepressiva (nach Clomipramin- bzw. Maprotilinbehandlung sowie nach Desimipramin- bzw. Imipraminbehandlung) bei depressiven Patienten. Die Veränderungen der Hormonkonzentration korrelierten dabei signifikant zum Grad der klinischen Remission. Daher sollte die Einleitung 
einer Substitutionstherapie mit Schilddrüsenhormonpräparaten im Sinne einer antidepressiven Begleittherapie grundsätzlich erwogen werden.

Prange et al. berichteten bereits 1969, dass $25 \mu \mathrm{g}$ T3/Tag die antidepressive Wirkung von Imipramin signifikant steigerte (Prange et al. 1969). Joffe und Singer konnten diese Beobachtung 1990 bestätigen, indem sie eine signifikant stärkere Abnahme der Depressionswerte der Hamilton-Skala bei bislang therapieresistenten Patienten nach T3-Applikation (um $40 \%$ ) zusätzlich zu Desimipramin bzw. Imipramin im Verhältnis zu einer T4-Substitution (um 22 \%) aufzeigten (Joffe und Singer 1990). Allerdings war der antidepressive Effekt von T3, wie in anderen Arbeiten gezeigt wurde, nur nach 2 und 3 Wochen, jedoch nicht mehr nach 4-6 Wochen messbar. Offen bleibt, warum diese sehr geringen T3-Dosierungen bei chronischer Applikation zu erhöhten Spiegeln der T3-Konzentration im Serum oder gar in einzelnen Organen führen sollen. Eine T3-Zusatzmedikation führt über den bekannten Feedbackmechanismus zu einer Hemmung der TSH- und somit konsekutiv der T4Sekretion. Auf diese Weise werden vermutlich innerhalb von relativ kurzer Zeit die physiologischen T3-Spiegel wieder hergestellt sein.

Genau dieser Mechanismus könnte möglicherweise die oben beschriebene Wirkung von T3 in der Zeitachse erklären: In den ersten Wochen ließ sich eine antidepressive Wirkung in einigen Studien nachweisen, nach Ablauf von 4 Wochen jedoch in keiner mehr. Joffe et al. stellten demgegenüber die Hypothese auf, dass der antidepressive Effekt von T3 gerade aufgrund der über den Feedbackmechanismus erzeugten Absenkung der Serum-T4-Spiegel hervorgerufen werden könnte - in Analogie der entsprechenden Wirkung von Antidepressiva (Joffe et al. 1984).

Schumm-Draeger et al. berichteten 1999 im Rahmen einer Studie mit euthyreoten AIT-Patienten über einen signifikanten Rückgang der Tg- und TPO-Ak-Titer nach einjähriger LT4-Prophylaxe und kamen zu dem Schluss, dass der prophylaktische Einsatz von LT4 bei euthyreoten Patienten mit einer AIT ein effektives Therapiekonzept sei (Schumm-Draeger et al. 1999).

Die ersten Berichte über eine T4-Augmentation bei bislang therapie- oder prophylaxeresistenten Rapid-cycling-Patienten gehen auf offene Studien aus dem Jahr 1982 zurück (Stancer und Persad 1982). Hier zeigte sich, dass die adjuvante Gabe von Schildrüsenhormonen (L-Thyroxin) in supraphysiologischen Dosierungen bei bipolar affektiven Patienten mit „rapid-cycling“ eine effektive Therapieoption 
darstellen kann. Diese Beobachtungen konnten in Folgestudien repliziert werden (Bauer und Whybrow 1990b). Es gilt, die phasenprophylaktische Wirkung von T4 zu validieren sowie dessen mögliche antidepressive Wirkung zu untersuchen, und schließlich der Frage nachzugehen, ob eine hochdosierte T3-Applikation zu einem akuten antidepressiven Effekt führt.

Eine für die Klinik und Forschung ebenfalls sehr relevante Fragestellung besteht darin, ob es einen echten Unterschied zwischen akut-antidepressiven bzw. phasenprophylaktischen Effekten von T3 und T4 gibt. Da T4 im ZNS zu T3 dejodiert wird, müssten beide den gleichen Effekt erzielen. Wenn T3 tatsächlich antidepressiv wirkt und T4 nicht, so wäre dies eventuell ein Hinweis auf eine Störung einer zentralen T4-Aufnahme oder -Dejodierung.

Eine weitere Möglichkeit könnte künftig die Identifikation biologischer Marker z.B. im Sinne eines gemeinsamen Antigens von Schilddrüse und Gehirn darstellen, die mit der Entwicklung einer affektiven Störung im Rahmen einer Autoimmunthyreoiditis assoziiert sind, wobei hier die Pathogenese der Hashimoto-Enzephalopathie modellhaft für eine Verbindung zwischen immunologischen Prozessen der Schilddrüse und neuropsychiatrischen Erkrankungen stehen könnte (Canton et al. 2000, Latinville et al. 1985). Bei autoimmunen Schilddrüsenerkrankungen konnte eine vermehrte mRNA-Expression der ADAR (RNA-editierenden AdenosinDesaminase), zu deren Zielgenen die Glutamat- und Serotoninrezeptoren gehören, gezeigt werden (Karbownik et al. 2003). In einer 2006 begonnenen Pilotstudie an der Universität Erlangen wird prospektiv der Zusammenhang zwischen autoimmunen Schilddrüsenerkrankungen und Depressionen bezüglich der Expressionsveränderungen der ADAR-Genfamilie untersucht, wobei hierzu bislang keine Daten veröffentlicht wurden (Universitätsklinikum Erlangen, Medizinische Klinik $12007)$.

Wenn sich die vorliegenden Beobachtungen bestätigen, sind im Zuge der Krankheitsprävention in Zukunft bei Personen mit positiven Titern für TPO-Ak systematische Screeninguntersuchungen bezüglich affektiver Störungen sowie ein gezieltes Screening hinsichtlich Schilddrüsenerkrankungen bei Patienten mit affektiven Störungen prophylaktisch sinnvoll und empfehlenswert. Durch eine 
frühzeitige Diagnostik können möglicherweise therapiemodifizierende Faktoren und neue therapeutische Ansätze gefunden und der individuelle Krankheitsverlauf günstig beeinflusst werden. Die Entwicklung von Präventivmaßnahmen ist auch aus sozioökonomischer Sicht bei einer Lebenszeitprävalenz für affektive Störungen von $1,5 \%$ von hoher Relevanz.

Weitere Studien zu diesem Thema mit größeren Fallzahlen könnten einerseits neue Erkenntnisse hinsichtlich der Ätiologie und Nosologie affektiver Störungen aufzeigen, andererseits durch das frühzeitige Erkennen einer Autoimmunerkrankung möglicherweise dazu beitragen, die grundsätzlichen therapeutischen Möglichkeiten zur Behandlung einer affektiven Störung zu optimieren bzw. zu erweitern. 


\section{ZUSAMMENFASSUNG}

Ziele der vorliegenden Arbeit waren die Erfassung der Prävalenz und möglicher Zusammenhänge zwischen einer AIT und depressiven Störungen sowie der Vergleich der Ergebnisse mit einer Kontrollgruppe (schizophrene Patienten, altersgematcht und geschlechtsbalanciert) und mit Angaben aus der Literatur (bevölkerungsbasiert, epidemiologische Studien in der Normalbevölkerung).

Insgesamt wurden 71 konsekutive ambulante Patienten der Poliklinik der Klinik für Psychiatrie und Psychotherapie der Universitätsmedizin Göttingen prospektiv und nicht selektiert mit einer psychiatrischen Erkrankung (Schizophrenie, Depressionen, Depressionen bei bipolarer Störung) untersucht. Neben TSH, fT3 und fT4 wurden auch TPO- und TG-Ak bestimmt. Bei erhöhten anti-TPO-Ak-Titern (cut-off $>60 \mathrm{U} / \mathrm{ml}$ ) wurde zusätzlich eine Sonographie der Schilddrüse zur Sicherung der Diagnose einer AIT durchgeführt. 52 Patienten hatten eine depressive Störung $(28 \mathrm{w} / 24 \mathrm{~m}$; mittleres Alter: $46 \mathrm{~J}$.), in die Kontrollgruppe der schizophrenen Patienten wurden 19 Patienten (mittleres Alter: $43 \mathrm{~J}$.) eingeschlossen. Die Gruppen wurden in einer vergleichenden Statistik einschließlich Multivariater-Ansätze hinsichtlich unterschiedlicher Parameter (u.a. Diagnosegruppe, Alter, Geschlecht, Medikation) ausgewertet, wobei nichtparametrische Verfahren wie der Chi-Quadrat-Test, MannWhitney-U oder auch Spearman-Korrelationen neben parametrischen Tests (z.B. tTest für unabhängige Stichproben) verwendet wurden.

Bei 16/52 depressiven Patienten (30,8\%; 12w/4m) konnte eine AIT gesichert werden. In der Kontrollgruppe der schizophrenen Patienten fand sich bei nur 2 Patienten eine AIT (10,5\%; 1w/1m). Das TSH basal (Normbereich $0.4-4.0 \mu \mathrm{lU} / \mathrm{ml}$ ) unterschied sich nicht bei depressiven (unipolar oder bipolar) und schizophrenen Patienten (1.6 $\mu \mathrm{lU} / \mathrm{ml}(\mathrm{SD} 1.5$ ) vs. $1.6 \mu \mathrm{lU} / \mathrm{ml}$ (SD 1.5); $\mathrm{T}=-0-09, \mathrm{p}=0.926$ ), die T3- und T4Werte lagen im Normbereich.

Bezüglich der allgemeinen Bevölkerung zeigte sich auch im Vergleich mit dem Kontrollkollektiv ein statistisch signifikantes ca. 10-fach erhöhtes (Chi-Quadrat-Test $\left(x^{2} 2=5.53, p=0.019\right)$ Risiko einer AIT bei Patienten mit einer affektiven Störung (odds ratio [OR] (95\% Cl= 1.2- 85.3). Innerhalb der Gruppe der depressiven Störungen (ICD-10: F 31,32 und 33) gab es keine statistischen Unterschiede bezüglich der Häufigkeit einer Komorbidität mit einer AIT. Risikofaktoren waren das Geschlecht, bei Frauen zeigte sich eine signifikant höhere Assoziation zwischen 
depressiver Störung und AIT als bei Männern. Die Dauer der Erkrankung spielte hinsichtlich des anti-TPO-Spiegels keine Rolle (rho=-0,065; $p=0,600$ ). Es gab ebenfalls keine signifikante Korrelation zwischen Alter und anti-TPO (Spearmanrho=-0,14, $p=0,265$ ). Dies war konsistent für depressive (uni- oder bipolar) und für schizophrene Patienten.

Es konnte keine spezifische antidepressive Medikation in Verbindung mit erhöhten anti-TPO-Spiegeln gebracht werden. Die Gabe von phasenprophylaktischen Präparaten (z.B.Lithium) bei depressiven Patienten hatte ebenfalls keinen Einfluss auf anti-TPO-Spiegel (Mann-Whitney-U, $Z=-1,1, p=0,271$ ).

$\mathrm{Da}$ in der vorliegenden Arbeit gezeigt werden konnte, dass Patienten mit einer affektiven Störung ein deutlich erhöhtes Risiko für eine AIT aufweisen, könnten diese Ergebnisse, im Zuge einer Krankheitsprävention angewandt, in Zukunft bei Personen mit positiven Titern für TPO-Ak zu systematischen Screeninguntersuchungen bezüglich affektiver Störungen sowie zu einem gezielten Screening hinsichtlich Schilddrüsenerkrankungen bei Patienten mit affektiven Störungen führen. Durch eine frühzeitige Diagnostik, z.B. auch durch die Identifikation neuer biologischer und genetischer Marker, könnten möglicherweise therapiemodifizierende Faktoren und neue therapeutische Ansätze gefunden und der individuelle Krankheitsverlauf günstig beeinflusst werden. Darüber hinaus könnten zudem spezifische Subgruppen (z.B. Patientinnen mit einer postpartalen Depression bzw. sonstigen geschlechtsspezifischen Determinanten oder Patienten mit therapierefraktären Depressionen) ermittelt und ggf. einer optimierten und individualisierten Therapie zugeführt werden. 


\section{LITERATURVERZEICHNIS}

Abraham P, Avenell A, Park CM, Watson WA, Bevan JS (2005): A systematic review of drug therapy for Graves' hyperthyroidism. Eur J Endocrinol 153, 489-498

Angst J (1980): Verlauf unipolarer depressiver, bipolar manisch-depressiver und schizoaffektiver Erkrankungen und Psychosen. Ergebnisse einer prospektiven Studie. Fortschr Neurol Psychiatr $\underline{48}$, 3-30

Asher R (1949): Myxoedematous madness. Br Med J 1949, 2, 555-562

Axelrod J, Whitby LG, Hertting G (1961): Effect of psychotropic drugs on the uptake of H3-norepinephrine by tissues. Science $\underline{133}, 383-384$

Bailes BK (1999): Hyperthyroidism in elderly patients. AORN J $\underline{69}, 254-258$

Banga JP, Barnett PS, McGregor AM (1991): Immunological and molecular characteristics of the thyroid peroxidase autoantigen. Autoimmunity $\underline{8}, 335-343$

Barbesino G, Chiovato L (2000): The genetics of Hashimoto's disease. Endocrinol Metab Clin North Am $\underline{29}$, 357-374

Bartalena L, Pellegrini L, Meschi M, Antonangeli L, Bogazzi F, Dell'Osso L, Pinchera A, Placidi GF (1990): Evaluation of thyroid function in patients with rapid-cycling and non-rapid-cycling bipolar disorder. Psychiatry Res $\underline{34}, 13-17$

Bauer MS, Whybrow PC (1990a): Thyroid hormones and the central nervous system in affective illness: Interactions that may have clinical significance. Integr Psychiatry $\underline{6}, 75-100$

Bauer MS, Whybrow PC (1990b): Rapid cycling bipolar affective disorder: II. Treatment of refractory rapid cycling with high-dose levothyroxine: a preliminary study. Arch Gen Psychiatry 47, 435-440 
Bauer MS, Whybrow PC, Winokur A (1990): Rapid cycling bipolar affective disorder. I. Association with grade I hypothyroidism. Arch Gen Psychiatry 47, 427-432

Baumgartner A, Graf KJ, Kurten I, Meinhold H (1988): The hypothalamic-pituitarythyroid axis in psychiatric patients and healthy subjects: Parts 1-4. Psychiatry Res $\underline{24}, 271-332$

Becker KL FR, McConahey WH (1963): The connective-tissue diseases and symptoms associated with Hashimoto's thyroiditis. N Engl J Med 268, 277-280

Beckmann H, Jakob H (1994): Pränatale Entwicklungsstörungen von Hirnstrukturen bei schizophrenen Psychosen. Nervenarzt $\underline{65}$, 454-463

Bene MC, Derennes V, Faure G, Thomas JL, Duheille J, Leclere J (1983): Graves disease: in situ localization of lymphoid T cell subpopulations. Clin Exp Immunol $\underline{52}$, 311-316

Bertoni M, Falcini M, Sestini S, Niccoli L, Nannini C, Cantini F (2003): Encephalopathy associated with Hashimoto's thyroiditis: an additional case. Eur J Intern Med 14, 434-437

Bird T, Stephenson J (1973): Evaluation of a tanned red cell technique for thyroid microsomal antibodies. J Clin Pathol $\underline{26}, 623-627$

Bjoro T, Holmen J, Kruger O, Midthjell K, Hunstad K, Schreiner T, Sandnes L, Brochmann H (2000): Prevalence of thyroid disease, thyroid dysfunction and thyroid peroxidase antibodies in a large, unselected population. The Health Study of NordTrondelag (HUNT). Eur J Endocrinol 143, 639-647

Bleuler E: Dementia praecox oder die Gruppe der Schizophrenien. Handbuch der Psychiatrie. Deutike Verlag, Wien 1911

Bleuler E, Angst J, Ernst K, Hess R, Mende W, Reisner H, Scheidegger S: Lehrbuch der Psychiatrie. hrsg. v. Bleuler M; Springer-Verlag, Berlin 1983, 219 
Blume WT, Grabow JD (1969): The "cerebellar" signs of myxedema. Dis Nerv Syst $\underline{30}, 55-57$

Bocchetta A, Mossa P, Velluzzi F, Mariotti S, Zompo MD, Loviselli A (2001): Ten-year follow-up of thyroid function in lithium patients. J Clin Psychopharmacol $\underline{21}, 594-598$

Boehm BO, Kuhnl P, Loliger C, Ketzler-Sasse U, Holzberger G, Seidl S, Bauerle R, Schifferdecker E, Usadel KH (1993): HLA-DR3 and HLA-DR5 confer risk for autoantibody positivity against the thyroperoxidase (mic-TPO) antigen in healthy blood donors. Clin Investig 71, 221-225

Bogner U, Kotulla P, Peters H, Schleusener H (1990): Thyroid peroxidase/microsomal antibodies are not identical with thyroid cytotoxic antibodies in autoimmune thyroiditis. Acta Endocrinol (Copenh) 123, 431-437

Brady KT, Anton RF (1989): The thyroid axis and desipramine treatment in depression. Biol Psychiatry 25, 703-709

Brain L, Jellinek EH, Ball K (1966): Hashimoto's disease and encephalopathy. Lancet $\underline{1966,2}, 512-514$

Braun J, Donner H, Siegmund T, Walfish PG, Usadel KH, Badenhoop K (1998): CTLA-4 promoter variants in patients with Graves' disease and Hashimoto's thyroiditis. Tissue Antigens $\underline{51}, 563-566$

Brix TH, Kyvik KO, Hegedus L (2000): A population-based study of chronic autoimmune hypothyroidism in Danish twins. J Clin Endocrinol Metab 85, 536-539

Brouwer JP, Appelhof BC, Hoogendijk WJ, Huyser J, Endert E, Zuketto C, Schene AH, Tijssen JG, Van Dyck R, Wiersinga WM, et al. (2005): Thyroid and adrenal axis in major depression: a controlled study in outpatients. Eur J Endocrinol 152, 185-191

Brunn J, Block U, Ruf G, Bos I, Kunze WP, Scriba PC (1981): Volumetric analysis of thyroid lobes by real-time ultrasound. Dtsch Med Wochenschr 106, 1338-1340 
Brunnhuber S, Lieb K: Kurzlehrbuch Psychiatrie. 4. Auflage, Urban und Fischer Verlag, München 2000

Bryce GM, Poyner F (1992): Myxoedema presenting with seizures. Postgrad Med J $\underline{68}, 35-36$

Bryhni B, Aanderud S, Sundsfjord J, Rekvig OP, Jorde R (1996): Thyroid antibodies in northern Norway: prevalence, persistence and relevance. J Intern Med 239, 517523

Cade JF (1949): Lithium salts in the treatment of psychotic excitement. Med J Aust $1949,2,349-352$

Calabrese JR, Gulledge AD, Hahn K, Skwerer R, Kotz M, Schumacher OP, Gupta MK, Krupp N, Gold PW (1985): Autoimmune thyroiditis in manic-depressive patients treated with lithium. Am J Psychiatry 142, 1318-1321

Campbell PN, Doniach D, Hudson RV, Roitt IM (1956): Auto-antibodies in Hashimoto's disease (lymphadenoid goitre). Lancet 1956, 271, 820-821

Canton A, de Fabregas O, Tintore M, Mesa J, Codina A, Simo R (2000): Encephalopathy associated to autoimmune thyroid disease: a more appropriate term for an underestimated condition? J Neurol Sci 176, 65-69

Carroll BJ, Feinberg M, Greden JF, Tarika J, Albala AA, Haskett RF, James NM, Kronfol Z, Lohr N, Steiner M, et al. (1981): A specific laboratory test for the diagnosis melancholia. Arch Gen Psychiatry $\underline{38}, 1-22$

Carta MG, Loviselli A, Hardoy MC, Massa S, Cadeddu M, Sardu C, Carpiniello B, Dell'Osso L, Mariotti S (2004): The link between thyroid autoimmunity (antithyroid peroxidase autoantibodies) with anxiety and mood disorders in the community: a field of interest for public health in the future. BMC Psychiatry 2004, 4, 25 
Chen IW, Sperling MI: Clinical chemistry: theory, analysis and correlation. 2. Auflage, Mosby Verlag, St. Louis 1989

Chistiakov DA (2005): Immunogenetics of Hashimoto's thyroiditis. J Autoimmune Dis 2, 1

Chistiakov DA, Turakulov RI (2003): CTLA-4 and its role in autoimmune thyroid disease. J Mol Endocrinol 31, 21-36

Claussmann C, Offner C, Chevalier Y, Sellal F, Collard M (1994): Encephalopathy and Hashimoto thyroiditis. Rev Neurol 150, 166-168

Contreras AS, Rojas SA, Manosalva A, Patarroyo PAM, Lorenzana P, Restrepo JFL, Iglesias-Gamarra AI, Rondon F (2004): Hashimoto encephalopathy (autoimmune encaphalitis). J Clin Rheumatol $\underline{10}, 339-343$

Coppen A (1967): The biochemistry of affective disorders. Br J Psychiatry $\underline{113}, 1237-$ 1264

Cowdry RW, Wehr TA, Zis AP, Goodwin FK (1983): Thyroid abnormalities associated with rapid-cycling bipolar illness. Arch Gen Psychiatry 40, 414-420

Craddock N, Jones I (1999): Genetics of bipolar disorder. J Med Genet $\underline{36}, 585-594$

Davis KL, Kahn RS, Ko G, Davidson M (1991): Dopamine in schizophrenia: a review and reconceptualization. Am J Psychiatry $\underline{148}, 1474-1486$

Degner D, Meller J, Bleich S, Schlautmann V, Rüther R (2001): Affective disorders associated with autoimmune thyroiditis. J Neuropsychiatry Clin Neurosci $\underline{13}, 532-533$

Delay J, Deniker P, Harl JM (1952): Therapeutic use in psychiatry of phenothiazine of central elective action (4560 RP). Ann Med Psychol 110, 112-117 
Demet MM, Ozmen B, Deveci A, Boyvada S, Adiguzel H, Aydemir O (2002): Depression and anxiety in hyperthyroidism. Arch Med Res $\underline{33}, 552-556$

Dietlein M, Dressler J, Joseph K, Leisner B, Moser E, Reiners C, Rendl J, Schicha H, Schober O (1999): Leitlinien zur Schilddrüsendiagnostik. Nuklearmedizin $\underline{38}, 215-218$

DIMDI (= Deutsches Institut für Medizinische Dokumentation und Information) (2000): ICD-10 SGB V: internationale statistische Klassifikation der Krankheiten und verwandter Gesundheitsprobleme, 10. Revision. Bd. 1. Systematisches Verzeichnis. - Version 2.0. Verlag W. Kohlhammer, Stuttgart, 2000, 212-294

Eaton WW, Byrne M, Ewald H, Mors O, Chen CY, Agerbo E, Mortensen PB (2006): Association of Schizophrenia and Autoimmune Diseases: Linkage of Danish National Registers. Am J Psychiatry 163, 521-528

Ebel H, Beichert K (2002): Depressive Störungen bei Patienten der Allgemeinmedizin. Dtsch Ärztebl 99, 102-107

Elenkov IJ, Chrousos GP (2002): Stress hormones, proinflammatory and antiinflammatory cytokines, and autoimmunity. Ann N Y Acad Sci $\underline{966}, 290-303$

Falcone M, Sarvetnick N (1999): Cytokines that regulate autoimmune responses. Curr Opin Immunol 11, 670-676

Fernandez-Ulloa M, Maxon H: Clinical chemistry: theory, analysis and correlation. Mosby, St. Louis 1989, 620-638

Fieve RR, Platman S (1968): Lithium and thyroid function in manic-depressive psychosis. Am J Psychiatry 125, 527-530

Fliers E, Wiersinga WM (2003): Myxedema coma. Rev Endocr Metab Disord 4, 137141 
Forchetti CM, Katsamakis G, Garron DC (1997): Autoimmune thyroiditis and a rapidly progressive dementia: global hypoperfusion on SPECT scanning suggests a possible mechanism. Neurology $\underline{49}, 623-626$

Fountoulakis KN, Kantartzis S, Siamouli M, Panagiotigis P, Kaprinis S, latovedes A, Kaprinis G (2006): Peripheral thyroid dysfunction in depression. J Biol Psychiatry $\underline{7}$, $131-137$

Freisleder FJ, Schmauß M (1996): Venlafaxin. Stellenwert in der psychiatrischen Pharmakologie. Psychopharmakotherapie $\underline{3}, 152-157$

Gaertner R (2002): Entzündliche Schilddrüsenerkrankungen, Pathophysiologie, Diagnostik und Therapie. Der Internist $\underline{43}, 635-651$

Gaertner R, Duntas LH (2008): Effects of selenium supplementation on TPOAb and cytokines in acute autoimmune thyroiditis. Thyroid $\underline{18}, 673-684$

Gaitan E: Goitrogens in the etiology of endemic goiter; in: Endemic goiter and endemic cretinism. lodine nutrition in health and disease. hrsg. v. Stanbury JB, Hetzel BS; John Wiley Publishing, New York 1980, 219-236

Gelder M, Gath D: Affective disorders; in: Oxford textbook of psychiatry; hrsg. v. Gelder M, Gath D, Mayou R; Oxford Medical Publications, Oxford 1994, 133-162

Gesellschaft fuer Versicherungswissenschaften- und Gestaltung e.V. (2006): 6. Nationales Gesundheitsziel: Depressive Erkrankungen verhindern, früh erkennen, nachhaltig behandlen. www.gesundheitsziele.de

Ghobrial MW, Ruby EB (2002): Coma and thyroid storm in apathetic thyrotoxicosis. South Med J $\underline{95}, 552-554$

Gold MS, Pottash AL, Extein I (1982): "Symptomless" autoimmune thyroiditis in depression. Psychiatry Res $\underline{6}, 261-269$ 
Goldstein J, Van Cauter E, Linkowski P, Vanhaelst L, Mendlewicz J (1980): Thyrtropine nycthemeral pattern in primary depression: differences between unipolar and bipolar women. Life Sci $\underline{27}, 1695-1703$

Gough SC (2000): The genetics of Graves' disease. Endocrinol Metab Clin North Am $\underline{29}, 255-266$

Guilherme L, Cunha-Neto E, Coelho V, Snitcowsky R, Pomerantzeff PM, Assis RV, Pedra F, Neumann J, Goldberg A, Patarroyo ME, et al. (1995): Human heartinfiltrating $\mathrm{T}$-cell clones from rheumatic heart disease patients recognize both streptococcal and cardiac proteins. Circulation 92, 415-420

Gutekunst R, Hafermann W, Mansky T, Scriba PC (1989): Ultrasonography related to clinical and laboratory findings in lymphocytic thyroiditis. Acta Endocrinol $\underline{121}, 129-$ 135

Haefner H (1993): What is schizophrenia? Neurol Psychopharmacol Brain Res $\underline{2}$, 3652

Haggerty JJ, Jr., Prange AJ, Jr (1995): Borderline hypothyroidism and depression. Annu Rev Med $\underline{46}$, 37-46

Haggerty JJ, Jr., Simon JS, Evans DL, Nemeroff CB (1987): Relationship of serum TSH concentration and antithyroid antibodies to diagnosis and DST response in psychiatric inpatients. Am J Psychiatry 144, 1491-1493

Haggerty JJ, Jr., Evans DL, Golden RN, Pedersen CA, Simon JS, Nemeroff CB (1990): The presence of antithyroid antibodies in patients with affective and nonaffective psychiatric disorders. Biol Psychiatry 27, 51-60

Haggerty JJ, Jr., Silva SG, Marquardt M, Mason GA, Chang HY, Evans DL, Golden RN, Pedersen C (1997): Prevalence of antithyroid antibodies in mood disorders. Depress Anxiety $\underline{5}, 91-6$ 
Hall RC (1983): Psychiatric effects of thyroid hormone disturbance. Psychosomatics $\underline{24}, 7-11$

Hall RC, Popkin MK, DeVaul R, Hall AK, Gardner ER, Beresford TP (1982): Psychiatric manifestations of Hashimoto's thyroiditis. Psychosomatics $\underline{23}, 337-342$

Hashimoto H (1912): Zur Kenntniss der lymphomatosen Veranderung der Schilddruse (struma lymphomatosa). Arch Klin Chir $\underline{97}$, 219-225

Hassman RW, McGregor AM: Lithium and autoimmune thyroid disease. Lithium and the Endocrine System; Karger Verlag, Basel 1988, 134-146

Hatzinger M, Holsboer-Trachsler E (1999): Therapy refractory depression. Wien Med Wochenschr 149, 511-514

Heinrich TW, Grahm G (2003): Hypothyroidism Presenting as Psychosis: Myxedema Madness Revisited. Prim Care Companion J Clin Psychiatry $\underline{5}$, 260-266

Henchey R, Cibula J, Helveston W, Malone J, Gilmore RL (1995): Electroencephalographic findings in Hashimoto's encephalopathy. Neurology $\underline{45}$, 977-981

Henley WN, Koehnle TJ (1997): Thyroid hormones and the treatment of depression: an examination of basic hormonal actions in the mature mammalian brain. Synapse $\underline{27}, 36-44$

Heuer M, Aust G, Ode-Hakim S, Scherbaum WA (1996): Different cytokine mRNA profiles in Graves' disease, Hashimoto's thyroiditis, and nonautoimmune thyroid disorders determined by quantitative reverse transcriptase polymerase chain reaction (RT-PCR). Thyroid $\underline{6}$, 97-106

Heufelder AE, Hofbauer LC (1998): Die Thyreoiditiden: Aktueller Stand der Pathogenese, Diagnostik und Therapie. Dtsch Ärztebl 95, 466-476 
Hörmann R: Hyperthyreose: klinische Symptome. Schilddrüsenerkrankungen. 2. Auflage. Blackwell Wissenschafts-Verlag, Berlin 1998

Hornig M, Amsterdam JD, Kamoun M, Goodman DB (1999): Autoantibody disturbances in affective disorders: a function of age and gender? J Affect Disord $\underline{55}$, 29-37

Hotze LA, Schumm-Draeger PM: Schilddrüsenkrankheiten: Diagnose und Therapie. Berliner Medizinische Verlagsanstalt, Berlin 2003

Huber G: Psychiatrie: Lehrbuch für Studierende und Ärzte. Stuttgart, New-York: Schattauer, 1994, 165-216

Huber G: Psychiatrie. Systematischer Lehrtext für Studenten und Ärzte. Schattauer Verlag, Stuttgart 1999, 180-187

Hunt PJ, Marshall SE, Weetman AP, Bell JI, Wass JA, Welsh KI (2000): Cytokine gene polymorphisms in autoimmune thyroid disease. J Clin Endocrinol Metab $\underline{85}$, 1984-1988

Hussain NS, Rumbaugh J, Kerr D, Nath A, Hillis AE (2005): Effects of prednisone and plasma exchange on cognitive impairment in Hashimoto encephalopathy. Neurology $\underline{64}, 165-166$

Illowsky BP, Juliano DM, Bigelow LB, Weinberger DR (1988): Stability of CT scan findings in schizophrenia: results of an 8 year follow-up study. J Neurol Neurosurg Psychiatry $\underline{51}$, 209-213

Jabbari B, Huott AD (1980): Seizures in thyrotoxicosis. Epilepsia 21, 91-96

Jackson I, Asamoah E (1999): Thyroid Function in Clinical Depression: Insights and Uncertainties. Thyroid Today 22, 1-11 
Jacobi F, Wittchen HU, Hölting C (2004): Prevalence, comorbidity and correlates of mental disorders in a general population: Results from the German health interview and examination survey (GHS). Psychol Med $\underline{34}$, 597-611

Janowsky DS, El-Yousef MK, Davis JM, Sekerke HJ (1972): A cholinergic-adrenergic hypothesis of mania and depression. Lancet 1972, 2, 632-635

Jansson R, Totterman TH, Sallstrom J, Dahlberg PA (1983): Thyroid-infiltrating T lymphocyte subsets in Hashimoto's thyroiditis. J Clin Endocrinol Metab $\underline{56}, 1164-$ 1168

Jensen SE, Amdisen A, Olsen T, Schou M (1968): lodine metabolism in lithium therapy. Ugeskr Laeger $\underline{130}, 1518-1520$

Jeste DV, Lohr JB (1989): Hippocampal pathologic findings in schizophrenia. A morphometric study. Arch Gen Psychiatry 느, 1019-1024

Joffe RT (1987): Antithyroid antibodies in major depression. Acta Psychiatr Scand 76, 598-599

Joffe RT (1990): A perspective on the thyroid and depression. Can J Psychiatry $\underline{35}$, 754-758

Joffe RT, Singer W (1990): A comparison of triiodothyronine and thyroxine in the potentiation of tricyclic antidepressants. Psychiatry Res $\underline{32}, 241-251$

Joffe RT, Roy-Byrne PP, Udhe TW, Post RM (1984): Thyroid function and affective illness: a reappraisal. Biol Psychiatry $\underline{19}, 1685-1691$

Joffe RT, Bagby RM, Levitt AJ (1992): The thyroid and melancholia. Psychiatry Res $\underline{42}, 73-80$ 
Joffe RT, Singer W, Levitt AJ, MacDonald C (1993): A placebo-controlled comparison of lithium and triiodothyronine augmentation of tricyclic antidepressants in unipolar refractory depression. Arch Gen Psychiatry $\underline{50}$, 387-393

Jordan SC, Johnston WH, Bergstein JM (1978): Immune complex glomerulonephritis mediated by thyroid antigens. Arch Pathol Lab Med 102, 530-533

Kaczur V, Vereb G, Molnar I (1997): Effect of anti-thyroid peroxidase (TPO) antibodies on TPO activity measured by chemiluminescene assay. Clin Chem $\underline{43}$, 1392-1396

Kahaly G, Tettenborn B, Mihaljevic V, Beyer J, Kramer G (1989): Petit mal status in hyperthyroidism. Dtsch Med Wochenschr $\underline{114}$, 1607-1611

Kalmijn S, Mehta KM, Pols HA, Hofman A, Drexhage HA, Breteler MM (2000): Subclinical hyperthyroidism and the risk of dementia. The Rotterdam study. Clin Endocrinol $\underline{53}, 733-737$

Kandel E SJ, Jessell TM: Neurowissenschaften: eine Einführung. Spektrum-Verlag, Heidelberg 1995

Kaplan MM (1999): Clinical perspectives in the diagnosis of thyroid disease. Clin Chem $\underline{45}, 1377-1383$

Karbownik M, Brzezianska E, Zasada K, Lewinski A (2003): Expression of Genes for Certain Enzymes of Pyrimidine and Purine Salvage Pathway in Peripheral Blood Leukocytes Collected From Patients With Graves' or Hashimoto's Disease. J Cell Biochem $\underline{89}, 550-555$

Karni A, Abramsky O (1999): Association of MS with thyroid disorders. Neurology $\underline{53}$, 883-885

Kasper S, Sack DA, Wehr TA, Kick H, Voll G, Vieira A (1988): Nocturnal TSH and prolactin secretion during sleep deprivation and prediction of antidepressant response in patients with major depression. Biol Psychiatry $\underline{24}$, 631-641 
Kleiner J, Altshuler L, Hendrick V, Hershman JM (1999): Lithium-induced subclinical hypothyroidism: review of the literature and guidelines for treatment. J Clin Psychiatry $\underline{60}, 249-255$

König F (1998): Zur Häufigkeit latenter Schilddrüsenfunktionsstörungen bei depressiven Patienten nach stationärer Aufnahme. Nervenheilkunde 17, 461-467

König F, von Hippel C, Petersdorff T, Kaschka W (1999): Thyroid autoantibodies in depressive disorders. Acta Med Austriaca 26, 126-128

Konno N, Yuri K, Taguchi H, Miura K, Taguchi S, Hagiwara K, Murakami S (1993): Screening for thyroid diseases in an iodine sufficient area with sensitive thyrotrophin assays, and serum thyroid autoantibody and urinary iodide determinations. Clin Endocrinol $\underline{38}, 273-281$

Kothbauer-Margreiter I SM, Komor J, Baumgartner R, Hess CW (1996): Encephalopathy associated with Hashimoto's thyroiditis: Diagnosis and treatment. J Neurol 243, 585-593

Kraepelin E: Psychiatrie. Ein kurzes Lehrbuch für Studierende und Ärzte. AbelVerlag, Leipzig 1899

Kronenberg M (1991): Self-tolerance and autoimmunity. Cell $\underline{65}, 537-542$

Kuhn R (1957): Treatment of depressive states with an iminodibenzyl derivative (G 22355). Schweiz Med Wochenschr $\underline{87}, 1135-1140$

Kupka RW, Nolen WA, Post RM, McElroy SL, Altshuler LL, Denicoff KD, Frye MA, Keck PE, Jr., Leverich GS, Rush AJ, Suppes T, Pollio C, Drexhage HA (2002): High rate of autoimmune thyroiditis in bipolar disorder: lack of association with lithium exposure. Biol Psychiatry $\underline{51}, 305-311$ 
Latinville D, Bernardi O, Cougoule JP, Bioulac B, Henry P, Loiseau P, Mauriac L (1985): Hashimoto's thyroiditis and myoclonic encephalopathy. Pathogenic hypothesis. Rev Neurol 141, 55-58

Laurberg P, Pedersen KM, Hreidarsson A, Sigfusson N, Iversen E, Knudesen PR (1998): lodine intake and the pattern of thyroid disorders; a comparative epidemilogical study of thyroid abnormalities in the elderly in Iceland and in Jutland. $J$ Clin Endocrinol Metab $\underline{83}, 765-769$

Lazarus JH, John R, Bennie EH, Chalmers RJ, Crockett G (1981): Lithium therapy and thyroid function: a long-term study. Psychol Med 11, 85-92

Lazarus JH, Burr ML, McGregor AM, Weetman AP, Ludgate M, Woodhead JS, Hall $R$ (1984): The prevalence and progression of autoimmune thyroid disease in the elderly. Acta Endocrinol 106, 199-202

Lazarus JH, McGregor AM, Ludgate M, Darke C, Creagh FM, Kingswood CJ (1986): Effect of lithium carbonate therapy on thyroid immune status in manic depressive patients: a prospective study. J Affect Disord 11, 155-160

Lehman AF, Lieberman JA, Dixon LB, McGlashan TH, Miller AL, Perkins DO, Kreyenbuhl J (2004): Practice guideline for the treatment of patients with schizophrenia, second edition. Am J Psychiatry 161, 1-56

Leigh H, Kramer SI (1984): The psychiatric manifestations of endocrine disease. Adv Intern Med 29, 413-445

Leroy MC, Villeneuve A, Lajeunesse C (1988): Lithium and antithyroid antibodies. Am J Psychiatry $\underline{145}, 534$

Lin R, Goering P, Lesage A, Streiner D (1997): Epidemiological assessment of overmet need in mental health care. Soc Psychiatry Psychiatr Epidemiol 32, 355-362 
Loosen PT, Wilson IC, Prange AJ, Jr. (1980): Endocrine and behavioral changes in depression after thyrotropin-releasing hormone $(\mathrm{TRH})$. Alteration by pretreatment with thyroid hormones. J Affect Disord 1980, 2, 267-278

Maes M, Meltzer HYM (1995): The serotonin hypothesis of major depression: A review. Rev Neurosci 4 , 407-416

Maier W, Lichtermann D, Rietschel M, Held T, Falkai P, Wagner M, Schwalb S (1999): Genetik schizophrener Störungen. Neue Konzepte und Befunde. Nervenarzt 70, 955-969

Marneros A: Handbuch der unipolaren und bipolaren Erkrankungen. Thieme Verlag, Stuttgart 1999

Matsuoka N, Harada T, Kitae S, Nakamura S, Sanomura M, Ishikawa K (2000): Hypothyroidism with severe cerebellar atrophy and ataxia. Nippon Naika Gakkai Zasshi 89, 1648-1650

Mauriac L (1982): Thyroidite de Hashimoto et encephalopathie. Rev Fr Endocrinol Clin $\underline{23}, 147-150$

McDermott MT, Ridgway EC (2001): Subclinical hypothyroidism is mild thyroid failure and should be treated. J Clin Endocrinol Metab 86, 4585-4590

Mednick SA, Machon RA, Huttunen MO, Bonett D (1988): Adult schizophrenia following prenatal exposure to an influenza epidemic. Arch Gen Psychiatry $\underline{45}, 189-$ 192

Meller J, Conrad M, Meyer P, Altenvoerde G, Grunewald RW, Leonhardt U, Hüfner M, Becker W: Assoziierte Autoimmunerkrankungen bei Immunthyreopathien; in: Schilddrüse 1999; hrsg. v. Seibel MJ, Weinheimer B, Ziegler R; de Gruyter Verlag, Berlin 2000a, 68-81 
Meller J, Schreivogel I, Bergmann A, Morgenthaler N, Hufner M, Becker W (2000b): Clinical implications of a new TSH receptor antibody assay (DYNOtest TRAKhuman) in autoimmune thyroid diseases. Nuklearmedizin $\underline{39}, 14-18$

Michels R, Marzuk P (1993): Progress in Psychiatry. First of two Parts. N Engl J Med $\underline{329}, 552-560$

Morita H, Arima T, Matsuda M (1995): Prevailance of nonthyroid specific autoantibodies in autoimmune thyroid diseases. J Clin Endocrinol Metab 80, 12031206

Morris JB, Beck AT (1974): The efficacy of antidepressant drugs. A review of research (1958-1972). Arch Gen Psychiatry 으, 667-674

Mulhern LM, Masi AT, Shulman LE (1966): Hashimoto's disease. A search for associated disorders in 170 clinically detected cases. Lancet 1966, 2, 508-511

Murray C, Lopez A (1996): Evidence-based health policy-lessons from the Global Burden of Disease Study. Science 274, 740-743

Myers DH, Carter RA, Burns BH, Armond A, Hussain SB, Chengapa VK (1985): A prospective study of the effects of lithium on thyroid function and on the prevalence of antithyroid antibodies. Psychol Med 15, 55-61

Nakamura T, Nomura J (1992): Comparison of thyroid function between responders and nonresponders to thyroid hormone supplementation in depression. Jpn J Psychiatry Neurol $\underline{46}, 905-909$

Nemeroff CB, Simon JS, Haggerty JJ, Jr., Evans DL (1985): Antithyroid antibodies in depressed patients. Am J Psychiatry 142, 840-843

Niederwieser G, Buchinger W, Onelli RM, Berghold A, Reisecker S, Kölltringer P, Archelos, JJ (2003): Prevalence of autoimmunethyroiditis and nonimmune thyroid diseases in multiple sclerosis. J Neurol $\underline{250}, 672-675$ 
Nierenberg AA, Cole JO (1991): Antidepressant adverse drug reactions. J Clin Psychiatry $\underline{52}, 40-47$

Nillni EA, Sevarino KA (1999): The biology of pro-thyrotropin-releasing hormonederived peptides. Endocr Rev 20, 599-648

Nolte KW, Unbehaun A, Sieker H, Kloss TM, Paulus W (2000): Hashimoto encephalopathy: a brainstem vasculitis? Neurology 54:769-770

Okamura K, Nakashima T, Ueda K, Inoue K, Omae T, Fujishima M (1987): Thyroid disorders in the general population of Hisayama Japan, with special reference to prevalence and sex differences. Int J Epidemiol 16, 545-549

Pedersen OM, Aardal NP, Larssen TB, Varhaug JE, Myking O, Vik-Mo H (2000): The value of ultrasonography in predicting autoimmune thyroid disease. Thyroid $\underline{10}, 251$ 259

Pfannenstiel P, Hotze LA, Saller B: Autoimmunthyreoiditis. Schilddrüsenkrankheiten: Diagnose und Therapie. 3. Auflage. Berliner Medizinische Verlagsanstalt, Berlin 1997, 237-240

Poirier MF, Loo H, Galinowski A, Bourdel MC, Remi-Bouissiere P, Piketty ML, Vanelle JM (1995): Sensitive assay of thyroid stimulating hormone in depressed patients. Psychiatry Res $\underline{57}, 41-48$

Pop VJ, Maartens LH, Leusink G, van Son MJ, Knottnerus AA, Ward AM, Metcalfe R, Weetman AP (1998): Are autoimmune thyroid dysfunction and depression related? J Clin Endocrinol Metab 수, 3194-3197

Prange AJ, Wilson IC, Rabon AM, Lipton MA (1969): Enhancement of imipramine antidepressant activity by thyroid hormone. Am J Psychiatry $\underline{126}$, 457-469 
Prange AJ, Wilson IC, Breese GR, Lipton MA: Hormonal alteration of imipramine response: A review; in: Hormones, Behavior and Psychopathology; hrsg. v. Sachar EJ; Raven Press, New York 1976, 41-67

Quaratino S, Badami E, Pang YY, Bartok I, Dyson J, Kioussis D, Londei M, Maiuri L. Degenerate self-reactive human $\mathrm{T}$-cell receptor causes spontaneous autoimmune disease in mice. Nat Med 2004;10:920-6.

Ramm B, Hofmann G, Hahn N: Biomathematik und Medizinische Statistik. Ferdindand Enke Verlag, Stuttgart 1976

Rapaport MH (1994): Immune parameters in euthymic bipolar patients and normal volunteers. J Affect Disord 32, 149-156

Reinhardt W, Luster M, Rudorff KH, Heckmann C, Petrasch S, Lederbogen S, Haase R, Saller B, Reiners C, Reinwein D, Mann K (1998): Effect of small doses of iodine on thyroid function in patients with Hashimoto's thyroiditis residing in an area of mild iodine deficiency. Eur J Endocrinol 139, 23-28

Reus VI, Berlant J, Galante M, Becker N (1986): Autoimmune Thyroiditis in female depressives. 41st Annual Meeting, Society of Biological Psychiatry. Washington DC, 1986

Richelson E (1991): Biological basis of depression and therapeutic relevance. J Clin Psychiatry $\underline{52}, 4-10$

Romball CG, Weigle WO (1987): Transfer of experimental autoimmune thyroiditis with T cell clones. J Immunol $\underline{138}, 1092-1098$

Roth G, Prinz W: Kopf-Arbeit: Gehirnfunktionen und kognitive Leistungen. Spektrum Verlag, Heidelberg 1996 
Roti E, Gardini E, Minelli R, Bianconi L, Braverman LE (1992): Prevalence of antithyroid peroxidase antibodies in serum in the elderly: comparison with other tests for anti-thyroid antibodies. Clin Chem $\underline{38}, 88-92$

Rubin RT, Poland RE, Lesser IM, Martin DJ (1987): Neuroendocrine aspects of primary endogenous depression--IV. Pituitary-thyroid axis activity in patients and matched control subjects. Psychoneuroendocrinology 12, 333-347

Sachar EJ, Hellman L, Fukushima DK, Gallagher TF (1970): Cortisol production in depressive illness. A clinical and biochemical clarification. Arch Gen Psychiatry $\underline{23}$, 289-298

Sahlmann CO, Siefker U, Lehmann K, Harms E, Conrad M, Meller J (2004): Quantitative thyroid scintigraphy for the differentiation of Graves' disease and hyperthyroid autoimmune thyroiditis. Nuklearmedizin $\underline{43}, 124-128$

Saller B, Stapfer G, Bein B, Hoermann R, Spelsberg F, Mann K (1993): Increased binding capacity of receptors for the epidermal growth factor in benign thyroid nodules and thyroid malignancies. Clin Investig $\underline{71}, 898-902$

Sass H, Wittchen HU, Zaudig M: Diagnostisches und Statistisches Manual Psychischer Störungen (DSM-IV-TR): Textrevision. Hogrefe-Verlag, Göttingen 2003

Scherbaum WA (1993): Pathogenese der Autoimmunthyreoiditis aus der Sicht des Immunologen. Der Nuklearmediziner $\underline{3}$, 241-249

Schiffer RB, Weitkamp LR, Wineman NM, Guttormsen S (1988): Multiple sclerosis and affective disorder. Family history, sex, and HLA-DR antigens. Arch Neurol $\underline{45}$, $1345-1348$

Schildkraut JJ (1965): The catecholamine hypothesis of affective disorders: a review of supporting evidence. Am J Psychiatry 122, 509-522

Schneider K: Klinische Psychopathologie. Thieme-Verlag, Stuttgart 1939 
Schneider K: Primäre und sekundäre Symptome bei der Schizophrenie. Fortschritte der Neurologie/Psychiatrie. Thieme-Verlag, Stuttgart 1957

Schumm-Draeger PM, Padberg S, Heller K (1999): Prophylactic levothyroxine therapy in patients with Hashimoto's thyroiditis. Exp Clin Endocrinol Diabetes 107, 84-87

Settle EC (1992): Antidepressant side effects: issues and options. J Clin Psychiatry $\underline{10}, 48-61$

Shein M, Apter A, Dickerman Z, Tyano S, Gadoth N (1986): Encephalopathy in compensated Hashimoto thyroiditis: a clinical expression of autoimmune cerebral vasculitis. Brain Dev $\underline{8}, 60-64$

Skanse B, Nyman GE (1956): Thyrotoxicosis as a cause of cerebral dysrhythmia and convulsive seizures. Acta Endocrinol 22, 246-263

Small GW (1991): Recognition and treatment of depression in the elderly. J Clin Psychiatry $\underline{50}, 11-22$

Spaner D, Bland RC, Newman SC (1994): Epidemiology of psychiatric disorders in Edmonton. Major depressive disorder. Acta Psychiatr Scand Suppl 주6, 7-15

Spitzer R, Kroenke K, Linzer M, Hahn S, Williams J, deGruy F (1995): Health-related quality of life in primary care patients with mental disorders. JAMA $\underline{274}, 1511-1517$

Stancer HC, Persad E (1982): Treatment of intractable rapid-cycling manicdepressive disorder with levothyroxine. Clinical observations. Arch Gen Psychiatry $\underline{39}, 311-312$

Steinberg PI (1994): A case of paranoid disorder associated with hyperthyroidism. Can J Psychiatry $\underline{39}, 153-156$ 
Stern RA, Robinson B, Thorner AR, Arruda JE, Prohaska ML, Prange AJ, Jr. (1996): A survey study of neuropsychiatric complaints in patients with Graves' disease. J Neuropsychiatry Clin Neurosci $\underline{8}, 181-185$

Sullivan PF, Wilson DA, Mulder RT, Joyce PR (1997): The hypothalamic-pituitarythyroid axis in major depression. Acta Psychiatr Scand $\underline{95}$, 370-378

Sulser F, Janowsky AJ, Okada F, Manier DH, Mobley PL (1983): Regulation of recognition and action function of the norepinephrine (NE) receptor-coupledadenylate cyclase system in brain: implications for the therapy of depression. Neuropharmacology 22, 425-431

Tait KF, Gough SC (2003): The genetics of autoimmune endocrine disease. Clin Endocrinol $\underline{59}, 1-11$

Thrush DC, Boddie HG (1974): Episodic encephalopathy associated with thyroid disorders. J Neurol Neurosurg Psychiatry $\underline{37}$, 696-700

Tölle R: Psychiatrie. Springer Verlag, Berlin 1999

Tomer Y, Davies TF (1997): The genetic susceptibility to Graves disease. Baillieres Clin Endocrinol Metab 11, 431-450

Trivedi MH (2006): Major depressive disorder: remission of associated symptoms. J Clin Psychiatry $\underline{6}, 27-32$

Tunbridge WM, Evered DC, Hall R, Appleton D, Brewis M, Clark F, Evans JG, Young E, Bird T, Smith PA (1977): The spectrum of thyroid disease in a community: the Whickham survey. Clin Endocrinol $\underline{7}, 481-493$

Tunbridge WM, Brewis M, French JM, Appleton D, Bird T, Clark F, Evered DC, Evans JG, Hall R, Smith P, et al. (1981): Natural history of autoimmune thyroiditis. BMJ $\underline{282}$, 258-262 
Universitätsklinikum Erlangen, Medizinische Klinik 1 (2007): Forschungsbericht 2006. Universität Erlangen, Erlangen 2007, 39

Vaidya B, Kendall-Taylor P, Pearce SH (2002): The genetics of autoimmune thyroid disease. J Clin Endocrinol Metab 87, 5385-5397

Vanderpump MP, Tunbridge WM, French JM, Appleton D, Bates D, Clark F, Grimley Evans J, Hasan DM, Rodgers H, Tunbridge F, et al. (1995): The incidence of thyroid disorders in the community: a twenty-year follow-up of the Whickham Survey. Clin Endocrinol $\underline{43}, 55-68$

Voelzke H, Luedemann J, Robinson DM, Spieker K W, Schwahn C, Kramer A, Ulrich J, Meng W (2003): The Prevalence of Undiagnosed Thyroid Disorders in a Previously lodine-Deficient Area. Thyroid $\underline{13}, 803-810$

Vie J, Baruk H: Geschichte der Psychiatrie. Illustrierte Geschichte der Medizin. Andreas \& Andreas Verlag, Salzburg 1990, 1945-1965

Weetman AP: Werner \& Ingbar's the thyroid. Chronic autoimmune thyreoiditis. Lippincott, Williams \& Wilkins, Philadelphia 2000, 721-732

Weetman AP, McGregor AM (1994): Autoimmune thyroid disease: further developments in our understanding. Endocr Rev $\underline{15}, 788-830$

Weiss C: Basiswissen Medizinische Statistik. 2. Auflage; Springer-Verlag, Berlin 2001, 306

WHO (Weltgesundheitsorganisation): Weltgesundheitsbericht. Psychische Gesundheit: neues Verständnis - neue Hoffnung. WHO, Kopenhagen, 2001

Wilson R, McKillop JH, Crocket GT, Pearson C, Jenkins C, Burns F, Burnett AK, Thomson JA (1991): The effect of lithium therapy on parameters thought to be involved in the development of autoimmune thyroid disease. Clin Endocrinol 34, 357361 
Wittchen HU, Schuster P, Pfister H, Müller N, Storz S, Isensee B (1999): Depressionen-in der Allgemeinbevölkerung - schlecht erkannt und selten behandet. Nervenheilkunde $\underline{18}$, 202-209

Wittchen HU, Jacobi F: Die Versorgungssituation psychischer Störungen in Deutschland. Eine klinisch epidemiologische Abschätzung anhand des Bundesgesundheitssurveys 1998. Bundesgesundheitsblatt - Gesundheitsforschung Gesundheitsschutz, Berlin 2001, 933-1000

Zoephel K, Pinkert J, Wunderlich G, Grüning T, Franke WG (1999): Can immunoradiometric measurement of thyrotropin (TSH) in human serum compete with a luminometric assay? Nuklearmedizin $\underline{38}, 150-155$

Zubin J (1985): Negative symptoms: are they indigenous to schizophrenia? Schizophr Bull 11, 461-470 


\section{DANKSAGUNG}

Ich möchte mich bei allen bedanken, die mich bei dieser Arbeit unterstützt und die Durchführung ermöglicht haben. Insbesondere bei:

Herrn Prof. Dr. med. E. Rüther, dem damaligen Leiter der Abteilung für Psychiatrie und Psychotherapie im Zentrum Psychosoziale Medizin der Universitätsmedizin Göttingen, für die Überlassung des Themas sowie für die Möglichkeit zur Durchführung der Untersuchungen in seiner Klinik.

Herrn Dr. med. D. Degner, Oberarzt der Abteilung für Psychiatrie und Psychotherapie der Universitätsmedizin Göttingen, für die fachliche Unterstützung, die engagierte Betreuung sowie seine große Hilfsbereitschaft.

Herrn Prof. Dr. med. J. Meller, dem Leiter der Abteilung für Nuklearmedizin der Universitätsmedizin Göttingen, für die fachliche Unterstützung, die gemeinsamen qualifizierten und konstruktiven Diskussionsrunden sowie die Empfehlung von Literatur und die Bereitstellung der Ultraschallbilder.

Herrn Prof. Dr. med. L. Füzesi, seinerzeit Abteilung für Gastroenteropathologie der Universitätsmedizin Göttingen, für die freundliche Überlassung der Histologiebilder.

Herrn Dr. med. U. Reulbach, aus der Abteilung für Psychiatrie und Psychotherapie der Universität Erlangen, jetzt Trinity College Dublin, für seine Unterstützung bei der statistischen Auswertung der erhobenen Daten.

Herrn Dr. med. C.-O. Sahlmann, Oberarzt der Abteilung Nuklearmedizin der Universitätsmedizin Göttingen, für die zusätzliche fachkompetente und konstruktive Betreuung. 